Illinois State University

ISU ReD: Research and eData

Theses and Dissertations

$4-9-2020$

\title{
An Analysis Of School Climate Surveys As A Measure Of Student Voice
}

Deanna L. Oliver

Illinois State University, dloliver44@yahoo.com

Follow this and additional works at: https://ir.library.illinoisstate.edu/etd

Part of the Educational Administration and Supervision Commons

\section{Recommended Citation}

Oliver, Deanna L., "An Analysis Of School Climate Surveys As A Measure Of Student Voice" (2020). Theses and Dissertations. 1339.

https://ir.library.illinoisstate.edu/etd/1339

This Dissertation is brought to you for free and open access by ISU ReD: Research and eData. It has been accepted for inclusion in Theses and Dissertations by an authorized administrator of ISU ReD: Research and eData. For more information, please contact ISUReD@ilstu.edu. 


\title{
AN ANALYSIS OF SCHOOL CLIMATE SURVEYS
}

\section{AS A MEASURE OF STUDENT VOICE}

\author{
Deanna L. Oliver
}

\section{Pages}

Student voice may seem like a new concept; however, it has a long history of being engrained in public schools in the United States. The trend towards incorporating and expanding student voice opportunities in high school is based on the tenets of democracy. Educators seek to provide an opportunity for students to practice democracy in their school environment. Students are commonly disregarded as viable stakeholders in their schools. The Illinois State Board of Education offers students in grades 4 through 12 the opportunity to provide input on their schools using the Illinois 5Essentials Survey.

This research sought the input from high school principals in Illinois on their usage of the student data from the Illinois 5Essentials Survey. The Illinois principals were asked to complete an original survey of 18 questions about the methods in which they use the student data on the Illinois 5Essentials Survey and its impact on school improvement and school climate. The principals were given multiple choice survey questions with opportunities to expand on their responses.

While many principals found value in the Illinois 5Essentials Survey, they were not likely to share the responses with their students. There is inconsistent usage of the data for the purposes of school improvement and school climate initiatives. Several principals indicated that 
professional development was not provided to analyze the results that they received from the Illinois State Board of Education. These reasons would indicate that student climate surveys are not always a successful measurement of student voice. Recommendations for further research and policy implications are provided.

KEYWORDS: Student Voice, Surveys, School Climate, High School, Illinois 


\title{
AN ANALYSIS OF SCHOOL CLIMATE SURVEYS
}

AS A MEASURE OF STUDENT VOICE

DEANNA L. OLIVER

\author{
A Dissertation Submitted in Partial \\ Fulfillment of the Requirements \\ for the Degree of \\ DOCTOR OF EDUCATION \\ Department of Educational Administration and Foundations \\ ILLINOIS STATE UNIVERSITY
}


Copyright 2020 Deanna L. Oliver 


\section{AN ANALYSIS OF SCHOOL CLIMATE SURVEYS}

AS A MEASURE OF STUDENT VOICE

DEANNA L. OLIVER

COMMITTEE MEMBERS:

Guy Banicki, Chair

Lisa Hood

Dianne Renn

John Rugutt 


\section{ACKNOWLEDGMENTS}

While it has taken me more time than I care to admit completing my dissertation, I have done so with the incredible support of my family, friends, professors, and colleagues.

Dr. Banicki picked me up as a doctoral student when I honestly did not think any professor would serve as my chair. He never wavered in his belief that I could achieve this goal. I have been blessed to have him in my life. I am incredibly grateful not only to Dr. Banicki as my chair but to my dissertation committee including the very patient Dr. John Rugutt, Dr. Dianne Renn, and Dr. Lisa Hood. Their perspective on my writing and the process is beyond appreciated. Thank you to the ISU Department of EAF for allowing me to go past the deadline for completing my dissertation. Some learners just need "extended time".

I am thankful to the Illinois State Board of Education and the Illinois Principals Association for helping with the distribution of the research survey by providing email addresses of school administrators. To my colleagues past and present, thank you for being the support system that I needed to be successful. Most importantly to Bill Gamble, former principal at Bradley-Bourbonnais Community High School. He is the inspiration and example of leadership using student voice and influenced this dissertation more than he may ever know.

I cannot express what Illinois State University has meant to me. When I am on campus, it feels like home. Who doesn't want squirrels randomly popping up in front of you or squawking crows calling out in the dark when walking to the parking garage? Just kidding I love ISU for the culture and climate that has always been a focus of the university. I have earned all of my degrees from ISU and it has been life changing.

"And Gladly Would He Learn and Gladly Teach" 
I would be remiss if I didn't mention my favorite teacher in high school. Wanda Splear is the reason I became a teacher and I believe that she made me love school. Every child needs a "Wanda" that will push you when you need it and always with a smile. I was a struggling learner and she always made me feel smart and loved.

While not with us anymore, I fully believe that my parents Ray and Rosemary Raymond were with me on this journey. I am grateful to them for helping me to grow by instilling a strong work ethic, empathy, and a no quit attitude. I am thankful for my siblings and friends who have always asked how this process was going and told me not to quit. To my in-laws Tom \& JoLynn, who always knew that I would finish; their gentle nudges were greatly appreciated.

To my husband of over 30 years, Tom Oliver, who consistently supports me and never doubted that I would finish. He was always available for me and became super dad in the process. He is and always has been my self-esteem booster and the person that can calm my anxiety. I do not believe I would have finished without him. My daughters Courtney and Fallon have shown me considerable love and sometimes harassment when I dropped out of the program. They would call me "doctoral dropout" and sing it to "beauty school dropout" from Grease. While they did it in a joking manner, they (and their friends) never stopped calling me "Dr. Dee" to keep me motivated to keep moving forward. My girls have achieved incredible success professionally doing exactly what they love, and I am exceptionally proud of the women they have become.

Finally, to the students in our public schools that want to experience a more democratic environment, may future generations of K-12 students experience schools where they always feel that they have voice and are not as Pink Floyd sang "just another brick in the wall".

D. L. O. 


\section{CONTENTS}

$\begin{array}{lll}\text { Page } & \end{array}$

ACKNOWLEDGMENTS

$\begin{array}{lll}\text { CONTENTS } & \text { iii }\end{array}$

TABLES - vi

FIGURES viii

CHAPTER I: INTRODUCTION TO THE STUDY 1

Overview 1

Background 2

Statement of the Problem 5

$\begin{array}{ll}\text { Conceptual Framework } & 6\end{array}$

Purpose of the Study

$\begin{array}{ll}\text { Research Questions } & 10\end{array}$

Significance of the Study 11

$\begin{array}{ll}\text { Definition of Terms } & 12\end{array}$

Assumptions and Limitations of the Study 13

$\begin{array}{ll}\text { Overview of the Study } & 15\end{array}$

CHAPTER II: REVIEW OF THE LITERATURE 17

$\begin{array}{ll}\text { Introduction } & 17\end{array}$

$\begin{array}{ll}\text { Definition of Student Voice } & 18\end{array}$

$\begin{array}{ll}\text { Benefits of Student Voice } & 18\end{array}$

$\begin{array}{ll}\text { Historical Perspective of Student Voice } & 21\end{array}$

$\begin{array}{ll}\text { Types of Student Voice } & 30\end{array}$ 
Building Student Voice Capacity in Leadership 32

Student Voice in Collaboration with Adults $\quad 32$

Student Voice-Being Heard 36

Implementation of Student Voice $\quad 44$

$\begin{array}{ll}\text { Summary } & 50\end{array}$

CHAPTER III: METHODOLOGY

$\begin{array}{ll}\text { Positionality } & 52\end{array}$

$\begin{array}{ll}\text { Research Design } & 54\end{array}$

$\begin{array}{ll}\text { Research Questions } & 55\end{array}$

The Population and Sample $\quad 56$

$\begin{array}{ll}\text { Instrumentation } & 57\end{array}$

$\begin{array}{ll}\text { Instrument Development and Validation } & 60\end{array}$

$\begin{array}{ll}\text { Variables in the Study } & 61\end{array}$

$\begin{array}{ll}\text { Data Analysis and Interpretation } & 63\end{array}$

$\begin{array}{ll}\text { Internal and External Validity } & 63\end{array}$

$\begin{array}{ll}\text { Data Analysis Procedures } & 65\end{array}$

$\begin{array}{ll}\text { Final Study } & 65\end{array}$

$\begin{array}{ll}\text { Summary } & 67\end{array}$

$\begin{array}{ll}\text { CHAPTER IV: } & 68\end{array}$

Section One: Pilot Study Results $\quad 69$

$\begin{array}{ll}\text { Section Two: Final Survey } & 70\end{array}$

$\begin{array}{ll}\text { Survey Results } & 70\end{array}$ 
Results of the Analysis for Research Questions

Summary of Results from the Qualitative Analysis

Background

APPENDIX C: INFORMED CONSENT LETTER 


\section{TABLES}

Table

Page

1. Geographical Location of High School 71

2. High School Enrollment 72

$\begin{array}{ll}\text { 3. ISBE Summative Designation } & 73\end{array}$

4. Illinois 5Essentials Survey Student Response Rate 73

5. Principals Using Illinois 5Essentials Survey for Planning/Continuous $\begin{array}{ll}\text { Improvement } & 75\end{array}$

6. Principal Response on Usage of Illinois 5Essentials Data to Modify School $\begin{array}{ll}\text { Improvement Plans } & 75\end{array}$

7. Principal Response on Knowledge to Use Student Response Data 76

8. Principals were Provided/Supported with Professional Development by School District

9. School District Ensures Principal Knowledge on Use of Illinois 5Essentials Survey Data

10. Principal Methods for Communicating Student Data to Students for Illinois 5Essentials Survey

11. Summative Designation Category, Sample Size, Mean, and Standard Deviation 80

12. Geographical Usage Category, Sample Size, Mean, and Standard Deviation 80

13. School Enrollment and Leadership and Involvement Category, Sample Size, Mean, and Standard Deviation

14. Rankings of Principal Engagement in Types of Student Voice 
17. Describe Other Types of Groups/Teams that Involved Students in Which Data was Reviewed or Discussed 86

18. Parent Data was Reviewed/Discussed in other Groups that Involved Parents

19. Educator Results that were Reviewed/Discussed in Other Groups that Involved Educator

20. Principal Responses to Addressing School Climate Issues Using the Illinois 5Essentials Student Data

21. In What Ways Have You as a Principal Utilized the Student Voice Data from the Illinois 5Essentials Survey to Address School Climate Issues? 


\section{FIGURES}

Figure Page

1. Mitra Pyramid of Student Voice (2006) 9

2. Mitra Pyramid of Student Voice (2006) 31

3. Mitra Pyramid of Student Voice (2006) 94 


\section{CHAPTER I: INTRODUCTION TO THE STUDY}

\section{Overview}

Capturing authentic student voice is an important step in systemic school reform efforts. The students are the stakeholders walking the hallways in our school buildings and are eyewitnesses to the climate and culture of our schools. They do not observe their school environment from the sidelines; students are immersed and directly impacted by the daily operations of their school. The voices of these stakeholders can provide a more youthful insight that adults cannot articulate or comprehend. There are a multitude of ways in which school staff and administrators can integrate student voice opportunities in their schools. Examples of student voice opportunities include classroom choices, focus groups, co-researching, and student surveys.

The practice of using the perspectives of varied stakeholders has been widely researched and found to be a valuable approach towards building capacity within a school district. However, students are typically not found to be a voice in these conversations. When integration of student voice efforts has occurred in the schools, there is weak implementation and minimal sustainable efforts (Mitra, 2009). These approaches may lead students to feel frustrated because of disingenuous actions or failed student voice integration attempts.

In order to obtain the equitable perspectives from students, building administrators must be committed to seeking the voices of all of their students not just the majority. The challenge is identifying which demographics are not being heard and how to best obtain those opinions from less represented students. Administrators must be fully committed to the concept of student voice and supporting a comprehensive approach to student equity. Building administrators would need to conduct an analysis of student voice opportunities, students involved, and 
demographics. The time to collect and analyze data is typically not available to building principals with all of their other required tasks. In addition, some demographic information such as incarceration and foster care data are not always collected by districts and states in their school information system.

School climate surveys are one method to attempt to learn more about the school environment in high schools in an efficient manner and to gain those opinions from a large quantity of students. Typically, high school aged students have the capacity to read, comprehend, and respond to questions administered in a school climate survey. Data collection is much easier and less time consuming with a survey than personalized interviews since student responses are multiple choice and the data is available through technological means. Comparing the participants on a survey with the demographics can be more streamlined. The perceived quality and validity of a data collection tool such as a survey are important components in determining if principals value the information provided by a survey (Klostermann, White, Lichtenberger, \& Holt, 2014). This was a challenge when the Illinois State Board of Education (ISBE) initially introduced the Illinois 5Essentials Survey.

\section{Background}

School climate surveys provide data that "assess the quality and characteristics of school life" (Clifford, Menon, Gangi, Condon, \& Hornung, 2012, p. 3). According to the National School Climate Center (NSCC), there are several strategies that are effective when school administrators seek to improve the climate in their buildings. These strategies are based on the five National School Climate Standards. The National School Climate Standards are a "research-based framework" that include benchmarks for school district and building leaders and provide guidance, support, and measurement for improving school climate (Ciccone \& 
Freibeg, 2013, p. 2). The standards include a focus on a shared vision, positive social emotional policies, school community practices support student engagement for all, school environment that is safe in all ways, and the school community has infused practices driven to promote social justice (Villenas \& Zilinski, 2018).

According to research conducted by the National Threat Assessment Center (NTAC) (2019), several recommendations were made to prevent targeted school violence. NTAC research analyzed 41 targeted incidents of K-12 school violence from 2008-2017. With nearly 20 years of data, NTAC used their experience and comprehensive research to develop eight actionable steps. One vital component supports the focus on a positive climate in our schools. According to NTAC (2019), there is value in creating and promoting a safe school climate that is "built on a culture of safety, respect, trust, and emotional support for students" (United States Secret Service National Threat Assessment Center [NTAC], 2019, p. 53). The recommendation is directly related to the promotion of student voice by having adults in the school "encourage communication, intervene in conflicts and bullying, and empower students to share their concerns" (NTAC, 2019, p. 53). Tending to the creation of a safe school climate can be literally be lifesaving.

The five strategies linked to the National School Climate Standards as recommended by NSCC include the "raising awareness and support" for the School Climate Standards, the adoption of the Standards by school district boards of education, "planning and conducting school climate training for all school community members", researching, developing, and implementing school climate assessments, and the final standard is to "create and implement school climate improvement action plans" (Ciccone \& Freibeg, 2013, p. 1). School climate assessments can be created at the national, state, and local level. The instruments can be as 
formal as a survey or informal as observations made during classroom walkthroughs. Surveys can be purchased from businesses or nonprofit organizations by individual school districts or they can be obtained through a state contract. It is vital that school climate efforts be assessed to determine if the actions are effectively improving student learning conditions (Ciccone \& Freibeg, 2013). Instruments such as the Illinois 5Essentials Survey when taken by students "can illuminate students' sense of belonging at school" (Jordan \& Hamilton, 2020, p. 3).

Since the 2012-2013 school year, Illinois public school students in grades 6-12 have participated in the Illinois 5Essentials Survey biannually as required by law ("Illinois 5Essentials," 2012). Illinois along with seven other states have included a survey of student engagement or school climate survey for accountability purposes in their ESSA plan; the other states include Idaho, Iowa, Maryland, Montana, New Mexico, North Dakota and South Carolina (Jordan \& Hamilton, 2020, p. 1). Beginning with the 2018-2019 school year, the survey was required annually to students in grades 4-12 ("ISBE ESSA Plan," 2017). This survey allows students, educators, and parents the opportunity to rate their school environment based on ten multiple-choice questions each with a minimum of three subcategories ("Illinois 5Essentials," 2012). For students, they are provided an access code and complete the survey in a digital format online. The Illinois 5Essentials responses are then categorized and rated into five areas: "effective leaders, collaborative teachers, involved families, supportive environment, and ambitious instruction"(Jordan \& Hamilton, 2020, p. 3). This model was developed from research by the University of Chicago Consortium on School Research. A printed copy of the Illinois 5Essentials Survey is provided in Appendix A.

School administrators are provided the data, but it is unknown as to how those results benefit school districts and their students. The student input is essentially discarded if not used 
by administrators as a means towards school improvement. By failing to return information to the survey participants, there is a break in the communication cycle. This lack of closing the feedback loop can become frustrating for students who may elect to decline participation in not only the survey but also other student voice opportunities. Determining the use of this survey towards school improvement is valuable information that may contribute to the implementation and policy choices that state officials make regarding the Illinois 5Essentials Survey.

\section{Statement of the Problem}

In K-12 public education, there are inherent opportunities for student voice to be captured in intentional and purposeful methods. The challenge is garnering administrative support of including students as a voice at the table of school improvement. Educational leaders should be cognizant of the shifting demographics in the United States and the importance of allowing for an equitable approach to hearing the voices of students that may be marginalized and oppressed (Gonzalez, Hernandez-Saca, \& Artiles, 2016). The efforts to include students as stakeholders is a challenge as the adults seemingly downplay the importance of opinions, there is weak follow through, or not considered at all. One method that has gained momentum is the incorporation of student participation in school climate surveys.

There are gaps in the research on how student voice can best be obtained through school climate surveys (Gage, Larson, \& Chafouleas, 2016). The Illinois State Board of Education (ISBE) supports the incorporation of student voice in a school climate survey called the Illinois 5Essentials Survey. This study will review the literature that supports the incorporation of student voice in school decision making and provide insight into the use by high school administrators of the student voice portion of the Illinois 5Essentials Survey. By gaining a better understanding of how it is used in high schools statewide, policymakers may consider improved 
strategies to implement and support the use of the survey in school improvement. This study will examine the use of the student voice data of the Illinois 5Essentials Survey by high school principals.

\section{Conceptual Framework}

In research, a theoretical framework is present and is "derived from the orientation or stance that you bring to your study" (Merriam, 2009, p. 66). The conceptual or theoretical framework provides the lens in which one chooses to address a research topic and serves as the supporting design for the study. "A theoretical framework is the underlying structure, the scaffolding, or frame of your study" (Merriam, 2009, p. 66). Through the review of the literature of a research topic, one may begin to witness the trends in the frameworks. This framework will provide a guided path towards the development of the purpose of the study and problem statement. Within any particular research topic, several theoretical frameworks may be applicable and will drive the research questions and the type of study that will be conducted. Several of the frameworks applicable to student voice will be shared with a final focus on Mitra's Student Voice pyramid as the conceptual framework (2006). For this research, I will use the student voice pyramid as the conceptual framework.

The research on student voice has been approached using multiple theoretical and conceptual frameworks. Many of the studies on student voice are broadly supported by theoretical frameworks that surround student rights and student respect (Cook-Sather, 2006). Issues of the distribution of power has been discussed as a primary issue with implementing student voice initiatives in schools (Cook-Sather, 2006), (Mitra, Serriere, \& Stoicovy, 2012), (Conner, Ebby-Rosin, \& Brown, 2015). Students are not inherently in a position that places them as an equal with parents and staff which presents power struggles that 
are challenging to overcome. Self-Determination Theory (SDT) is another theoretical framework that is common in student voice literature. SDT is a theory of motivation and is important in student voice research because it supports the intrinsic needs of individuals to behave or experience autonomy, competence, and relatedness (Iceman Sands, Guzman, Stephens, \& Boggs, 2007), (Lemley \& Schumacher, 2014), (Garn \& Jolly, 2014). Other frameworks including social movement theory, authoritative school climate, constructivist, and motivation were identified in the literature (Iceman Sands et al., 2007), (Mitra, 2006) (Jia, Konold, \& Cornell, 2016). A primary lens that was present in the research was related to the concept of democracy and social justice. Democracy was a focal point in research conducted by (Schultz \& Oyler, 2006), (Mitra \& Gross, 2009), (Ozer \& Wright, 2012), (Yuen, 2010), (Joselowsky \& Aseltine, 2009).

Pedder and McIntyre (2006) adopted a social capital theoretical framework in their research on pupil consultation that is built on trust and communication. Social capital theory studies the formation of movements that create or support efforts to achieve a common good and "hold promise for changing the dynamics of politics, power arrangements, and policy through educator activism" (Marshall \& Gerstl-Pepin, 2005, p. 85). With social capital theory as a lens, there is a perspective that education must look at examining the needs of the disenfranchised and take a stand against typical professional norms. Much of the student voice activism has resulted from a group of researchers, educators and students committed to learning more about the cause and pushing the agenda forward. Past school reform has minimized the students as valid stakeholders in systemic school change. The movement towards the inclusion of student voice is grounded in this theory and that of creating more democratic schools. A basic definition of social capital is the "links, shared values and understandings in society that enable individuals 
and groups to trust each other and so work together" ("Social Capital," p. 102). The entire premise of school climate surveys is that all participants are equally responsible for the culture and climate in a school including students, staff, and parents.

Social capital theory was initiated by French sociologist Pierre Bourdieu in 1986; his work focused on the distinct differences between "economic capital, cultural capital, and social capital" (Liou \& Chang, 2008, p. 102). Followed by Coleman (1988) an American sociologist, he provided an expanded definition of social capital that provided a perspective of social capital as a resource that encompasses a network of individuals "whose relationships are governed by a high degree of trust and shared values" (Liou \& Chang, 2008, p. 103). The foundation of social capital theory is rooted in studies on sociology which focuses on the interconnection of social networks (Imandoust, 2011). When applied to education, social capital is useful as it is embedded in the relationships among school stakeholder groups rather than individual educators (Leana \& Pil, 2014).

The conceptual framework guiding this study will assist educational leaders to acknowledge the voices of students in a multitude of ways and ensure that all voices are honored equitably. To better understand the types and impact of authentic student voice, I will utilize a tiered framework developed by Dr. Dana Mitra (2006) which provides a visual demonstration of the capacity of youth development as student voice opportunities increase. For over 15 years, Dr. Mitra served as a professor of Education Policy Studies at Pennsylvania State University with considerable research in student voice and civic engagement (https://danamitra.net/go/dana/). Using the pyramid of student voice as depicted in Figure 1, students have greater access to student voice at the lowest tier; however, it typically has the least 
impact as a student voice measure. The highest tier has the most positive impact on implementation of student voice with the fewest number of students engaged in that process.

Figure 1

Mitra Pyramid of Student Voice (2006)

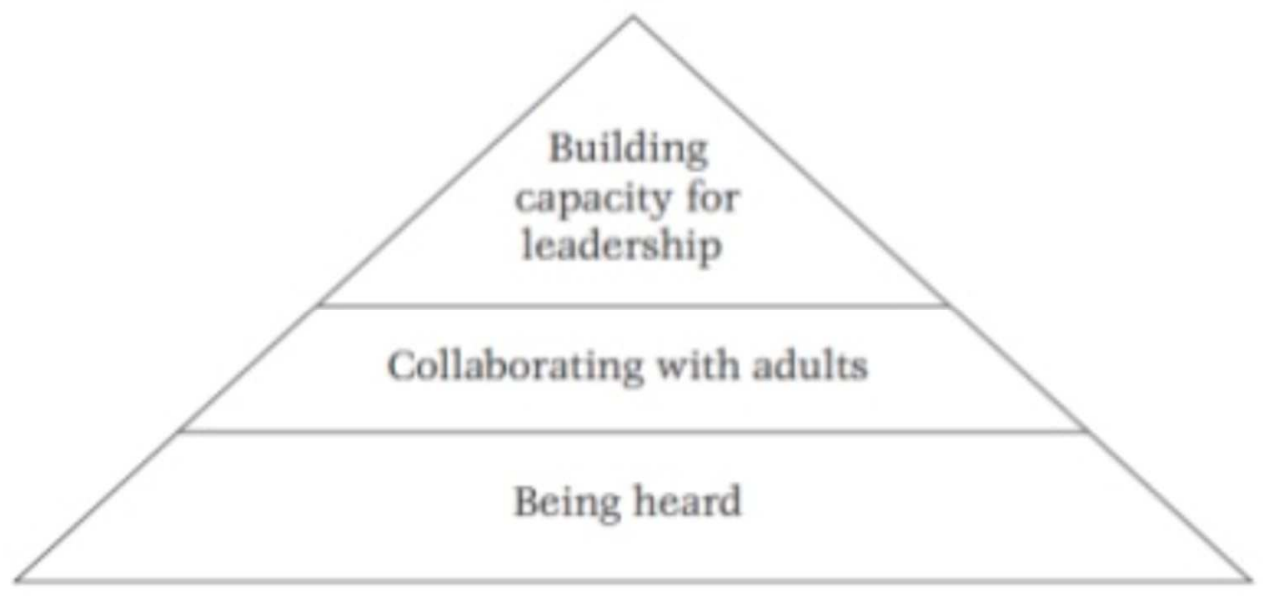

\section{Purpose of the Study}

The purpose of this quantitative study was to investigate the usage of the student voice data on school climate surveys. With a focus on the Illinois 5Essentials Survey as a school climate survey, there was an examination of the commitment by high school principals to use the student response data from the survey to institute changes in their schools and to determine the perceptions of principals of the Illinois 5Essentials Survey. By better understanding the opinions of the high school principals, one may determine the need for professional development, resources, and marketing that could support the use of the Illinois 5Essentials Survey. Information for this quantitative research will be collected by surveying high school principals in Illinois that currently serve in public school districts that utilize the Illinois 5Essentials Survey. The Illinois 5 Essentials provides an opportunity for all students in grades 4-12 to participate in a school climate survey. 
Using the following research questions, the independent variables to be examined include ISBE School Quality Summative Ratings, geographical location, school enrollment, and student voice options. The dependent variable is the principal usage of the student data from the Illinois 5Essentials Survey as reported in a questionnaire.

\section{Research Questions}

Six research questions concerning the commitment by Illinois principals will be explored. These research questions are as follows:

(RQ1): What does the statewide data tell us about the usage of the Illinois 5Essentials Survey by high school principals?

A. What is the percentage of high school principals utilize the student voice component of the Illinois 5Essentials Survey for school improvement?

B.What percentage of principals feel well prepared to utilize the data in the Illinois 5Essentials Survey?

C. What is the frequency that principals purposefully share the results of the student voice portion of the Illinois 5Essentials Survey with stakeholders?

(RQ2): Does the student voice data usage from the Illinois 5Essentials Survey vary based on the quality level of the ISBE summative designation rating for public high schools on the Illinois School Report Card?

(RQ3): Are there geographical differences in the state of Illinois high schools where the Illinois 5Essentials Survey are more commonly utilized as a tool for student voice by high school principals? 
(RQ4): Are there leadership and involvement differences by high school principals based on school enrollment size to implement and respond to student voice data from the Illinois 5Essentials Survey?

(RQ5): Are principals that utilize the Illinois 5Essentials Survey more engaged in implementing alternative types of student voice opportunities in their high school?

(RQ6): Do principals perceive that the data can aid them in supporting school climate in their schools?

\section{Significance of the Study}

This significance of this study is to expand the research on school climate surveys as an appropriate measure of gaining equitable student voice for high school students. ISBE allocates considerable financial resources to provide this survey service to school districts and it is required in Illinois School Code. It is also a school requirement in the federal legislation Every Student Succeeds Act (ESSA) that school districts provide a school climate survey annually. In addition, some school administrators will ensure that students have participation opportunities throughout the school day and outside of normal school hours which may require additional staff time and compensation. School districts may use the statewide instrument required in addition to their own survey that is created or purchased with district resources. A relatively small percentage will use a district purchased school climate instrument exclusively with no students participating in the Illinois 5Essentials Survey. The study may illuminate the need for support measures such as professional development for administrators to better understand their survey results and best practices for sharing those results. Ultimately, the significance would be to see an improved utilization of the student voice portion of the Illinois 5Essentials Survey as one measure of including equitable student voice in school improvement. 


\section{Definition of Terms}

The following terms will be defined in the context of this study:

Every Student Succeeds Act (ESSA): President Barack Obama signed this federal legislation into law in 2015 and serves as the national education law supporting equal opportunity for children in our schools ("ESSA," n.d.).

Illinois State Board of Education (ISBE): The governing educational body that oversees both public and recognized private schools in Illinois from PreK through Grade 12.

Illinois School Code: Illinois legislation passed by the Illinois General Assembly that directly impacts students and schools.

Illinois School Report Card: A yearly report released by ISBE that provides data on how the state, and each public school and district, are progressing on a predetermined classification of educational goals ("ISBE Report Card," n.d.).

ISBE Summative Designations: The designations assist school community members to better understand the overall capacity of the schools that are serving the students. Illinois uses four summative designations for public schools; these designations are Exemplary School, Commendable School, Underperforming School, and Lowest-Performing School("ISBE Summative Designation," n.d.). The two lowest performing school ratings will receive supplemental funding and supports to build and sustain local capacity in order to improve student outcomes. ESSA requires all states to categorize every school with a summative designation; ISBE announced these designations to the public for the first time on October 31, 2018 ("ISBE Summative Designation," n.d.). 
Illinois 5Essentials Survey: A mandated school climate instrument that is based on five components. Survey questions are focused on effective leaders, collaborative teachers, involved families, supportive environment, and ambitious instruction ("Illinois 5Essentials," 2012).

No Child Left Behind (NCLB): Federal legislation that was signed into law by President George W. Bush in 2001 which focused on testing and accountability in public schools ("NCLB," 2010).

School Climate: A multifaceted term that encompasses many aspects in a child's educational experience including the fostering of safety, as well as "promoting a supportive academic, disciplinary, and physical environment; and encouraging and maintaining respectful, trusting, and caring relationships throughout the school community" (https://safesupportivelearning.ed.gov/safe-and-healthy-students/school-climate).

School Climate Survey: Scientific, multidimensional assessments and measures that gauge the quality of an educational environment within a school.

Student Voice: A broad term that supports the perspectives and opinions of students as stakeholders in the decision-making processes in their schools.

\section{Assumptions and Limitations of the Study}

The following are the assumptions made for this study:

1. The high school principals that responded to the survey currently serve students in grades $9-12$.

2. Principals that responded to the survey have knowledge and experience with the Illinois 5Essentials Survey

3. The high school principals responded honestly to the survey questions without fear of reprisal from the school district or local or state agencies. 
4. The high school principals that responded understood the terminology associated with student voice efforts.

Limitations of the study include:

1. A limited number of high school principals in Illinois completed the research survey

2. The survey responses from a cross section of principals from various areas in the state and school sizes may not be equivalent to the number of principals in each area.

3. Illinois principals were surveyed on one specific school climate survey which may limit the broad assumptions that can be placed across all states regarding other school climate surveys.

4. The researcher used the Illinois 5Essentials Survey as a high school principal and perceived that it has value in supporting student voice efforts.

5. The preconceived perceptions and attitudes about the Illinois 5Essentials Survey may have interfered with principals responding in an unbiased manner.

6. The attitudes of school superintendents and school board members have a positive or negative impact on the responses of the high school principals.

7. Principals may have perceived that their responses would impact public policy on the implementation of the Illinois 5Essentials Survey which may have impacted the manner in which they responded.

The methods used for collecting data were based upon a scientific approach to data collection and analysis with efforts to ensure reliability of the information in this study. "No sampling technique will guarantee perfect representation, but probability techniques improve the odds" (Mertler, 2018, p. 112). While there were considerable efforts to ensure validity and 
reliability, there may be limitations to applicability to the population of high school principals as well as the vast array of school climate surveys.

\section{Overview of the Study}

The review of the literature highlighted the need for more information on the use of mandated school climate surveys as an appropriate measure of student voice in high schools. High school principals are responsible for serving the needs of students and hearing the voices of all stakeholders. It is questionable as to whether or not student responses on school climate surveys truly give students a voice in the leadership or school improvement in their own public high schools. If principals do not use the data from a mandated school climate the survey, the intent of the survey is not being recognized. Given that school climate assessments are a recommended strategy for improving school climate, there is a need to determine if this step is being addressed with fidelity.

This study will use a quantitative research approach. Since most research surrounding student voice is qualitative, it is unique to have a focus in student voice using quantitative research. "US K-12 student voice researchers overwhelmingly used qualitative research methods" as a methodology in student voice studies (Gonzalez et al., 2016, p. 461).

The structure of this study will be organized into five chapters. The literature review is in Chapter II and includes a broad definition of student voice, historical background of the student voice movement in the United States, the types and benefits of student voice. Using Mitra's Student Voice Pyramid (2006), the literature will also highlight the implementation of student voice and how it impacts accountability measures used in school improvement.

In Chapter III, I will discuss the methodology of the study, research design and questions, population, instrumentation, variables, and discuss the data with internal and external validity. 
The study will lead to a presentation of the data in Chapter IV. Using the data from the study, Chapter V will provide an analysis of the data and present the findings from the study including the implications of these findings. Chapter $\mathrm{V}$ will conclude with recommendations for further research. A comprehensive review of the literature will follow in the next chapter. 


\section{CHAPTER II: REVIEW OF THE LITERATURE}

\section{Introduction}

Educational leaders in American K-12 school systems should become more educated on the concept of including the perspectives of their stakeholders. The students may be one such stakeholder that has long been disregarded as a valid voice in school improvement. Student voice is a term that "has emerged to signal a range of efforts that strive to redefine the role of students in educational research and reform" (Cook-Sather 2006, p. 360). This educational reform initiative provides for the environment whereby students collaborate with their educators and school leaders to visualize and reconfigure leadership in their school environment (Mitra, 2009). The involvement of students as actively engaged educational participants is directly related to the school culture. The school culture encompasses the "assumptions, values, and norms that develop over time in an organization that are not always explicitly stated or visible to those affected by them" (Pritchard, Morrow, \& Marshall, 2005, p.154). The ultimate goal of student voice initiatives is that they become embedded in the cultural norms of the school.

This initiative to include students as partners rather than passive learners is grounded in research. Examining Mitra's student voice pyramid will provide guidance to better understand student voice as a concept of democracy in schools that has many levels of involvement. The review of the research literature will define student voice, provide insight into the types of student voice opportunities in our public high schools, discuss the benefits of voice, and identify successful implementation requirements. The review will also examine the means in which student responses on school climate surveys when conducted appropriately can benefit the understanding of student perspective and be considered a viable form of student voice implementation. 


\section{Definition of Student Voice}

Student voice can best be characterized as more than simply allowing for students to give opinions on trivial school issues such as homecoming themes and prom court. The implementation of the student voice movement allows for students to speak their mind, to be heard, counted by others, and that there would be outcomes because of the voice experience and fundamentally that voice is "having presence, power, and agency within a democratic context" (Cook-Sather, 2006, p. 363). It is a transformational movement and a cultural shift on how adults view students and students view themselves within the school environment. Mitra (2006) asserts that the student voice focus is on embedding student participation in "school-based reform initiatives, site-based decision making, and changes in classroom instruction and pedagogy" (p. 315). While on the surface this seems simple and uncomplicated to include high school students in school reform, the equitable and research-based implementation of student voice initiatives must be considered as a major component of student voice efforts. To better understand this vision in the school context, a foundational perspective will be provided including the benefits, history, and types of student voice.

\section{Benefits of Student Voice}

The advancement of student voice has historically been driven by the benefits that students receive from the experience. However, educators will recognize benefits as well. The concept of including students as viable stakeholders has been illuminated in research and the benefits are discussed as they relate to students and educators. "Fundamentally, lasting learning is the result of acts of co-creation in caring contexts, and that is what the pedagogy of student voice provides" (Elias, 2010, p. 27). 
A benefit of student voice includes the opportunity to engage in the process of democratic experiences in their school (Schultz \& Oyler, 2006). This democratic experience in schools allows students to develop skills that include reaching group consensus, preparation for public speaking and civil engagement, and negotiating conflicts (Schultz \& Oyler, 2006). Elias (2010) noted that there is a connection between educators supporting student voice and increased student engagement.

When students feel respected in the classroom, it aids in the building of relationships with the teachers and among the students (DeFur \& Korinek, 2010). The mutual respect and trust between the teacher and student increases student engagement (Pedder \& McIntyre, 2006). Students value a classroom environment in which their participation and personal contributions are encouraged by the educator (Pedder \& McIntyre, 2006). When students have the opportunity to express their own awareness of the methods that supports and motivates their learning, the students build social capital by demonstrating that they can contribute to their classes with innovative ideas and by extending trust with the teacher (Pedder \& McIntyre, 2006). There is a reduction in dropout rates when a supportive student-teacher relationship is present in the classroom (Jia et al., 2016).

De La Ossa (2005) found that students in public alternative schools are capable of providing their perspective on their academic program. This study of eight alternative schools in the state of Washington used students' personal perspectives to gain understanding on learning and experiences in their schools. A consistent theme was identified in that students want to be heard. Student perceptions can be elicited for insight and to also provide solutions to problems in current high schools (De La Ossa, 2005). When school leaders engage in conflict resolution with students, they are likely to gain knowledge on concerns that were previously unknown. 
Educators gain benefits by increasing the use of student voice in the classroom. Student voice has meaning when students are given the opportunity to reflect on classroom work and teachers provide personalized meaning to the content, learn to set individualized goals, and demonstrate knowledge through self-determined assessments (Elias, 2010). Giving students voice in the classroom assists in building strong relationships between teachers and students and provides a sense of empowerment to students (DeFur \& Korinek, 2010). This connection engages students and supports the educational process (Lemley \& Schumacher, 2014). According to Pedder (2006), one of the challenges for teachers who have students from diverse backgrounds, ability levels, and linguistic ability is to find common ground and interconnections in the classroom. While implementing student voice with fidelity has challenges, educators noted that they had a greater sense of their own leadership from collaboration rather than coercion and manipulation (Angus, 2006). Teachers reported that they became better listeners of their students' experiences in the classroom (Pedder \& McIntyre, 2006).

Educators must be more interactive with their students by asking the students about the effective teaching or instructional methods that would increase their own academic performance or increase their own effort in school (Iceman Sands et al., 2007). While previously not considered by educators, this practice of engaging student voice may provide student ideas and perspective (Iceman Sands et al., 2007). "Successful educational reform must include voices of students or school renewal efforts will continue to spin through unsuccessful cycles" (Iceman Sands et al., 2007). The process of acknowledging equitable student voice can assist educators with gauging the supports that students need to be successful in school (DeFur \& Korinek, 
2010). Using a historical foundation of student voice will provide greater depth in understanding the value of engaging youth.

\section{Historical Perspective of Student Voice}

While the current mainstream media would have us believe that student activism at the high school level is a new concept, children expressing themselves with a focus on change is grounded in research and historical events. The movement towards increased student voice is based on historical actions taken place since the beginning of the public-school system in the United States. While student voice is a discussion internationally, this brief historical overview of student voice will highlight the actions in the United States from the early 1900's through 2018 that would have impacted public school aged students.

One of Thomas Jefferson's founding ideals was to provide for all children to have the right to free public education (Carpenter, 2013). With this as a foundation in the United States, schools proceeded through a multitude of programs, legislation, and movements towards school improvement. During the 1800's through the late 1900's, there was progress made by Horace Mann in creating the common school, the civil rights movement began, and the feminist discourse was active; these actions not only impacted our schools but also communities (Gonzalez, Hernandez-Saca, \& Artiles, 2016). The concept of different voices in decision making was highlighted. In 1894, the first student government was formed in a school located in Freeville, New York (McKown, 1944). This formalized creation of a student government or student council continues as one of the primary types of student voice opportunities in schools today.

In the early 1900's, John Dewey's research examined the important concept of democracy infused into the U.S. education system (Schultz \& Oyler, 2006). Dewey's work was 
instrumental in highlighting the exploration of supporting students' individual thought processes rather than instruction driven by accountability of measuring ability to memorize explicit facts (Schultz \& Oyler, 2006). Dewey's focus of valuing student perspective in problem solving is a type of student voice opportunity in the classroom environment.

One of the earliest known student walkouts occurred in 1922 at Mineola High School in New York ("Mineola High School student strike," 1922). The walkout was a result of the senior class president receiving a suspension from school for skipping study hall that ended in a disagreement between the school and the students. These students chose to increase the attention of their perspectives through this nonviolent protest. During this time, teachers began to integrate the concept of student voice in their classrooms. From 1927-1960's, Grace Pilon worked in thousands of schools developing the concept of teaching called "The Workshop Way" (Fletcher, 2018). Her instructional practices were focused on students that actively participated in the learning and teaching in the classroom. This idea of students having voice in the instruction and curriculum was not the norm but now researched as one method to increase engage students in learning.

The American Youth Congress (AYC) was formed by several youth organizations in 1934 as a lobbying arm of the student movement and was well supported by First Lady Eleanor Roosevelt ("American Youth Congress," n.d.). In 1936, the AYC wrote the Declaration of the Rights of American Youth (Conner, Ebby-Rosin, \& Brown, 2015). The declaration was presented before Congress and affirmed the educational rights of all students regardless of their personal wealth and race. With a focus on racial justice, increasing federal education funding, and ending the requirement for Reserve Officers Training Corps (ROTC), the organization made forward progress but was ultimately disbanded as a result of internal student disagreements 
regarding politics in Nazi Germany and the Soviet Union ("American Youth Congress," n.d.). The implosion of the AYC "signaled the larger death of empowered student activism in the United States" until the Vietnam War involvement resulted in student protests ("American Youth Congress," n.d., p. 1).

During the 1950's and 1960's, student activism was primarily seen on college campuses and with college aged students (Conner et al., 2015). However, there were incidents in which high school aged students protested as well. In 1951, students at R.R. Morton High School in Farmville, Washington conducted a student strike over poor learning conditions and underfunding of their school (Conner et al., 2015). In 1962, Students for a Democratic Society (SDS) wrote in a student voice document about the importance of student involvement as a democratic measure in public schools. SDS was founded on the principles of "equality, economic justice, peace, and participatory democracy" and the student organization became stronger as the Vietnam War escalated ("Students for a Democratic Society," n.d., p.1). SDS self-proclaimed themselves to have been "the largest and most influential radical student organization of the 1960's" ("Students for a Democratic Society," n.d., p. 1).

U.S. Supreme Court landmark cases that impacted student rights included the 1954 Brown vs. Board of Education in Topeka, Kansas. This court case specifically examined the rights of students based on their race and the policy of state sponsored segregation in public schools. The Supreme Court Chief Justice Earl Warren delivered the opinion that 'separate but equal' has no place in public education and separate schools are inherently unequal ("Brown v. Board of Ed," n.d.). This case explored the need to examine the treatment of children as a focus in public policy and gave voice to African American children. 
Additional federal legislation was adopted in 1965 that supported the rights of children based on socioeconomic status or class. These included the Elementary and Secondary Act and Title I. This legislation provides for federal funding for local educational agencies (LEA's) and schools who have high percentages of children in preschool through high school that qualify as low income to provide services to children so that they may meet academic standards ("Title I, Part A," 2015). The funding is designated for the purpose of closing the achievement gap for children in the greatest need of assistance ("Title I Achievement," 2004). In 2010, the program supported 21 million children in 56,000 public schools ("Title I, Part A," 2015). Empowering disadvantaged youth as a mechanism of public policy aids in supporting the equity and voice of all children.

In the 1969 court case Tinker vs. Des Moines, the decision of whether school districts could deny the right to protest in schools was made ("Tinker v. Des Moines," n.d.). The issue was related to three students in Des Moines that were suspended as a result of wearing arm bands to school in protest of the Vietnam War ("Tinker v. Des Moines," n.d.). The most notable statement was that "students don't shed their constitutional rights at the school house gates" (Fletcher, 2018, p. 2). This decision was not unanimous yet a win for the student rights movement.

The federal legislation Title IX of 1972 provided for the rights of students based primarily on gender related issues ("Title IX," n.d.). This impacted the schools as it required equity for athletics based on gender in a publicly funded institution. It also reinforced that efforts must be taken to appropriately report sexual harassment and sexual violence against students. The American Civil Liberties Union (ACLU) maintains that students are "deprived of equal and free access to an education" when assaulted or harassed ("Title IX," n.d., p. 1). This 
legislation also gives voice to students through public policy and illuminated gender equity issues. According to the United States Department of Education, "the sexual harassment of students, including sexual violence, interferes with students' right to receive an education free from discrimination" ("Dear colleague letter," 2013, p. 1).

The 1960's and early 1970's were seen as the "student power" movement (Levin, 2000). In 1967, there were 3500 students from 12 high schools that marched to the Philadelphia Board of Education to protest on topics related to black history courses, lack of black principals, and the police presence in their schools (Countryman, 2006). Twelve high school aged activists met with the superintendent and board of education to discuss their concerns. Given that there was no social media to expand this message of the march, this coordinated effort across many public high schools was impressive. In 1968, 250 African American students at William Penn Senior High School in York, Pennsylvania refused to attend class and locked themselves in the school auditorium to commence Black Pride Day following the assassination of Reverend Dr. Martin Luther King, Jr. (Fletcher, 2018). Student voice opportunities continued with the California State Board of Education in 1969 as they were the first state to appoint a high school student to their board (Gross \& Gross, 1977).

During the 1970's, there was an increase in students running for elected school boards. One organization, the Youth Liberation of Ann Arbor in Michigan was instrumental in assisting students in running for their school board and founded the youth led media magazine FPS (Conner et al., 2015) The organization claims that the title was not an acronym for anything particular. The impact of student voice on local school boards continues with involvement in school policy. In 1971, the Montgomery County Board of Education in Maryland adopted a policy that students must be involved in their own learning process 
including encouraging students to participate in establishing grade goals, interest areas, and planning classroom activities and evaluation of the courses. The Board noted that student suggestions and recommendations concerning curriculum and other opportunities shall be permitted at any time and solicited by the professional staff (Fletcher, 2018).

Student involvement in state policy was expanded in 1971 when 16 students participated in the Task Force of Student Involvement with the North Carolina State Department of Education and released a statement on student voice. The statement concluded: "What students are saying is that they care about schools, they want to be contributors to the educational process, not just recipients. Educators greatest potential resource lies in taking advantage of this interest and channeling it into responsible areas of action" (Kleeman, 1972, p. 15). This is one of the earliest known opportunities that students were collaborating with adults in public policy.

In 1975, legislation came to the forefront on educational rights for disabled or handicapped children. President Gerald Ford signed the Education for All Handicapped Children (Public Law 94-142) and "Congress opened public school doors for millions of children with disabilities and laid the foundation of the country's commitment to ensuring that children with disabilities have opportunities to develop their talents, share their gifts, and contribute to their communities" ("IDEA," n.d., p. 1) While prior legislation on the rights of students based on race, gender, and socioeconomic status existed, there was a continuation of the individual needs of children based on student ability level. This trend towards seeing children in our schools as individuals with unique needs and interests was groundbreaking during this time. During the 1980's, there was minimal movement within the student voice initiative (Levin, 2000). In 1983, the Nation at Risk report was released. The recommendations in this report included educational structural changes such as reinforcing the core curriculum and 
increasing the amount of time students were in school so that students in the United States achieve at a higher rate than other countries and therefore determine the success of economy (Adams, Jr. \& Ginsberg, n.d.). This focus on core curriculum resulted in fewer opportunities for students to explore electives in their area of interest. Students had less voice in selecting courses or topics of interest as the curriculum became more streamlined.

In 1989, the United Nations Convention developed the Rights of the Child in Article 12 ("Convention Rights," 1989). The rights in article 12 are shown below:

1. States Parties shall assure to the child who is capable of forming his or her own views the right to express those views freely in all matters affecting the child, the views of the child being given due weight in accordance with the age and maturity of the child.

2. For this purpose, the child shall in particular be provided the opportunity to be heard in any judicial and administrative proceedings affecting the child, either directly, or through a representative or an appropriate body, in a manner consistent with the procedural rules of national law.

The United States did not sign it as it contradicted parental and states' rights; this was a setback to the child rights movement nationally and internationally (Bartholet, 2011). The United States and Somalia were the only member countries in the United Nations that did not sign the Rights of the Child ("Convention Rights," 1989). This was seen as a negative direction in the student voice movement as the U.S. seemed focused on adult rights rather than that of the child.

In the 1990's, Jonathan Kozol released his book Savage Inequalities; it blasted the public-school system for the lack of equitable opportunities and education for all children ("Kozol," n.d.). This served as a reminder that children in poverty did not have the same 
educational exposure as their middle class or wealthy peers. During the 1990's, there were other efforts in the student voice movement including the Oregon School Study Council, the youth centered radio station NPF, and The Tattoo which was an online teen written newspaper (Fletcher, 2018).

Expansion of legislation and student representation on school boards were seen during the $21^{\text {st }}$ Century. During the early 2000's, students were expanding their presence on both state and local school boards. In about half of the states, students were serving as either advisory or voting members on their own local and state school boards (Conner \& Pope, 2013). In 2001, the No Child Left Behind Act (NCLB) became a federal law ("NCLB," 2010). This legislation forced the disaggregation of student achievement data and demanded results for underserved groups of students. The punitive nature of NCLB and political leadership changes at the federal level eventually resulted in the adoption of the Elementary and Secondary Education Act (ESEA) and then Every Student Succeeds Act (ESSA) in 2015 ("ESSA," n.d.).

The ESSA legislation allows for states to implement individualized plans that meet the needs of their own communities. Included in ESSA is the requirement of utilizing school climate surveys as a measure of student engagement ("ESSA," n.d.). Requiring student input as a measure in evaluating their own schools demonstrates that student voices are being recognized as of value at the federal government level. As a component of the Illinois ESSA Plan in 2018, school districts are provided a summative designation from their state agency based on the quality of academic program in public schools and classifies schools as one of the following: Exemplary School, Commendable School, Underperforming School, and LowestPerforming School("ISBE Summative Designation," n.d.). A portion of the score for the summative designation is based on the overall participation on the mandated school climate 
survey ("ISBE Summative Designation," n.d.). The score does not require that districts use the data but rather it is based on the percentage of participants that take the survey. There is also no requirement to meet specific thresholds for categories such as ethnicity, gender or type of participants such as students, staff, and parents.

In February of 2018, high school students in Parkland, Florida became the center of the gun rights and school violence debate. After a shooting at their high school that resulted in nearly 20 fatalities, the media gave significant airtime to the students who were willing to share their experiences on the incident and perspectives of school safety (Bump, 2018). High school age students conversed with elected officials at the local, state, and federal level to advocate for safer schools. With the insurgence of social media, students were able to immediately get the message out about a national school walkout on March 14, 2018. As history has shown, school walkouts are not new, but this was a national school walkout that resulted in thousands of children leaving their classrooms. Many of the students were supported by their communities, building administrators, and teachers while other adults have been intentionally negative and critical of these protests. This initiative expanded to the March for Our Lives which was a national student march on March 24, 2018 ("March," 2018). While the primary focus was in Washington D.C., students also organized smaller marches in their hometowns. It is too soon to know the impact of this student movement. Overall, first amendment rights have historically and continue to be a factor in student voice work (Fletcher, 2018).

Student voice has historically and continues to be a movement in education. High school students are challenging the norms and have been for decades, yet they still lack full social capital in their schools. Students have been "speaking" for years but the challenge is finding listeners and supporting their efforts in meaningful ways. While some student voices are 
recognized, there is not a comprehensive and equitable approach for all students from all backgrounds to be heard. In many situations, the adults making decisions for students have had very different educational experiences than the students they serve. Using the student voice pyramid as the conceptual framework, there is recognition that some of the methods of increasing student voice in schools vary from the most basic which could be a student interest survey through the highest level of involvement that may include voting rights on a school board.

\section{Types of Student Voice}

Responsible use of student voice requires educators to better understand not only the types and examples of student voice but to also examine how those legitimate opportunities lead to systemic school reform (Mitra, 2006). While some may believe that student voice is simply students talking, it has deeper meaning rooted in the democratic ideal. Prior to categorizing voice opportunities into various levels, I am providing various sample concepts that allow for the opportunity see how voice is impacting public schools. Elias (2010) identified six examples of enhancing student voice including participation in student government, student mentoring programs, service-learning project leadership, student community action teams, research partnerships with teachers, and content reflection in class. Other examples of voice opportunities include administrators that seek direct student input, principal advisory groups, student meetings with school staff and student run professional development for teachers (Ozer \& Wright, 2012).

\section{Pyramid of Student Voice}

The pyramid of student voice framework developed by Mitra (2006) supports a visual approach of the capacity of youth development as student voice opportunities increase with the most basic approaches at the bottom moving to a seemingly more intense involvement 
of students in leadership. Figure 1 depicts the pyramid. Using each section in the pyramid, I will categorize examples of voice within each level in the following section.

Figure 2

Mitra Pyramid of Student Voice (2006)

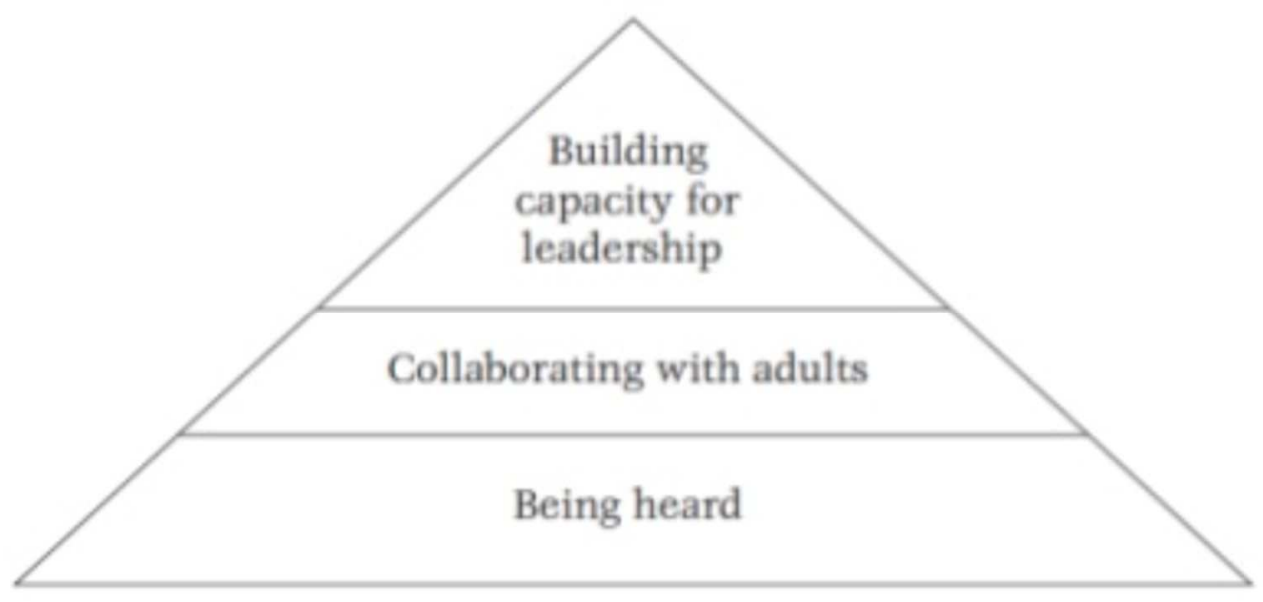

The most commonly available form of voice in schools begins at the bottom with "being heard". At this level, students have an opportunity to personally express their school experiences with school personnel. The next level up in the pyramid is "collaborating with adults". At this second level, students are working in partnership with teachers and administrators to identify issues at school and implement potential solutions (Mitra, 2006). The highest tier in the pyramid is "building capacity for leadership" and provides for "an explicit focus on enabling youth to share in the leadership of the student voice initiative" (Mitra \& Gross, 2009, p. 524). This level provides for the greatest positive outcomes for authentic youth development and is the least commonly found. Within each level found in the pyramid, a variety of examples of student voice can be classified. The following literature explores the types of student voice and the impact on continuous school improvement. 


\section{Building Student Voice Capacity in Leadership}

The highest tier of student voice allows for the development of student participation in leadership. At this level, a student may experience opportunity to serve as a representative on a school committee as an equal member. They may also provide professional development opportunities for teachers or serve on a committee that makes recommendations for educator professional development. This level of serving as an equal with educators is rarely achieved yet has the greatest impact on systemic change (Mitra, 2006).

\section{Student Voice in Collaboration with Adults}

Collaborating with adults is a student voice initiative that allows for students and adults to create a common ground in which to institute changes; this is the second tier of the pyramid of student voice (Mitra \& Gross, 2009). Examples of this include youth adult partnerships, youthled participatory action research, students as co-researchers, and personalized learning.

Youth Adult Partnerships. Youth Adult Partnerships (YAP) in a school setting are one example of a student voice opportunity (Mitra, Sanders, \& Perkins, 2010). In a YAP, the youth and adults have the ability and rights to participate and contribute to decisions made that impact them (Mitra, 2009). The YAP allows for students to engage in meaningful conversations that could potentially lead to positive changes in their schools (Mitra, Lewis, \& Sanders, 2013). One of the greatest barriers to implementing youth adult partnerships is the lack of professional development available for leadership of programs such as these (Mitra, Lewis, \& Sanders, 2013).

Youth-Led Participatory Research. The Youth-led Participatory Research (YPAR) model is one example of a student voice opportunity for students. It is an approach in which the youth will lead, conduct research, and advocate for change through the integration of their 
research in the school system; the student researchers are typically provided guidance from educators or community agency leaders (Ozer \& Wright, 2012). This research model of incorporating student voice in school improvement engages not only the teachers in the process but also the students. Young people are given an opportunity to identify their own school-based concerns, investigate the foundational issues with those concerns, and positively find ways to implement change based on their YPAR team research. YPAR creates student empowerment opportunities that enhance the relationships between students and teachers (Ozer \& Wright, 2012).

Students as Co-Researchers. The model of students as co-researchers (SCR) allows for students and educators to work collaboratively on school related issues. The guidelines for SCR can vary but typically allow for teams of teachers with students in small groups to collect school data towards data driven decisions, to promote balanced inclusivity of voice with teachers and students, and for the activities to be academically focused by encompassing a standards-based experience (Yonezawa \& Jones, 2009). This model also requires that students have a basic understanding of research design which may require training for the volunteer student participants. Adult participants in SCR work find that they gain substantial qualitative data about their students, that it provides a more complete vision of their needs, and changed the conversations between adults focused on improving schools (Yonezawa \& Jones, 2009). "Student co-research projects are also helpful in that they bring students to the table as educational partners" (Yonezawa \& Jones, 2009, p. 210).

Personalized Learning. When teachers provide for students to give input into the operations in the classroom, this is considered a form of student voice in schools. Cook-Sather (2006) further identifies the opportunity that should be afforded students through student voice 
initiatives and found that students have "unique perspectives on learning, teaching, and schooling that warrant both the attention and responses of educators" (p. 359). High school students in high ability classrooms are often given opportunities for selecting learning options more frequently than their peers who are younger and struggle academically (Flowerday \& Schraw, 2000). Through this research study, teachers made recommendations about when utilization of voice in the classroom is appropriate including the use in all grade levels and when students have expansive knowledge of a topic. Flowerday and Schraw (2000) also identified that student voice can be used in many content areas, different classroom tasks including homework and assessments, and in providing opportunities in the classroom as well as school social activities. Lemley \& Schumacher (2014) asserted the perspective that students in $21^{\text {st }}$ century learning environments consistently appreciated choice in seating arrangements, work partners, and 24-hour access to classroom materials. This autonomy provides unique ownership to the students over their own learning in partnership with their teachers. The outcomes also found that "presentation and student-teacher relationship were key factors in engagement and student enjoyment of the class" (Lemley \& Schumacher, 2014, p. 114). In order to support a positive learning experience, students connect with teachers through personalized conversations in which the educator has specific background information on the student; this component of student voice allows for a focus on building trusting relationships between teacher and student (Lemley \& Schumacher, 2014).

Conner and Pope (2013) investigated student engagement outcomes and various types of classroom engagement with research in 15 schools and 6,294 students. This research identified that students who attend high-performing schools consistently value strong student-teacher relationships which can be accomplished in many ways including the demonstration of the 
respect for student's wellbeing through the use of encouraging and insisting on student articulated concepts and ideas (Conner \& Pope, 2013).

Through personalization of learning, students are given a voice in what and how curriculum is provided. Garn \& Jolly (2014) identified that high-achieving students were more motivated by teachers who had personal knowledge of them and aligned instruction with the student goals made learning more meaningful. The teachers that offer the students choices in the instructional strategies and creativity in projects that address their diverse learning styles and interests experience higher levels of engagement (Garn \& Jolly, 2014).

High school students have an acute awareness of instructional methods that support their learning styles and ways to motivate them. Pedder \& McIntyre (2006) determined that students place "an importance to their learning on a balance between teacher and pupil talk and involvement" (p. 149). Students who are struggling learners have difficulty expressing their thoughts and perspectives and this appears to be a fundamental concern when working to implement student voice initiatives. "Lower attaining pupils are the pupils whom teachers most need to consult and yet they appear to experience most difficulty in articulating their insights" (Pedder \& McIntyre, 2006, p. 152). The long-range successful implementation of student voice requires specific conditions within the classroom. There must be mutual respect and trust between the teacher and students and a true belief that both parties are gaining benefits from the more democratic relationship. An additional challenge for teachers involves finding ways to support students from diverse backgrounds, with different personalities and levels of communication skills, to find common purpose and solidarity in the classroom through student voice initiatives (Pedder \& McIntyre, 2006). 
To better understand student engagement in personalized learning, it is important to explore the students' response mechanisms to the actions of their teachers, families, and students themselves as they complete schoolwork. In research conducted by Iceman Sands et al., (2007), 91 student participants were selected in grades 4, 7, 9 and 11. Students were placed in focus groups based on their grade level and included students of varied academic abilities. They were asked to describe their learning and share the factors that impact the learning as it pertained to their personal actions and those of their families and their school when asked one guiding question about effort in school or on schoolwork. Students in the study were forthcoming about the actions that were helpful or not helpful to their personalized learning. This is valuable information as educators seek to improve achievement and equitable conditions in schools. Without a formal process of engagement, this data is not considered in many school reform efforts but should be part of process (Iceman Sands et al., 2007). It is important to note that this study provided insight as the participants were primarily Latino and have an important voice in systemic change efforts as our schools become more diverse. The purposeful selection of students was based on their gender, ability, English language acquisition, and grade in school. While this study pertained to mostly Latino students, it is a positive step towards better understanding the equitable needs of all students in the instructional process and the ways in which their families and schools support their learning.

\section{Student Voice-Being Heard}

As discussed, the top two tiers of the student voice pyramid provide for the greatest opportunity for gaining social capital through student voice. The bottom tier of the pyramid is the most basic to attain with the least impact on school reform (Mitra \& Gross, 2009). I will focus on youth activism and student surveys as examples of the one-way communication that 
occurs with this form of student voice. Students may articulate their message very well at this level, but it is optional for adults to engage or acknowledge their perspectives.

Youth Activism. As a democratic society, it is expected to inform students in the classroom on the tenants of democracy in the United States. Through the public-school system, student voice is an opportunity to incorporate their opinions on a part of their world that directly impacts them. "Schools tend to teach students to be passive participants in a democracy rather than leaders" (Mitra \& Gross, 2009, p. 523). Educating students on processes that replicate a democratic environment allows students the academic structure to practice effective democratic methods including collaboration, public speaking, and cultural sensitivity. The students could witness their own teachers providing an environment whereby the students are permitted to participate in a classroom that honors their voice in a democratic society.

Without institutional leadership at the federal, state, and local level towards promoting student voice, there remains the opportunities for bottom-up voice efforts. Youth activism is focused on students working towards the action of challenging injustices while youth leadership allows students the opportunity to share in school decisions (Mitra, Serriere, \& Kirshner, 2014). This form of social capital development allows for students to move their agenda of student voice into the forefront of school reform. Energizing students towards the cause of democracy is foundational to the student voice movement.

Student Surveys. When examining school reform efforts related to $21^{\text {st }}$ century learners, public-school students may have powerful insights in the efforts to provide support for the changes and are motivated intrinsically to support the changes. Student voice literature illuminates that students are important stakeholders to include when discussing a learning environment that meets their generation's specific needs. In research conducted by Lemley \& 
Schumacher (2014), nearly 1,400 students in the $11^{\text {th }}$ grade were surveyed on their learning conditions. The study found that the students were motivated by strong student-teacher relationships that fostered autonomy, relevance, and connection in the learning environment. For this research, there was no purposeful selection of students in various under-represented groups including gender, race, ethnicity or socioeconomic status. This was acknowledged as a gap in the research study. Surveys are one way to gain the greatest quantity of student voice insight. However, personal student interviews through qualitative research allows one to gain deeper understanding into student perspective (Lemley \& Schumacher, 2014).

Gathering student information can be conducted in many ways. Researchers can use surveys, interviews, student records, achievement data, etc. One method of gathering pertinent information on the perspectives of students is through student surveys. Obtaining student voice through youth participatory research, surveys, and interviews allows for educators to gain a viewpoint that has long been neglected (Iceman Sands et al., 2007). Research results have identified that students in elementary grades through high school have the ability to articulate the reasons they may increase or improve their effort in school (Iceman Sands et al., 2007). School reforms efforts can be improved through student feedback on teachers by "creating systems, policies, and procedures to seek student feedback” (Iceman Sands et al., 2007. p. 340).

Seeking student feedback through student voice can be obtained in many ways and for a multitude of purposes. School districts may use student surveys as a mechanism for identifying the status of their school climate. These types of surveys are either voluntary for districts and participants or mandated by the state and/or federal government. The American Institutes for Research (2013) found the availability of nearly 40 survey instruments that assess school climate ("School Climate Survey," n.d.). Bradshaw, Waasdorp, Debnam, \& Lindstrom Johnson (2014) 
utilized the Maryland Safe and Supportive Schools Climate Survey data from nearly 25,000 students and the United States Department of Education model of school climate to determine if the student survey data was an appropriate means in which to gain knowledge on issues related to safety, engagement, and school environment. This information is valuable as students tend to have more difficulty concentrating and are less successful in school when they believe their environment is in social disorder (Bradshaw et al., 2014). Student perceptions about their own experiences can only be obtained through data and dialogue directly from them.

The impact of school climate on high school dropout rates has been widely researched. Peguero \& Bracy (2014) conducted research to examine student perceptions on five dimensions of school climate including "security, discipline, disorder, procedural justice, and student-teacher relationships" (p. 413). Results from this study indicated that a healthy school climate reduced the likelihood of students dropping out. The data collection process for this research required students to self-report their own perceptions which was determined to be an appropriate method of gathering data (Peguero \& Bracy, 2014).

A research study conducted by Jia, Konold, \& Cornell (2016) utilized data from the Virginia Secondary School Climate Survey to investigate the relationship between school climate and dropout rates. The survey used is "a statewide assessment of school climate and safety conditions in Virginia public secondary schools" (Jia, Konold, \& Cornell, 2016, p. 292). Analyzing data from this survey, researchers found that lower dropout rates in schools were associated with "high academic expectations and supportive student-teacher relationships" (Jia et al., 2016, p. 300). These results are pertinent as it resulted from the student climate survey data which was obtained in one year from 52,012 public high school students enrolled in grades 9-12. The results of student responses to climate surveys illuminates the importance of 
formally gathering student perspective and using that data towards school improvement. Surveys are a viable option for collecting large quantities of data; however, they "are not intended to replace all other methods of hearing student voice" (Watson, 2003, p. 155). Other examples of school climate surveys in the United States include the Alliance for the Study of School Climate-School Climate Assessment Inventory, Brief California School Climate Survey, Comprehensive Assessment of Leadership for Learning, Comprehensive School Climate Inventory, Creating a Great Place to Learn Survey, Culture of Excellence and Ethics Assessment, Inventory of School Climate-Teacher, Organizational Climate Inventory, The Teacher Version of My Class Inventory, School Climate Inventory, and Teaching Empowering Leading and Learning Survey (Clifford et al., 2012).

While most school climate surveys are quantitative, there is considerable research on student voice that has been qualitative in nature including case studies and program analysis. However, there is a shift towards large scale research using student voice and collecting vast quantities of student data. Mitra et al. (2014) believes that "student-voice researchers must investigate whether these new forms of data collection value and explore the concepts" that are valued by student voice experts (p. 301). Without conversing with students on a personal level, it is unknown whether the results on a student voice survey are valid when students are only allowed to express their voice on a pre-developed, multiple-choice paper-pencil or computer-based survey.

While districts may use high quality instruments to gauge school climate, it is necessary to then provide feedback back to the students. Watson (2003) asserts that student views must be translated into action and that students are then provided information about the school improvements. This closing of the feedback loop "will improve the likelihood of students 
providing feedback in the future" (Watson, 2003, p. 156). The continuous cycle of providing feedback also increases student confidence in the results and is an ethical step in the process. While school district administration may not be capable of improving all levels of feedback, it is vital to let students know that their views are being considered (Watson, 2003). When there is no response to their voice and no action towards resolving those issues, students may not choose to participate in any further surveys.

Illinois public schools are consistently inundated with funded and unfunded mandated obligations through the Illinois General Assembly, Illinois State Board of Education (ISBE), local governing bodies, and laws passed through the federal government. The Illinois 5Essentials Survey is one such mandate by ISBE which requires every public-school district in Illinois to participate in a school climate survey on alternating school years beginning in 20122013 and then every year beginning in 2018 ("ISBE ESSA Plan," 2017). Students in grades 4-12 are asked to participate in the survey and may be given time during the school day to respond. However, there is no expectation by ISBE that survey results be shared in any manner with the students. This contradicts best practice for survey response distribution. According to Watson (2003), there must be careful attention to the methods of formally collecting student input to determine if they are beneficial to the school, school district, and the students themselves.

The Illinois 5Essentials Survey was developed through UChicago Urban Education Institute Chicago Impact as a result of the UChicago Consortium on Chicago School Research (CCSR) on Chicago Public Schools (Klugman, Gordon, Bender Sebring, \& Sporte, 2015). Prior to the implementation of the Illinois 5Essentials Survey, the UChicago CCSR developed and administered the survey in the Chicago Public Schools from 1991 through 2009 which allowed 
for several years of data collection (Klugman et al., 2015). Moving forward, Chicago Impact continues to collaborate with ISBE on the implementation of the survey while CCSR will review and analyze data and survey questions.

The five essential learning condition supports that guide the survey are effective leaders, collaborative teachers, involved families, supportive environment, and ambitious instruction ("Illinois 5Essentials," 2012). Questions on the survey are focused on providing information on the level in which schools have achieved a strength in these constructs. Student survey questions are focused on three of the five areas including involved families, supportive environment, and ambitious instruction ("Illinois 5Essentials," 2012). The levels of strength within each of the five essential areas are rated as most, more, average, less, and least implementation; the final category is not applicable/low response which would a comment provided if an essential support area did not meet the required number of participants ("ISBE Report Card," n.d.). The combination of the five essential areas will provide insight into the organizational strength of the schools to make sustained school improvements. "The five essentials framework also posits that leadership and the other four core supports exist within a broader context of a climate of mutual trust” (Klugman et al., 2015, p. 7). Research conducted in 2015 on the Illinois 5Essentials Survey identified that the "largest percentage of schools strong in climate and instruction in Illinois are located in urban and suburban communities" (Klugman et al., 2015, p. 27).

Results from the Illinois 5Essentials Survey are provided annually by ISBE on the Illinois School Report Card. Typically, the school climate survey is released for participation in November with approximately three months to complete it by students, staff, and parents. Results from the Illinois 5Essentials Survey are provided to school district administration in May of the following calendar year then released to the public in October on the Illinois School 
Report Card. Given that the data collection reports from the Illinois 5Essentials Survey may not be provided to districts until almost five months after the survey distribution has taken place, it could result in some students no longer attending the schools because of graduation or transfer. In addition, there could be a change in school administration that may not believe the data from the prior school year is applicable or valuable to them. Watson (2003) confirms that "the set-up of some student surveys does not allow for the loop to be closed" (p. 150). Some practices for distributing survey results can be through marketing efforts of printed materials, Internet resources, and direct communications with students (Watson, 2003).

In 2014, the Illinois Education Research Council (IERC) conducted research with the support of the Illinois State Board of Education to examine implementation concerns related to the Illinois 5Essentials Survey (Klostermann, White, Lichtenberger, \& Holt, 2014). Several recommendations were made to improve the logistics associated with the survey so that districts would find value in using it as a school improvement instrument. The recommendations included increased professional development for educators, improving technical assistance for data interpretation, adding a secure log in for survey participants, and adjusting the survey timeline (Klostermann et al., 2014) Students were not provided an opportunity to participate in this research nor to provide any feedback through the IERC surveys.

The levels of student voice within the context of the pyramid of student voice allows for a visual approach that is similar to response to intervention (Mitra, 2006). The bottom level "being heard" is one-way communication from students towards the educators with minimal impact yet the most commonly used. As one moves up the pyramid, the sections become increasingly smaller which is representative of the narrowing use of that form of student voice which is "collaborating with adults". The pinnacle of the pyramid is the ultimate goal of the 
student voice movement which is "building capacity for leadership". This foundational information aids in better understanding the value of proper implementation of student voice.

\section{Implementation of Student Voice}

The classroom teaching methods of the teacher speaking and students listening is a passive approach to learning. Moving away from this traditional approach in public high schools towards building student capacity for leadership with student voice requires high quality planning and meaningful delivery. Using student voice in schools, there are methodologies that must be considered for successful implementation. "As with any educational change, the quality of implementation will prove to be as important as the merit of the idea itself' (Mitra \& Gross, 2009 , p. 536). In this section, implementation of student voice will be discussed as it relates to leadership, equity, and challenges of implementation.

Meaningful student involvement requires a cyclical process for successful voice implementation. Fletcher (2014), refers to this four-phase process as the "Cycle of Engagement" (Fletcher, 2014, p. 17). The cycle includes listening, validating, authorizing, action, and reflecting. Beginning with listening, opportunities are provided to listen to the perspective of students in both verbal and written formats. The next step is validation of student through the providing of both positive and negative genuine feedback to the student comments. The third step is adults providing students with the authority to develop their voices towards actionable steps followed by shifting the authority to students which "allows them to affect cultural and systemic educational transformation and encourages adults to acknowledge students as partners" (Fletcher, 2014, p. 17). The final phase in the Cycle of Engagement is reflecting on the successes and impact of the implementation. Upon reflection, the cycle returns to listening to 
student voices to consistently maintain forward progress. Ensuring proper implementation requires a skill set for school leaders.

Leadership Requirements. The value of high school principals in implementing student voice opportunities is a vital component to the success of the implementation. Research indicates that a highly effective principal can improve the achievement of students by two and seven months each year whereby those principals deemed ineffective can lower the achievement by the same amount (Branch, Hanushek, \& Rivkin, 2013, p. 63). Principal leadership in adjusting the environments academically and social emotionally must be done with an equitable approach.

There are several situations that exist that can cause either bias or frustration with the equitable implementation of student voice. These situations must be rectified before student voice can be utilized with fidelity in systemic school change. Rudduck and Fielding (2006) argue that the authenticity of the implementation of student voice initiatives is critical. The research identified three areas in which students would gauge the authenticity of the implementation that includes the student involvement in the focus of the voice opportunity, genuine interest of the adults in the student comments and perceptions, and the follow through by the adults based on the discussion and/or actions of the student participation (Rudduck \& Fielding, 2006). The importance of responding effectively to the feedback of students is shown to be an important factor in supporting student voice initiatives. According to Rudduck and Fielding (2006), school improvement is the primary purpose for student voice implementation in the current standardized assessment climate and that student voice benefits can be overshadowed by schools using it as a quick fix in their school reform efforts. 
The limitations to student voice opportunities can be found with a strong national focus on schools which reduces local control efforts. The No Child Left Behind (NCLB) Act which was signed in 2001 resulted in an increased drive to produce higher test scores (Mitra et al., 2014). The perceived penalties under NCLB included the possibility of teachers losing jobs and schools being closed for lack of performance. This federal legislation also resulted in moving towards the Common Core Standards and "deemphasizing subjects such as history and civics that may frame an idea of youth participation as crucial for democracy" (Mitra et al., 2014, p. 293). The prominent justification for student voice in this performance-dominated educational climate was school improvement (Rudduck \& Fielding, 2006). School leaders should be cognizant of the impact that mandates have on student voice in their schools.

School leadership in the realm of the student voice movement requires a basic understanding regarding the acceptance of a power shift within the school environment. "Seeking and responding to student voice challenges traditional power structures in schools" (Iceman Sands et al., 2007, p. 326). Implementation requires school leaders and teachers to take considerable efforts to build a student voice culture in their schools as a norm not an anomaly. "There is a moral responsibility for leaders and teachers to invoke student voice - to insist upon, enquire into, try to understand, interrogate, and generate student voice as best they can" (Angus, 2006, p. 378). As with any successful school improvement initiative, student voice requires support from the school administration. This effort at the top level of leadership adds legitimacy to any student voice initiative and will encourage students to be viewed as active decision makers and school reform leaders (Mitra, 2006).

Mitra \& Gross (2009) emphasized the value of proper implementation of student voice efforts. When implemented with fidelity, the profound benefits of student voice include student 
engagement, student freedom to express themselves, citizenship preparation, student feeling of respect, and the creation of a listening culture (Cook-Sather, 2006). Students that experience student voice opportunities that are poorly organized and lack proper execution may become frustrated and distrustful of the intentions of the school leaders and teachers. "Surface level implementation could create greater alienation among young people by offering insincere gestures rather than authentic partnership" (Mitra \& Gross, 2009, p. 536). Improper implementation sends a message that it is token attempt at student voice opportunities rather than an authentic approach to change. This leads to frustration by the youth; the failure to respond to unfavorable comments within student voice opportunities is an implementation concern as well (Cook-Sather, 2006).

While some student voice programs are internally derived from within the school, other programs are initiated, lead, and implemented by outside agencies in partnership with school districts. There are benefits and detriments to both methods. External programs may lack internal legitimacy; however, they may be able to subsidize these programs with financial support and appropriate staffing (Mitra, 2006). Student voice initiatives that are school based programs have more immediate legitimacy than community-based programs and communitybased organizations will trade that legitimacy for the opportunity to blatantly challenge the norms of the organization (Mitra, 2006).

School leaders and teachers have an important role in implementing student voice. Flowerday and Schraw (2000) suggest that teachers consider offering basic choices at the beginning and that the teachers assist the students in the practicing of making informed decisions. The research also indicates that students be given feedback on their choices. When implementing with younger students, Flowerday and Schraw (2000) suggest the use of team 
choices to provide collective support for the students who lack capacity to make classroom choices independently. Additionally, it is vital for the teacher to be explicit with the choices to ensure understanding.

Effective implementation of student voice measures presents specific challenges in public high schools. The focus on standardized testing may result in schools narrowing their curriculum to a level that does not allow for youth development activities (Mitra, Sanders, \& Perkins, 2010). The research also indicates that there is value in providing professional learning and technical assistance for the adults around leadership of youth adult partnerships (Mitra, Sanders, \& Perkins, 2010). This training supports the process by adults better understanding the importance of the roles in the partnership as well as the best practices in being inclusive with student voice measures. "The youth adult partnerships need help with youth leadership skill development, team building, project development, and targeted training for adults" (Mitra, Sanders, \& Perkins, 2010, p. 106). Educators may see this sharing of the power by providing authentic student input opportunities as uncharted territory; they may not be comfortable with relinquishing the power (Mitra \& Gross, 2009). Teachers may feel threatened by this new approach if they do not feel confident in their role. It is vital for school leadership to assist teachers to feel empowered through professional learning and to increase teacher collaboration opportunities. By helping teachers to feel confident about the experience, they will be more likely to move away from the traditional roles in schools towards fully supporting equitable student voice endeavors for all students.

Implementation of student voice requires that school leadership value particular concepts to garner an optimal student voice climate. These include a "clear vision of school that is incorporated deeply into practice, allowing opt-in strategies for teachers, and recognizing that 
implementation across classrooms and personnel will vary depending on individual contexts, beliefs, and experiences" (Mitra, Serriere, \& Stoicovy, 2012, p. 104). Creating an environment that allows for regularly embedded student voice opportunities requires a leadership vision that shifts the school culture from an adult driven environment towards a day-to-day philosophy of student voice practices. Since all teachers do not have the immediate skills to participate fully in this philosophy shift, it is best practice to allow teachers to voluntarily connect with students in these practices rather than being forced to engage in student voice initiatives (Mitra et al., 2012). While flexibility of participation in student voice initiatives in a school does allow for teacher opt-in, it may leave some of the nonparticipating teachers to lack buy-in and continue to run their classrooms in a traditional, less democratic format. However, teachers who favor the student voice philosophy will continue to encourage the practices in their own classrooms (Mitra et al., 2012). School leadership should continue to integrate this democratic philosophy by blending volunteer teacher opt-in and "creating activities and structures that demand participation" (Mitra et al., 2012, p. 109). This relentless action towards creating a culture of empowering students translates to new norms for school leadership, teachers, and students.

Equity. The importance of responding effectively to the feedback of students is shown to be an important factor in supporting student voice initiatives. "Providing a safe environment in which students can speak without fear of reprisal and actually using student feedback to implement change are keys to quality input from students" (DeFur \& Korinek, 2010, p. 19). The goal should be to not only seek the voices of the high achieving students but to identify equitable student voice opportunities for all types of students. Using the perspectives of all demographics of students results in identifying issues, promotes community, increases student engagement, and gives focus to faculty on student interventions (DeFur \& Korinek, 
2010). School leadership and researchers in student voice must be cognizant of who and how students are provided opportunities for gathering information in order to insure equitable treatment. DeFur \& Korinek (2010) were intentional in their development of specific focus groups to seek more information exclusively on gender, race, varied achievement levels, and IEP status. With careful consideration of those students in special education, students were provided the appropriate supports to feel more comfortable in sharing their concerns. The research identified that all participants were willing and pleased to openly discuss their schools and education regardless of their academic status or grade level. The research results suggest that garnering the collective voices of students can be an effective approach for school reform (DeFur \& Korinek, 2010).

\section{Summary}

Appropriately implemented student voice opportunities are a mechanism for increasing student engagement for all students. In Chapter II, the review of the literature was provided to gain a better understanding of the concept of student voice, the historical background of student voice in the United States and the types of student voice. Implementation of student voice must be conducted with purpose and care so that students are not insulted by token style approaches. As with all systemic changes in school including school climate, leadership plays a crucial role in the success of implementing and supporting student voice efforts.

According to Angus (2006), "to make such a decision to comply with the institution of schooling, the young person has to have some personal connection to the school, a stake in what the school is perceived to offer, and a sense of the worthwhileness of the schooling experience" (p. 370). It is no small challenge to listen to and effectively respond to the individual voices of the children in our schools. To move towards equitable treatment and representation of our 
diverse students requires that the adult members of the school community provide a system in which our youth can be heard.

This study will examine the current usage of the student response data from the Illinois 5Essentials Survey by public high school principals. In Chapter 3, the methodology used for this study will be discussed. 


\section{CHAPTER III: METHODOLOGY}

This chapter provides a description of the methods that were utilized in conducting this research study. There will be a discussion of the research design and procedures, sample, data collection, and variable identification. Within Chapter Three, there will be information provided about the instrumentation with the methods to support internal and external validity. This chapter identifies the process for the creation and administration of both the pilot and final research survey which includes quantitative and qualitative data. These responses will illuminate the utilization of the student responses on the Illinois 5Essentials Survey by high school principals. The final section of this chapter will specify the steps that will be taken to analyze and interpret the data.

This study is significant to the field of public-school education as it addresses the need for equitable opportunities for student voice in school climate, decision making, and sustainable school improvement. By determining high school principal use of student data from mandated school climate surveys, an analysis was conducted on the value of these surveys in gathering authentic student voice. The findings of this study provide insight into the actual use of the state mandated survey by Illinois high school principals which could be used to positively impact school, district, and public policy on the implementation of these types of surveys.

\section{Positionality}

As a professionally licensed educational leader, I am compelled to maintain a studentcentered focus in the decision-making process. At the school building level, I have served as a teacher, assistant principal, and principal in public high schools. For five years, I have served as an Assistant Superintendent in a county regional office of education as an employee of State of Illinois. Since 1990, I have devoted my time to children in school districts. I have a broad and 
unique perspective of education as I have worked in large and small schools, unit and high school districts, and rural and urban schools. With oversight of nine, unit suburban districts, I have found that there are vast differences among all of them. As a community volunteer, my time is centered around abused and neglected children and providing the support they need to have a voice in the legal system.

As an educator in Illinois, I have had experience with developing programs that welcome and encourage student voice. The Illinois 5Essentials Survey was mandated bi-annually during my principalship. This survey and many requirements by ISBE influenced my daily work. There has been a stream of policy changes and educational trends that have come and, in some cases gone, during my tenure in education. With limited resources and many unfunded mandates, I believe in examining the use of school funds and maximizing their potential. The hope is that this work leads to further examination of the use of student voice data and influences principals to faithfully engage students in leadership in their schools.

My research position would be characterized as an "insider" or immersed in the educational system in the state of Illinois. I am an educational leader with a professional network of administrators locally, statewide, and through social media outlets such as Twitter and Facebook. I serve on a statewide task force for the Illinois 5Essentials Survey and oversee compliance audits with county school districts. As an educator and doctoral student, I am cognizant of the knowledge, opinions, and biases I may bring to the research. However, through this awareness, I will make all efforts to honestly and accurately reflect, respect, and report survey respondent data. 


\section{Research Design}

With a focus on the research questions, the research design provides for an opportunity to highlight the ways that the study on student voice was structured including the population and sample, instrumentation, and variables. The purpose of this study gathered input on the use of the student data from the Illinois 5Essentials Survey by high school principals in Illinois. The methodology employed is a correlational quantitative research design. The research design suggests that the "dependent variable is the outcome variable and that the independent variables are all of the other things than can impact the outcome variable" (Butin, 2010, p. 87).

A pilot study was conducted as the questions used in the survey required validation given that they were self-developed, original survey questions. Using Qualtrics research software, a link to the survey and informed consent was emailed directly to 135 high school principals in Illinois. A complete list of principals in the state was provided by ISBE. The list included the names, emails, and enrollment of those principals whose school participated in the Illinois 5Essentials Survey during the 2018-2019 school year. The principal pilot survey was completed by 30 principals from across the state. Reminders were sent after two weeks with yet another request two weeks later. The data was reviewed statistically to ensure the survey questions were valid.

The final research survey was distributed through a web link created by Qualtrics and emailed to the participants with the informed consent letter content is provided in the Appendix B and Appendix C. A web link to the survey was distributed via a direct email from addresses obtained from the Illinois Principal Association and the Illinois State Board of Education. An informed consent letter accompanied each survey that provided an explanation of the survey and 
risks associated with the survey as shown in Appendix C. A reminder was sent two weeks after the initial survey distribution date.

Using the following research questions, the independent variables to be examined include ISBE School Quality Summative Ratings, geographical location, school enrollment, and student voice options. The dependent variable is the principal usage of the student data from the Illinois 5Essentials Survey as reported in a questionnaire. The researcher examined the variables and qualities of the specified sample and demonstrate the variable distribution.

\section{Research Questions}

Six research questions concerning the commitment by Illinois principals were explored. These research questions are as follows:

(RQ1): What does the statewide data tell us about the usage of the Illinois 5Essentials Survey by high school principals?

A. What is the percentage of high school principals utilize that utilize the student voice component of the Illinois 5Essentials Survey for school improvement?

B. What percentage of principals feel well prepared to utilize the data in the Illinois 5Essentials Survey?

C. What is the frequency that principals purposefully share the results of the student voice portion of the Illinois 5Essentials Survey with stakeholders?

(RQ2): Does the student voice data usage from the Illinois 5Essentials Survey vary based on the quality level of the ISBE summative designation rating for public high schools on the Illinois School Report Card? 
(RQ3): Are there geographical differences in the state of Illinois high schools where the Illinois 5Essentials Survey are more commonly utilized as a tool for student voice by high school principals?

(RQ4): Are there leadership and involvement differences by high school principals based on school enrollment size to implement and respond to student voice data from the Illinois 5Essentials Survey?

(RQ5): Are principals that utilize the Illinois 5Essentials survey more engaged in implementing alternative types of student voice opportunities in their high school.

(RQ6): Do principals perceive that the student data can aid them in supporting school climate in their schools?

\section{The Population and Sample}

The population and sample for this study focused on high school principals in the state of Illinois. Since a pilot and final survey was conducted, baseline demographics will be provided for both samples. The pilot survey was conducted in April and May of 2019 with the final survey being conducted in September and October of 2019. Since the surveys covered two different school years, some participants in the pilot survey may no longer be serving as high school principals or in the same school districts.

For the pilot survey, 135 high school principals from across the state were randomly selected and emailed the survey. There were 30 high school principals that completed the pilot survey. The participants were high school principals from all but one area of the state. While a request was made to participate in the pilot survey, no principals from Area 6 completed the survey. The final research survey was administered to 760 high school principals in public schools that participate in the Illinois 5Essentials Survey. This final survey was completed by 
130 high school principals from all areas of the state, all school sizes, and represented each of the ISBE quality summative ratings.

A questionnaire was disseminated to currently employed public high school principals in Illinois. Survey designs in quantitative research allows for the administration of a questionnaire to a small sample of individuals within an identified group in order to identify trends that could be applied to a larger group or population (Creswell, 2012). The research participants were employed as high school principals in a district that currently utilizes the Illinois 5Essentials Survey. Those principals in districts that use the Illinois State Board of Education alternatively approved school climate surveys were not eligible participants in the study. While students from Illinois middle schools participate in the Illinois 5Essentials Survey, the age range variability in those schools make it more difficult to identify principals that are directly impacted by their student body participating in the survey. For the purpose of dissemination of the survey, high school principal email addresses were obtained through an email request from the Illinois State Board of Education and Illinois Principal Association databases. These two agencies have professional relationships with school district educators, administrators, and licensed support staff throughout Illinois.

\section{Instrumentation}

This study was conducted by using a survey of participants who currently serve as high school principals in Illinois. By obtaining information from a sample of high school principals, the purpose was to garner insight of a larger population of participants. This type of instrumentation was selected in order to collect the greatest quantity of data in an expeditious manner from high school principals spanning the state of Illinois which is " 57,914 square miles" (Cartwright, Simon, \& Lockhart, 2019). There is little known about the use of the Illinois 
5Essentials Survey while there is considerable data regarding the quantity of individuals that participate in the survey.

As required by Institutional Review Board (IRB) at Illinois State University, approval was requested and granted to conduct the study with high school principals. In order to conduct research on human subjects, federal regulations require that this study by approved by IRB prior to conducting research. The researcher completed all components of the mandatory CITI training. IRB protocols were completed after approval of the dissertation proposal by the dissertation committee and prior to beginning of the research.

Beginning in April of 2019, high school principals were asked to complete a questionnaire based on their use of the data obtained from the student voice portion of the Illinois 5Essentials Survey school climate instrument. Prior to dissemination, the pilot survey was shared with a sample of high school principals for the purpose of pretesting the questionnaire and gaining input on individual questions. The pilot responses allowed for clarification of ambiguous questions and clarification of survey instructions (Fraenkel, Wallen, \& Hyun, 2012). The survey was created specifically for this study. Because many high school principals have experience with the Illinois 5Essentials Survey, they were an appropriate audience in which to vet potential questions. While the Illinois 5Essentials Survey is offered to younger grade levels, middle and elementary school principals were not included as a sample of the population for the research study as the focus is on high school principal perceptions of student voice. The questionnaire included multiple questions that were originally disseminated in the ISBE Implementation Feedback Survey for Principals as well as selfdeveloped questions that support the student voice lens. Permission to use the ISBE 
Implementation Feedback Survey was granted by a staff member at the Illinois State Board of Education on February 11, 2019.

In January and February 2014, ISBE surveyed superintendents and principals from all Illinois public schools about their opinions of and experiences with several ISBE initiatives, including the 5Essentials Survey and data reports using the ISBE Implementation Feedback Survey. There was a total of 18 questions in the ISBE Implementation Feedback Survey. Seven of the 18 questions were specifically related to the 5Essentials Survey. The remaining 11 questions were for collecting district demographics and information on other ISBE initiatives that were being newly implemented in 2014 and unrelated to the Illinois 5Essentials Survey. This ISBE Implementation Survey was completed by 273 superintendents (32 Percent) and 634 principals (16 Percent) (Klostermann et al., 2014). The Illinois Education Research Council (IERC) collected and analyzed the data from this survey and further investigated the use of the Illinois 5Essentials Survey through 15 site visits in school districts throughout the state. An interview protocol of 43 questions was followed up by the researchers and data from the survey and site visit protocol was analyzed in the IERC report to gather more reliable information regarding the Illinois 5Essentials Survey. All data for both the survey and site visit are found in the IERC report.

For this research, a survey was developed with a blend of original questions and those found on the ISBE Implementation Survey. This high school principal survey was electronically sent to principals via email using Qualtrics which is an Internet based survey tool. The advantages of using a web-based survey software is that it is inexpensive, convenient, allows for use on mobile devices, and reduces data entry for results (Fraenkel et al., 2012). Illinois State University provides complimentary Qualtrics access to graduate students conducting research. 
The survey was limited to less than 18 multiple choice/closed-ended questions and one open response question. "Close-ended questions are easy to use, score, and code for analysis on a computer" (Fraenkel et al., 2012, p. 399). The focus of the principal survey was on the utilization of the student response data of the Illinois 5Essentials Survey.

An email including the informed consent and the survey link was disseminated to participants through Qualtrics. The pilot survey was sent directly to principals through Qualtrics with email addresses obtained from ISBE. The informed consent for the pilot and final survey described the topic of the survey and explain the purpose of the research. An assurance of confidentiality and the providing of feedback of survey results was provided within the cover letter. After the original request to complete the survey, two reminder emails were sent to the high school principals in order to increase the responses to the surveys.

\section{Instrument Development and Validation}

In order to ensure the highest possible quality for the survey, a pilot study was conducted for the purpose of pre-testing question content and the use of the system used to collect data. A pilot survey allows for a "trial run of the data collection process to determine if any revisions should be made before actual data collection occurs" (Mertler, 2018, p. 12). While conducting a pilot survey does not guarantee a completely valid final survey with flawless results, it does improve conditions for a successful research study.

This pilot study was conducted with 135 high school principals from regions across the state of Illinois using the geographical areas developed by the Illinois Association of Regional School Superintendents. For the pilot study, survey items 1-4 were demographic measures. Survey items 5-18 were a blend of force choice, four-point Likert Scale with measurement ratings of Strongly Disagree, Disagree, Agree, and Strong Agree. These items also 
included open ended response opportunities, one yes or no multiple-choice question, and one question that asked participants to place items in rank order. The instrument used for the final research study was identical to the pilot survey.

\section{Variables in the Study}

For this research study, an analysis was conducted of the use of the student response data from the Illinois 5Essentials Survey by high school principals for the pilot and final survey. By using causal-comparative research, the goal is to explain and describe the current use of a state mandated school climate instrument using a questionnaire with high school principals. While the statistics are readily available through ISBE on the number of students and schools participating in the Illinois 5Essentials Survey, there is no data on the actual principal use of the student response data garnered through that survey. This study illuminated practical usage of the student survey data rather than data on quantity of student participants on the Illinois 5Essentials Survey.

The independent variables are measured by using responses to the survey including ISBE School Quality Summative Ratings, geographical location, school enrollment, and student voice options. The dependent variable is the principal usage of the student data from the Illinois 5Essentials Survey as reported on a questionnaire.

Annually, ISBE provides a School Quality Summative Rating for each public school in Illinois. The highest rating is an Exemplary School rating followed by three lower categories which are a rating of Commendable School, Underperforming School, and Lowest-Performing School. "Multiple measures of school performance and growth determine a school's designation" ("ISBE Summative Designation," n.d.). According to ISBE, these designations are based on preparing each student for college and career readiness and the progress that schools are making towards this benchmark ("ISBE Summative Designation," n.d.). The ISBE 
accountability system evaluates schools based on more than just a standardized test score but also on school quality and equity. For this study, the designation was requested for the 20182019 school year. New summative designations were made public to school districts in October of 2019. The new ratings used different data to assign ratings and many schools received a different rating than in prior years.

Geographical location was based on the location of the public high school in the state of Illinois using the area map from IARSS. These designations include the regions of Cook County, Suburban Chicago, Northern Illinois, Central Illinois, Southeast Illinois and Southwest Illinois. These geographical or area regions were developed by IARSS with the final iteration occurring in 2015 when many regional offices were combined or closed. A copy of the map was provided in the research survey and appears in Appendix B.

The school enrollment was based on the ISBE Implementation Feedback Survey for district enrollment. For the purpose of this survey, it was altered for high school building enrollment rather than district enrollment as stated in the ISBE Implementation Feedback Survey. The range of student enrollment was from less than 300 students to more than 2000 students in the high school building. Participants were asked to select an enrollment from six options within this range. The ranges were: less than 300, 301-599, 600-999, 1000-1500, 15012000, and more than 2000 .

Student surveys are just one of many options that principals can use to obtain student voice. Other methods to consider are student membership on school boards, personalized learning, research partnerships with teachers, students serving on school improvement teams, student government, and student activism. For the purpose of this research, principals were asked to respond to questions about the methods in which student voice is most likely gained 
from their students. A Likert scale was utilized with an open response opportunity for the principal to provide additional methods.

Additional questions were asked within the questionnaire regarding the general usage of the Illinois 5Essentials Survey by high school principals. With a focus on the research questions and student voice, topics will include usage of the instrument for school improvement, preparation to use the Illinois 5Essentials Survey and the means in which the results are shared with stakeholders. Essentially gaining a broad understanding of what the statewide data tell us about the usage of the Illinois 5Essentials Survey by high school principals through descriptive research.

\section{Data Analysis and Interpretation}

"Analyzing and interpreting the data involves drawing conclusions about it; representing it in tables, figures, and pictures to summarize it; and explaining the conclusions in words to provide answers to your research questions" (Creswell, 2012, p. 10). The data obtained from this research was used to determine if high school principals find value in the student response data from the Illinois 5Essentials Survey and to illuminate potential reasons that principals are reluctant to use the data. Data collected from the principals' surveys was analyzed using the Statistical Package for the Social Sciences (SPSS). Descriptive statistics were generated using SPSS for demographic variables and selected instrument items that will include frequencies, percentages, standard deviations, and correlations that identify trends among the sample.

\section{Internal and External Validity}

"Validity is the degree to which all of the evidence points to the intended interpretation of test scores for the proposed purpose" (Creswell, 2012, p. 159). The two types of validity within a research study are internal validity and external validity. Internal validity is the study's ability 
to identify the degree to which there is a cause and effect that is attributable to the research results. External validity is the level to which research results from a study can be applied to the general population of the sample or similar situations (Merriam, 2009). The findings from data collected, analyzed, and interpreted was used to make inferences about the use of school climate surveys by high school principals as an appropriate opportunity for student voice.

Threats to internal validity can negatively impact the researcher's ability to interpret data for the intended purpose. Threats to internal validity in this study include mortality and history. Mortality refers to the loss of participants in the midst of the research study due to a variety of reasons including illness or dropping out (Mertler, 2018, p. 33). In this study, participants may vary from the pretest to the posttest as a result of principal retirement, position change, or relocating to a district that does not participate in the Illinois 5Essentials Survey. History is a threat to internal validity resulting in other factors impacting the study as a result of the duration of time from beginning to end of the study. For this study, the initial pilot survey was conducted in one school year and the final survey was conducted in the following school year.

The threat to external validity in this study is population validity. Since participants came from across the state of Illinois in all of the school sizes as provided in the survey, a representative sample of principals in the state was obtained. However, less than 20 percent of the high school principals participated which is concerning when trying to draw inferences from the sample data. Population validity "refers to the degree of similarity" of the survey participants, population of the sample, and the "target population to which results are to be generalized" (Mertler, 2018, p. 34). 
The threats to internal and external validity are a component in the responses by high school principals. This a considered a limitation to the study as it applies to generalization that can be made by the responses.

\section{Data Analysis Procedures}

\section{Final Study}

Quantitative Analysis. Descriptive statistics were computed for survey questions 1 to 4 . These initial questions were used to group data and provide demographic identifiers to better understand data for analyzing. By using descriptive analyses, the data can be organized and summarized as well as to "identify major characteristics of the population" (O'Rourke, Hatcher, \& Stepanski, 2005, p. 12).

Frequency distributions were generated for Research Question One. Exploratory factor analysis was completed on the variables related to principals sharing the student data with stakeholders. Using exploratory factor analysis allows the researcher to "identify the number and nature" of factors that "exert causal influence on the observed variables" (O'Rourke et al., 2005, p. 437)

Research question two was answered by calculating the Cronbach Alpha internal consistency reliability coefficients for two composite variables questions related to principal use of the data and the ISBE summative rating. The two sections were tested for reliability with a minimum acceptable Cronbach Alpha reliability coefficient of .82 or greater.

For research question three, rankings were generated by examining the frequency distributions of the geographical areas in Illinois where the Illinois 5Essentials Survey is more commonly utilized as a tool for student voice by high school principals and usage based on question five on the research survey. 
To address research question four, a one-way analysis of variance (ANOVA) was conducted to address leadership and involvement by high school principals mean differences and school enrollment differences across six categories. The ANOVA tested for the difference in group means for any significant statistical differences between the demographic variable of school enrollment which was question two on the research survey and question seven on the research survey which addresses leadership and involvement.

Qualitative Analysis. In order to address Research Questions five and six, a review of the qualitative data was conducted using an analysis coding log and descriptive statistics. The survey included four questions that allowed participants to further explain their multiple-choice answers in a text box. These four questions were focused on the methods in which principals communicate the Illinois 5Essentials data, ability to use the data, and survey administration in the schools. There was one additional survey question that was open ended to gain information related to how high school principals have utilized the student voice data from the Illinois 5Essentials Survey to address school climate issues. A summary of the explanation questions was developed for each of the opportunities that were provided to participants. These general summaries are provided in Chapter 5. It is common for a researcher to develop "terms, concepts, and categories that reflect what he or she sees in the data" (Merriam, 2009, p. 184).

For research question 5, a summary with descriptive statistics were employed to better understand if principals perceive that the student data from the Illinois 5Essentials Survey can aid them in supporting school climate in their schools or if they are more engaged in implementing alternative types of student voice opportunities in their school.

Examining question 18 on the survey, the responses were reviewed and coded into six primary codes. This question specifically asked how principals use the student data from the 
Illinois 5Essentials Survey for addressing school climate issues which is directly related to research question six. The codes include school improvement plans, safety plans, communication, social emotional learning, educator professional development, and lack of interest in the Illinois 5Essentials Survey. Qualitative methods were used to analyze a portion of this study in order to provide voice to the participants so that the researcher may better understand the impact of the student data usage on school climate.

\section{Summary}

The purpose of this study was to examine the use of the student data from the Illinois 5Essentials Survey by high school principals. By using the student data, student voice is being tended to within the school climate survey. However, failure to use the data may be indicative of the negative value of the Illinois 5Essentials Survey as a measure of student voice. Through the use of descriptive statistics and statistical tests, there was a better understanding of high school principal perceptions and utilization of school climate surveys. As school climate surveys become more prevalent, there is merit in understanding the best practices in responding to the student data by school leadership. If schools want to hear the voices of all children, they need to employ reliable, equitable, and comprehensive mechanisms to ensure all student voices are acquired. 


\section{CHAPTER IV: RESULTS}

This chapter provides a comprehensive analysis of the collected data as it pertains to the research questions using the procedures described in Chapter III. The pilot and final research surveys were administered to high school principals in public high schools in Illinois. The purpose of the survey was to determine the principal use of the student data on the Illinois 5Essentials Survey as a measure of student voice. As a mandated survey in the state of Illinois, the survey must be administered but it is unknown if the voices of the participants including students have an impact on school climate. The ESSA Plan for Illinois requires that public school students in grades 4 through 12 participate annually in the administration of the Illinois 5Essentials Survey. It is important to note that educators and parents are also permitted to participate in the Illinois 5Essentials Survey, but this study does not focus on their responses.

Using the Mitra Pyramid of Student Voice (2006) as the framework, collecting student perspectives through student surveys is the lowest level of participation for student voice. Given that the information from students is commonly one-way communication, it is likely that students are unaware if they will receive feedback on the responses or if action will be taken by principals based on those responses. The Illinois 5Essentials Survey requires that students respond to a series of questions by logging into the survey with a unique and confidential login that is provided by ISBE. Students then click on the bubbles ranking their level of agreement or disagreement on a Likert scale. There is no opportunity for open ended response or for students to elaborate on their responses. In addition, the responses of individual students are not provided to the principal so that they may seek students out to address their concerns. The confidentiality component of the Illinois 5Essentials Survey allows for students to "speak freely" but does not provide for deeper dialogue to create solutions in partnership with individual students. 
The findings presented in this chapter utilize the research questions presented in Chapter 3. There are four sections in this chapter. The first section will provide the data collected from the pilot survey with the second section presenting the data collected from the final survey administration. The third section will present the findings from each of the research questions and relevant data. The fourth and final section will include a summary of the results which will be analyzed to determine if a correlation exists that school climate surveys are an appropriate measure of student voice.

\section{Section One: Pilot Study Results}

The survey was designed in three sections which included demographic information, perspectives in a multiple-choice format, rank order, and a final open-ended response question. A portion of the questions were taken from a survey administered in 2013 by ISBE; the use of the ISBE Implementation Feedback Survey was approved by a staff member at ISBE. The subsequent report on the data was provided by the Illinois Education Research Council (Klostermann et al., 2014). The demographic data included the area of the school location in Illinois based on the IARSS area map for regional offices of education, school enrollment, ISBE summative designation and the student percentage that responded on the Illinois 5Essentials Survey. To determine the area of the school, the participant was provided a color-coded map and multiple-choice selections. For the remaining demographic questions, a multiple-choice list was provided. The following 12 questions were Likert scales with an opportunity for limited open response to extrapolate on answers provided. One survey question requested that participants rank order from 1 through 10 a list of student voice opportunities in the United States that the principals believed would have the greatest impact on school climate. The final two questions were connected by first asking a yes or no question related to 
the principal's opinion of the Illinois 5Essentials Survey helping them to address school climate and asking for a follow up in the open-ended response.

To ensure reliability and validity of the survey instrument, the pilot survey was administered to a sample of high school principals. Using the email system through Qualtrics, 135 high school principals were randomly selected from across the state to participate. A total of 30 responses were received for a response rate of $22 \%$, of which $83 \%$ of the respondents completed the entire survey. Participants were reminded on two occasions to participate in the survey. During the pilot survey, the respondents were provided the researcher contact information in which to provide questions or feedback. There were no comments provided to improve the survey. Therefore, no changes were made from the initial survey to the final survey.

\section{Section Two: Final Survey}

\section{Survey Results}

The purpose of the final survey was to collect both quantitative and qualitative data on the use of the Illinois 5Essentials Survey by high school principals. The researcher gathered demographic information, correlated the use of the student data by high school principals, and collected qualitative data related to the use of the student data to address school climate issues. The survey was administered to 760 high school principals in Illinois. A total of 130 responses were received for a response rate of $17.1 \%$. The survey was administered via the email distribution function in Qualtrics. Illinois State University provides complimentary usage of Qualtrics which is a web-based online software system that allows the user to create surveys, collect feedback, and generate reports in a secure digital environment. The survey was open for 
four weeks; respondents were emailed twice through Qualtrics following the initial request to participate.

\section{Descriptive Statistics for Demographic Data}

There was a total of 130 high school principals in Illinois that completed the survey. Principals were asked to specify demographic information about their school building. The purpose of collecting demographic information is to determine if there is a correlation between the demographic data and the findings of the correlational research.

This table identifies the data collected based on where the principal's school is located. Table 1 displays the geographical location of the school in Illinois based on the IARSS Area Map. This table indicates that Area 1 and Area 4 had the greatest percentage of participant responses at $46.9 \%$ and $16.9 \%$ respectively. $12.3 \%$ of principal participants work in schools from Area 3 and 8.5\% are schools in Area 2. In the southern region of the state, Areas 5 and 6 returned some of the lowest representation at $8.5 \%$ and $6.9 \%$ respectively. Area 1 encompasses Cook County and the collar suburban counties in Illinois. These are heavily populated communities that encompass the greatest percentage of students in Illinois.

Table 1

Geographical Location of High School

\begin{tabular}{lrr}
\hline Response & Frequency & Percent \\
\hline Area 1 & 61 & 46.9 \\
Area 2 & 11 & 8.5 \\
Area 3 & 16 & 12.3 \\
Area 4 & 22 & 16.9 \\
Area 5 & 11 & 8.5 \\
Area 6 & 9 & 6.9 \\
\hline
\end{tabular}

Table 2 identifies the responses of the enrollment range for the high school principal participant. School sizes that were 300 and below made up for $30.8 \%$ of the participants; 
principals in schools with a range of 301 to 599 were represented by $20.8 \%$ of the total participants. High Schools that have between 600 to 999 students encompassed $11.5 \%$ of the sample. The school buildings that are sized from 1000 to 1500 and 1501 to 2000 had a participant percentage of $6.2 \%$ and $13.8 \%$. The largest schools were greater than 2000 had a principal participant rate of $16.9 \%$ of the 130 participants.

Table 2

High School Enrollment

\begin{tabular}{lcr}
\hline Response & Frequency & Percent \\
\hline Less than 300 & 40 & 30.8 \\
301 to 599 & 27 & 20.8 \\
$600-999$ & 15 & 11.5 \\
$1000-1500$ & 8 & 6.2 \\
$1501-2000$ & 18 & 13.8 \\
More than 2000 & 22 & 16.9 \\
\hline
\end{tabular}

Participants were then asked to provide the ISBE Summative Designation from the Illinois School Report Card that was publicized in October 2018. Upon release of the survey, new summative designations were not yet available for 2019. From the total of 130 participants, the largest percentage of participants identified that their school received a commendable rating. $75.4 \%$ received this rating. However, $14.6 \%$ stated that their rating was exemplary. Underperforming and lowest performing high school principals encompassed the smallest percentage at $6.2 \%$ and $3.8 \%$ respectively. These summative designation responses are shown in Table 3. 
Table 3

ISBE Summative Designations

\begin{tabular}{lrr}
\hline Response & Frequency & Percent \\
\hline Exemplary & 19 & 14.6 \\
Commendable & 98 & 75.4 \\
Underperforming & 8 & 6.2 \\
Lowest Performing & 5 & 3.8 \\
\hline
\end{tabular}

Principals provided the percentage of their students that responded to the Illinois 5Essentials Survey by selecting the appropriate range of percentages on the survey (Table 4). This is data that ISBE provides to the school districts annually. The first two ranges were from 0 to 20 percent and 21 to 40 percent; the principals provided that the participation rate in their buildings were $2.3 \%$ and $0.8 \%$ respectively. The following percent ranges were from 41 to 60 percent and 61 to 80 percent with total participant percentages of $10 \%$ and $20 \%$ respectively. The greatest percentage of participants were at $66.9 \%$ under the category range of 81 to 100 percent.

Table 4

Illinois 5Essentials Survey Student Response Rate

\begin{tabular}{lrr}
\hline Response & Frequency & Percent \\
\hline $0-20$ Percent & 3 & 2.3 \\
21-40 Percent & 1 & 0.8 \\
$41-60$ Percent & 13 & 10 \\
$61-80$ Percent & 26 & 20 \\
$81-100$ Percent & 87 & 66 \\
\hline
\end{tabular}

\section{Results of the Analysis for Research Questions}

There were six research questions which required responses in this study. The first five of the six research questions are quantitative. The first question examines the statewide data usage obtained through the Illinois 5Essentials Survey by high school principals including the 
student data usage for school improvement planning. It also includes principal preparation to utilize the 5Essentials data and the frequency of sharing the student data with stakeholders. The second research question seeks a correlation of the ISBE summative designation and the use of the student data by high school principals. Research question three examines the potential geographical differences in the use of the Illinois 5Essentials Survey data collected from students. Research question 4 seeks to answer whether school size has an impact on student data usage by principals. While principals may not utilize the Illinois 5Essentials student data, research question 5 examines the alternative student voice opportunities and implementation in public high schools that the principals prefer. Finally, research question 6 seeks to clarify if collecting student data on the Illinois 5Essentials Survey supports the work of the principal in addressing school climate. This research question allows for responses to be both quantitative and qualitative.

Research Question one provides insight into what that data tells us about the usage of the Illinois 5Essentials Survey by high school principals. Using responses from the research survey, principals were asked if their school has made use of this data for planning and/or continuous improvement. A 4-point Likert scale was provided with a range from strongly agree to strongly disagree. 123 principals responded to the question. The data provided in Table 5 shows that $72.4 \%$ strongly agree or agree with the statement that they use the data for planning and/or school improvement in their role as building principal. Alternatively, $27.6 \%$ disagreed with this statement. 
Table 5

Principals Using Illinois 5Essentials Survey for Planning/Continuous Improvement

\begin{tabular}{lrc}
\hline Response & Frequency & Percent \\
\hline Strongly Agree & 36 & 29.3 \\
Agree & 53 & 43.1 \\
Disagree & 24 & 19.5 \\
Strongly Disagree & 10 & 8.1 \\
\hline
\end{tabular}

Principals next responded to a Likert scale question on whether their school has modified their school improvement plan based on results from the Illinois 5Essentials Data. 123 principals responded to the question. Table 6 provides data on the responses provided by the principals. $56.9 \%$ of the principals strongly agreed or agreed that they modify the school improvement plan based on the survey data. While $43.1 \%$ strongly disagreed or disagreed that modification to the SIP are done as a result of the data.

Table 6

Principal Response on Usage of Illinois 5Essentials Data to Modify School Improvement Plans

\begin{tabular}{lrr}
\hline Response & Frequency & Percent \\
\hline Strongly Agree & 22 & 17.9 \\
Agree & 48 & 39.0 \\
Disagree & 39 & 31.7 \\
Strongly Disagree & 14 & 11.4 \\
\hline
\end{tabular}

Continuing to explore the statewide data, principals were asked if they feel well prepared to utilize the data in the Illinois 5Essentials Survey. Principals were asked three different survey questions to address this research question. 123 of the 130 participants responded on a Likert scale on their level of agreement that they had the knowledge to use the student response data from the Illinois 5Essentials Data. $96.8 \%$ of the principals agreed or strongly agreed that they 
were knowledgeable in this area. Only 4\% disagreed or strongly disagreed with this statement. Table 7 provides a breakdown of the responses.

Table 7

Principal Response on Knowledge to Use Student Response Data

\begin{tabular}{lrr}
\hline Response & Frequency & Percent \\
\hline Strongly Agree & 58 & 47.2 \\
Agree & 61 & 49.6 \\
Disagree & 2 & 1.6 \\
Strongly Disagree & 2 & 1.6 \\
\hline
\end{tabular}

Principals were then asked if their district provided or supported professional development on interpreting, analyzing, and presenting survey results. 113 participants responded to this question. Responding on a Likert Scale, 35.4\% responded that they agreed or strongly agreed that professional development was provided or supported. However, $64.6 \%$ of the principals disagreed or strongly disagreed with this statement. Table 8 includes the data for this survey question.

Table 8

Principals were Provided/Supported with Professional Development by School District

\begin{tabular}{lrr}
\hline Response & Frequency & Percent \\
\hline Strongly Agree & 13 & 11.5 \\
Agree & 27 & 23.9 \\
Disagree & 55 & 48.7 \\
Strongly Disagree & 18 & 15.9 \\
\hline
\end{tabular}

To further gain insight into how well prepared a principal is to utilize the data from the Illinois 5Essentials Survey, participants were asked if their school district ensures that they are knowledgeable about the use and implementation of the Illinois 5Essentials Survey data. 113 of 
the 130 participants responded to the item. 56.6\% responded that they agreed or strongly agreed with the statement with $43.4 \%$ disagreed with the statement as shown in Table 9.

Table 9

School District Ensures Principal Knowledge on Use of Illinois 5Essentials Survey Data

\begin{tabular}{lrr}
\hline Response & Frequency & Percent \\
\hline Strongly Agree & 17 & 15.0 \\
Agree & 47 & 41.6 \\
Disagree & 39 & 34.5 \\
Strongly Disagree & 10 & 8.9 \\
\hline
\end{tabular}

To better understand the usage of the data by principals, a series of ten Likert scale questions were asked regarding the communication of the student data from with Illinois 5Essentials Survey. 113 participants responded to each of the types of communications and their level of agreement as to how student data was provided. Table 10 provides a report for each of the communication types and the level of agreement. Principals were asked if they emailed the students with the results. $31.9 \%$ stated that they agreed or strongly disagreed which was 46 participants. Principals also provided that only 17 of the 113 participants share the student data in a student assembly which is $16 \%$ of the sample. Even fewer agreed or strongly agreed that the information was shared in the school newspaper. 13 stated it was in the paper which is $11.5 \%$ of the participants. Principals were then asked about their level of agreement that they made sure students received the data in focused small group meetings. 25 responded that they agreed or strongly agreed with the statement which represented $22.1 \%$ of the sample.

Classroom presentations could be an opportunity for students to receive the student data. 19 principals responded that they agreed or strongly agreed that they communicate the data this way. This represents $16.8 \%$ of the 113 principals. Data can also be addressed with individual students. However, only 26 principals or $23 \%$ used this mode of communication. The principals 
were asked if they featured the student data on the website, social media, or in any school communication. 45 responded that they agreed or strongly agreed with the statement which represents $39.8 \%$ of the principals. When asked if the data reports were provided to student organizations, 23 principals agreed or strongly agreed.

Student data was most likely to be provided to administrators and SIP teams where no students are present. 59 or $52.2 \%$ of the principals responded with agree or strongly agree that they would review and or discuss student results at district leadership level. 69 principals agreed or strongly agreed that they reviewed and or discussed student data results in school improvement teams where no students serve as members. This represents $61.1 \%$ of the principals. Table 10 provides a comprehensive report of the data frequency including the levels of disagreement with the statements about purposefully sharing results with stakeholders.

Table 10

Principal Methods for Communicating Student Data to Students for Illinois 5Essentials Survey

\begin{tabular}{lrrrr}
\hline Communication & Strongly Agree & Agree & Disagree & Strongly Disagree \\
\hline Email & 13 & 23 & 55 & 22 \\
Assembly & 6 & 11 & 59 & 37 \\
School Newspaper & 5 & 8 & 58 & 42 \\
Student Small Group Meetings & 12 & 13 & 53 & 35 \\
Classroom & 7 & 12 & 61 & 33 \\
Individual Students & 5 & 21 & 54 & 33 \\
School Communications & 13 & 32 & 40 & 28 \\
Student Organizations & 5 & 18 & 54 & 36 \\
District Leadership & 22 & 37 & 37 & 17 \\
SIP/No Students & 28 & 41 & 31 & 13 \\
\hline
\end{tabular}

The purpose of Research Question one was to gain insight into the functional use of the student voice portion of the Illinois 5Essentials Data by high school principals. We know that administering the survey is mandatory but using the survey data is not required by the state or 
federal government. A discussion of the results will be conducted at the end of this chapter. The following research question will examine the differences in use of the data by school types.

For Research Question two, a one-way analysis of variance (ANOVA) was conducted to measure the differences of the student voice data usage from the Illinois 5Essentials Survey variances based on the quality level of the ISBE summative designation rating for public high schools. The independent variable, summative rating, included four levels: exemplary, commendable, underperforming, and lowest performing. Question three on the research survey was utilized for the independent variable. The dependent variable was student voice data usage. Using question five $\mathrm{b}$ and $\mathrm{c}$ on the research survey, student voice data usage was identified. These two survey questions required principals to respond on a four-point Likert scale with a range of strongly agree to strongly disagree. Survey question $5 \mathrm{~b}$ asked if the school used the student data for planning and or continuous school improvement. Participants were then asked to respond in question $5 \mathrm{c}$ if the school modified their school improvement plan as a result of the data from the Illinois 5Essentials survey. These two questions were used as the dependent variable School Use of Survey Data.

The ANOVA was insignificant, $\mathrm{F}(3,119)=.57, \mathrm{p}=.639, \mathrm{~N} 2=.014$. The relationship strength between summative designation and student voice data usage, as assessed by $\mathrm{N} 2$, was weak with the summative rating accounting for $1.4 \%$ of the variance of the dependent variable. The sample sizes, means, and standard deviations for the four summative rating groups are reported in Table 11.

An additional Post hoc test was conducted to evaluate pairwise differences among the means. Using the Tukey test, post hoc comparisons were completed. There were not significant differences in the means between the summative designation groups. 
Table 11

Summative Designation Category, Sample Size, Mean, and Standard Deviation

\begin{tabular}{lrrr}
\hline Summative Designation & $\mathrm{N}$ & Mean & Std. Deviation \\
\hline Exemplary School & 17 & 6.06 & 2.38 \\
Commendable School & 95 & 6.06 & 2.08 \\
Underperforming School & 6 & 6.00 & 2.45 \\
Lowest Performing School & 5 & 4.80 & 1.30 \\
Total & 123 & 6.01 & 2.11 \\
\hline
\end{tabular}

For research question 3, a one-way analysis of variance was conducted to evaluate the student voice usage mean differences across six geographical areas. The independent variable, geographic regions, included six areas in Illinois: Area 1, Area 2, Area 3, Area 4, Area 5, and Area 6. The dependent variable was student voice data usage. The dependent variable was derived from survey question five $\mathrm{b}$ and $\mathrm{c}$ as described in research question 2 . The ANOVA was significant, $\mathrm{F}(5,117)=2.99, \mathrm{p}=.014, \mathrm{n} 2=.113$. The rank order for usage for greatest to least usage is Area 4 then Area 3 followed by Area 6, Area, 2, Area 5 then Area 1. Table 12 identifies the sample sizes, means, and standard deviations for the four summative rating groups from the research data.

Table 12

Geographical Usage Category, Sample Size, Mean and Standard Deviation

\begin{tabular}{lrrr}
\hline Geographical Area & $\mathrm{N}$ & Mean & Std. Deviation \\
\hline Area 1 & 58 & 5.38 & 1.89 \\
Area 2 & 11 & 6.27 & 2.24 \\
Area 3 & 14 & 6.71 & 2.20 \\
Area 4 & 22 & 7.14 & 2.21 \\
Area 5 & 10 & 5.6 & 2.06 \\
Area 6 & 8 & 6.38 & 1.77 \\
Total & 123 & 6.01 & 2.11 \\
\hline
\end{tabular}


An additional post hoc test was done to evaluate the differences among the means. These comparisons were conducted using the Tukey test.

To address Research Question 4, a one-way analysis of variance was performed to measure the leadership and involvement mean differences across six school enrollment categories. The independent variable, school enrollment, included six levels: less than 300, 300599, 600-999, 1000-1500, 1500-2000, and more than 2000. The dependent variable was leadership and involvement. The Leadership and Involvement category was based on survey question seven a through e as well as question eight a through $\mathrm{h}$. The ANOVA was insignificant, $F(5,107)=0.22, \mathrm{p}=0.96, \mathrm{n} 2=0.01$. The strength of the relationship between student enrollment and leadership and involvement, as assessed by n2, was weak with student enrollment accounting for $1.0 \%$ of the variance of the dependent variable. Table 13 provides the category, sample size, mean and standard deviation for school enrollment and Leadership and Involvement.

Table 13

School Enrollment and Leadership and Involvement Category, Sample Size, Mean and Standard Deviation

\begin{tabular}{lrrr}
\hline School Enrollment & $\mathrm{N}$ & Mean & Std. Deviation \\
\hline Less than 300 & 35 & 21.29 & 5.51 \\
$301-599$ & 25 & 21.44 & 3.08 \\
$600-999$ & 12 & 21.00 & 5.43 \\
$1000-1500$ & 8 & 22.25 & 2.77 \\
$1501-2000$ & 14 & 20.29 & 3.89 \\
More than 2000 & 19 & 21.26 & 4.84 \\
Total & 113 & 21.23 & 4.51 \\
\hline
\end{tabular}

While this study seeks to understand the value placed on student voice through the use of a mandated school climate survey through research question 5, it also incorporated school climate surveys in the context of other types of student voice opportunities. Participants were 
provided a list of ten alternative types of student voice options for schools and asked to rank them in order of importance that would have the greatest impact on school climate. 99 participants responded to the question. The greatest number of principals ranked personalized learning as the most impactful for schools. Table 14 provides the order in which the items were listed on the research survey and the rankings for each item by the participants.

Table 14

Rankings of Principal Engagement in Types of Student Voice

\begin{tabular}{|c|c|c|c|c|c|c|c|c|c|c|}
\hline Type/Ranking & One & Two & Three & Four & Five & Six & Seven & Eight & Nine & Ten \\
\hline $\begin{array}{l}\text { Students on a School } \\
\text { Board }\end{array}$ & 6 & 6 & 8 & 5 & 6 & 6 & 9 & 8 & 15 & 30 \\
\hline Personalized Learning & 24 & 17 & 9 & 11 & 7 & 6 & 7 & 4 & 9 & 5 \\
\hline $\begin{array}{l}\text { Research Partnerships } \\
\text { with Teachers }\end{array}$ & 2 & 3 & 14 & 7 & 13 & 10 & 13 & 15 & 16 & 6 \\
\hline Students on SIP Teams & 12 & 13 & 9 & 18 & 8 & 11 & 7 & 12 & 8 & 1 \\
\hline $\begin{array}{l}\text { Student Data from } \\
\text { 5Essentials }\end{array}$ & 3 & 7 & 5 & 6 & 11 & 13 & 13 & 10 & 11 & 20 \\
\hline Student Government & 12 & 4 & 14 & 17 & 12 & 17 & 12 & 5 & 3 & 3 \\
\hline $\begin{array}{l}\text { Student Led } \\
\text { Clubs/Activities }\end{array}$ & 18 & 19 & 9 & 6 & 12 & 11 & 13 & 7 & 3 & 1 \\
\hline Student Activism & 2 & 3 & 8 & 11 & 11 & 12 & 7 & 23 & 15 & 7 \\
\hline $\begin{array}{l}\text { Principal Advisory } \\
\text { Committee }\end{array}$ & 6 & 14 & 15 & 9 & 9 & 8 & 9 & 6 & 12 & 11 \\
\hline $\begin{array}{l}\text { School Leadership } \\
\text { Partners }\end{array}$ & 14 & 13 & 8 & 9 & 10 & 5 & 9 & 9 & 7 & 15 \\
\hline
\end{tabular}

To address Research Question six, principals were asked if they perceived that the Illinois 5Essentials student data helped them to address school climate issues in their school. 99 principals responded to the survey question. 45 principals stated that it did help them while 17 stated that it did not. An additional 37 principals replied with an open response that required more than a one-word answer. Table 15 provides the count and frequency of each choice. The results of the open response portion of the question are provided in the Summary of Results. 
Table 15

Principal Perceptions on Student Data Addressing School Climate

\begin{tabular}{lrr}
\hline Response & Frequency & Percent \\
\hline Yes & 45 & 45.5 \\
No & 17 & 17 \\
Open Response & 37 & 37 \\
\hline
\end{tabular}

\section{Summary of Results from the Qualitative Analysis}

The survey contained five open ended items related to the use of student voice data by high school principals that were surveyed. In this section, an overview of the responses is provided.

Item $5 \mathrm{a}, \mathrm{b} \& \mathrm{c}$ was a Likert scale question on the principals' knowledge and use of the Illinois 5Essentials student response data including planning, school improvement, and continuous improvement. The principals could respond in one of four ways from Strongly Agree to Strongly Disagree. Principals were given the opportunity to share the other ways that their school made use of the data. For this response, 86 principals provided no additional information and 44 provided an open response. The responses were coded into emergent codes that identified the other ways in which principals were using the student data from the Illinois 5Essentials Survey. The major themes and frequencies for Item 5 were identified as No Additional Use (6), Planning and Goal Setting (16), School Climate \& Safety (12), Professional Development (3), School Communications (10), Instruction (5), and Student Discussions \& Services (3).

Participants utilized the Illinois 5Essentials data for other purposes than those that were specifically asked about in the research survey. The principals stated that the data is used to create or update the school improvement plans, district plans, strategic plans, and for goal setting. Others mentioned that it was used to measure school climate, safety, trust, and 
culture. Professional development selection for educators was stated as one way that a district uses the data. One principal stated, "the survey data is utilized by individual departments to inform curriculum, instruction, and student support services". Using the survey data for the purpose of communication was highlighted by several of the participants. Principals commented that the data is shared and discussed among students, school leaders, board of education, staff, and teachers. A second-year principal stated that "we use the data to analyze the two-year trend in a lot of areas". Another principal explained that they used the data "to see how challenged and safe students feel". An additional comment was how the data was used to address a specific data point. This principal stated "one of the primary issues at our school when I started as principal 7 years (ago) was teacher trust in administration and teacher-teacher trust. We have used our 5Essentials data, which has steadily improved, as positive reinforcement for the outstanding work our staff has done in these areas." While there were many principals that found the data useful, other principals were not as positive about the Illinois 5Essentials data. A few of the statements were "I do not find the data useful" and "our district does not mandate we use the data for any given purpose". Table 16 outlines the themes and frequencies for Item 5.

Table 16

My School has Made Use of the Illinois 5Essentials Data for Other Reasons

\begin{tabular}{lr}
\hline Response & Frequency \\
\hline Planning \& Goal Setting & 16 \\
School Climate \& Safety & 12 \\
School Communications & 10 \\
No Additional Use & 6 \\
Instruction & 5 \\
Professional Development & 3 \\
Student Discussion \& Services & 3 \\
\hline
\end{tabular}


Item 8 requested that principals examine the student groups in their school community that were purposefully involved in the reviewing and discussion of student responses on the Illinois 5Essentials Survey. There were 10 sub questions to Item 8 that specifically identified the types of communications and involvements specifically for students. A four-point Likert scale was provided with an opportunity to provide additional information in an open-ended question. 113 principals responded to each of the sub questions in Item 8. 19 principals provided content in the text box provided for the optional open-ended question. These responses were reviewed and coded into five emerging themes. These included the Classroom (2), Principal led teams with students (3), Student advisory/SIP groups (3), Teacher and Parent Teams (8), and No Use (5).

When asked to describe the other types of groups/teams that involved students in which data was reviewed or discussed, there was a range of responses that included none to providing a list of the groups. Nineteen of the participants responded to the question. The principals mentioned other student focused groups included classrooms of students, principal led teams with students, student school improvement plan team, and the principal student advisory group. One principal stated that the survey is a "waste of time". However, another principal shared the data extensively with student groups including the Principal's Advisory Council (student group), Student Government, Democracy School Leaders (student and staff group), Superintendent and District Leadership teams, High School Administrative team, School Improvement teams, and our School Climate Committee." Table 17 provides a visual of the data for the open-ended responses for Item 8. 
Table 17

Describe Other Types of Groups/Teams that Involved Students in Which Data was Reviewed or Discussed

\begin{tabular}{lr}
\hline Response & Frequency \\
\hline Teacher \& Parent Teams & 8 \\
No Additional Use & 5 \\
Student Advisory/SIP Teams & 3 \\
Principal Led Teams with Students & 3 \\
Classroom & 2 \\
\hline
\end{tabular}

Similar to Item 8, Item 12 asked the respondents to identify other groups that reviewed or discussed the responses. However, this question was related to parent responses not student responses. 113 participants responses to Item 12 that included 10 sub questions. There were 10 responses to the open-ended question. Given the low number of open-ended questions, there were fewer codes than in Item 8. The following themes were prevalent: Parent-Teacher Organization (2), District Superintendent Group (1), Parent Data Reports to Staff (1), Lack of Parent Data (6), and Other/Unrelated (1).

When asked if there were other parent groups that were included in the sharing of the data, the remarks had a mixed review. Of the 130 survey participants, only ten of the principals responded to the open-ended question. Most of the comments included that they do not share it with additional groups for a variety of reasons. One of the most prevalent comments was that they did not have enough data collected from the parents to use the data. "We can't get the parents to complete the survey so the validity is poor. We didn't even meet the benchmark this past year in the number of parents needed to complete the survey." However, some comments mentioned that the data are shared with the local parent teacher organization, staff, and the superintendent's community council. Table 18 shows the breakdowns for each of the codes for Item 12. 
Table 18

Parent Data was Reviewed/Discussed in other Groups that Involved Parents

\begin{tabular}{lr}
\hline Response & Frequency \\
\hline Lack of Parent Data & 6 \\
Parent-Teacher Organizations & 2 \\
District Superintendent Group & 1 \\
Parent Data Reports to Staff & 1 \\
Other/Unrelated & 1 \\
\hline
\end{tabular}

For Item 14, participants were provided an opportunity to share input on the ways in which the Illinois 5Essentials Survey is communicated with educators. This item had $10 \mathrm{sub}$ questions similar to survey items 8 and 12. 109 participants completed all of the sub questions for Item 14. Upon completion of the 10 Likert scale items, principals were again asked to respond to an open-ended question about the other groups that educators may have reviewed or discussed their data on the Illinois 5Essentials Survey. There were 10 responses to the openended question. These responses were reviewed for coding purposes. The following codes emerged: Parents (1), SIP (3), School Communication (1), Teacher Teams (2), Union (1), and No Additional Use (5).

Given that there were limited responses to the open-ended questions, there was minimal variety in the responses. One principal commented, "an anonymous survey is useless. If it is OK, we should evaluate teachers anonymously". Another survey participant commented that they have "discussed educator results in just about every way imaginable: Union, School Improvement Team, Climate Committee, Discipline Committee, Administrative Team, etc." It was evident in the open-ended responses that there is a significant gap among principal usage where some are invested in sharing it with many educator teams others do not find value in the 
data and it transcends across the student, parent, and educator groups. Table 19 identifies the codes and frequency of the responses by principals.

Table 19

Educator Results that were Reviewed/Discussed in Other Groups that Involved Educator

\begin{tabular}{lr}
\hline Response & Frequency \\
\hline No Additional Use & 5 \\
SIP & 3 \\
Teacher Teams & 2 \\
Parents & 1 \\
School Communication & 1 \\
Union & 1 \\
\hline
\end{tabular}

For Item 17, 99 of the 130 participants responded to the question with a choice of Yes or No when asked if the principals feel that the Illinois 5Essentials Survey student data helps to address school climate issues in their school. There were 37 open ended responses of varying lengths. Each of the responses was reviewed for the purpose of coding responses. The coding related to the positive use of the data for school climate included: Student Feedback (8), Communication (2), Data/Trend Data (9), and Systemic changes-SIP (2). The negative comments about the use of the Illinois 5Essentials Survey to address school climate included: Survey Administration/Reliability (6), Data Lacking Validity or Usability (11), Not Used (4), and Legislative Mandate (2).

When asked to explain if the student data helps you as a principal to address school climate issues in your school, there was a varied response to the question. Principals again commented that it is not used and is a "waste of time". Other responses included that they believed the students provided dishonest responses to the Illinois 5Essentials Survey questions, they use their own local survey, and that the reliability of the instrument is questionable. Another comment was made was that the data arrives too late to be used and that if the school or 
enrollment size is too small that the data is skewed. One principal commented, "I believe the data is invalid due to the way it is collected". Another principal commented that "it is a one size fits all assessment that does not address the issues that different size schools have". In Appendix $\mathrm{D}$, a list of the comments is provided.

Many of the principals commented that they utilize the student feedback to address school climate issues and to communicate climate issues with others. Some use it as a piece of information about the current school climate issues. One principal stated, "that data received supports the idea that our programs aimed at generating positive school climate are working". Comments were made that suggest that principals use the student data to identify strengths and weaknesses, track improvements in school climate, and address the issues of school climate in the SIP plan. One principal commented that "we examine the data annually, ensure that we get a very representative sample of our students taking it, and use the results to make systemic changes in the building". Several principals use the data from the students to dig deeper into the building issues and determine trends from the data.

While some had not considered using it to address school climate, they believe that it has the potential. Principals find it beneficial at the building level but would desire a district wide emphasis in order to gain more buy-in. Others commented that they would like the responses from the Illinois 5Essentials returned much sooner so they could more rapidly address school climate issues. While some thought the survey was a waste of time, other principals desired that it would be offered more than once a year so that they could compare the beginning of the school year to the end of the school year. 
Table 20

Principal Responses to Addressing School Climate Issues Using the Illinois 5Essentials Student Data

\begin{tabular}{lr}
\hline Response & Frequency \\
\hline Yes-Student Feedback & 8 \\
Yes-Use Data-Trend Data & 9 \\
Yes-Communication Purposes & 2 \\
Yes-Systemic Changes/SIP & 2 \\
No-Data Validity/Usability Issues & 11 \\
No-Survey Administration/Reliability & 6 \\
No-Not Used & 4 \\
No-Legislative Mandate & 2 \\
\hline
\end{tabular}

The final open-ended question was Item 18. This qualitative question provided an opportunity for participants to provide comments regarding the student voice data from the Illinois 5Essentials Survey and addressing school climate issues. There were 50 responses to this question. After analysis, six primary codes emerged. These codes and their frequencies included SIP (22), School Safety (4), Communication (12), Social Emotional Learning (4), Professional Development/Teacher Quality (3), and Not Used (14).

Student data from the Illinois 5Essentials Survey is used to varying depths by high school principals. There are principals that refuse to use the data because of the bureaucratic requirement by ISBE and believe there are other instruments that better serve their needs. A principal stated that the he/she takes "the information as a suggestion rather than factual data". The negative perception of the Illinois 5Essentials Survey data validity was stated as a concern. "I have only used the data in my School Instructional Leadership Team-it does not fully show the whole picture. I would much prefer having a one on one conversation with student groups". Some principals will identify very particular reasons that they do not trust the questions on the Illinois 5Essentials Survey. A principal commented that the question about the quality of 
teachers is concerning as his/her school "often get the last pick of teachers due to the amount we pay compared to surrounding districts".

Overwhelmingly, principals found a purpose for the data and found the information beneficial for the purpose of school climate. Principals used the student voice to consider changes to course offerings, improving student supports, and addressing the school safety plan. "We made the decision to invest in a School Resource Officer to help make students feel safer in school". Others commented that they used it to develop programs, policies and procedures that would address school climate and to make adjustments to the SIP. Communication was a key component in how the student data was used. They will address student concerns in discussions with staff and administration. One principal commented that the data is discussed among administrators at the summer retreat. Others will request additional anecdotal information directly from the students. The administration "looked for trends to share with student council and get feedback on how to improve this and ways the students want to see things improve for school climate". Professional development for teachers was influenced by the responses by students with the goal of it improving the school environment. In addition, principals stated that they would set goals directly related to school climate based on the data from the Illinois 5Essentials. Table 21 provides an overview of the coding and frequencies for Item 18. 
Table 21

In What Ways Have You as a Principal Utilized the Student Voice Data from the Illinois 5Essentials Survey to Address School Climate Issues?

\begin{tabular}{lr}
\hline Response & Frequency \\
\hline SIP & 22 \\
Not Used/Lack of Interest & 14 \\
Communication & 12 \\
School Safety & 4 \\
Social Emotional Learning & 4 \\
Professional Development/Teacher Quality & 3 \\
\hline
\end{tabular}

This chapter provided the results for both the pilot and research survey. There was an explanation of the descriptive statistics for the demographic data which included geographical locations, enrollment, summative designations and the student response rates for the high school principals that participated in the research survey. The results of the analysis for each of the six the research questions. The chapter ends with a summary of the results from the qualitative analysis which provides both frequency statistics and a narrative. The following chapter includes a discussion of the findings, implications and conclusion. 


\section{CHAPTER V: FINDINGS, IMPLICATIONS, CONCLUSIONS}

The purpose of this quantitative study was to analyze high school principal perceptions and usage of the Illinois 5Essentials student data using an original survey instrument. For this study, six research questions concerning the commitment to use the Illinois 5Essentials data by high school principals were explored. Much of this research is descriptive so that exploration of the actual usage of student data could be obtained and understood. With student voice and school climate as a lens, the data analysis was focused on the differences of the student data based on a school's summative rating, geographical region in Illinois, school enrollment, as well as the alternative methods available for student voice. The following sections provide detailed information including the findings, implications and recommendations, and areas for future study. A summary and conclusion will finalize this research study illuminating the role of mandated school climate surveys as a measure of student voice.

\section{Background}

Since 2012, schools in Illinois have been mandated to participate in the Illinois 5Essentials Survey. Students in high school and middle school have been asked to take the survey while parents and teachers in all grades were asked to participate. Schools have been aiding in the completion of the survey by providing technology, staffing, and class time to the students. Given the vast differences in the schools in Illinois, it is unknown exactly how data is used. While some school districts have buildings with double digit enrollment, others have thousands of students. The time committed and usage of the survey varies by the school enrollment. Some high school principals may find the data valuable and others may not use it at all. 
The Illinois 5Essentials Survey is a component of the ESSA Plan for Illinois as a School Quality and Student Success Indicator. ISBE utilizes student survey participation rates in the accountability rubric which amounts to about 5 percent of the overall accountability rating (Jordan \& Hamilton, 2020). The survey used by Illinois is a result of research conducted by the University of Chicago Consortium on School Research (Jordan \& Hamilton, 2020). The mandated survey required by Illinois had substantial implementation issues which has led many to question the reliability (Klostermann et al., 2014).

Using Mitra's Pyramid of Student Voice as a framework for this research study, an examination was conducted which focused specifically on how high school principals use the student response data from the Illinois 5Essentials Survey. The student surveys are the lowest level of student participation in comparison to other student voice opportunities. Essentially, the bottom tier incorporates one-way dialogue from student to teacher without an opportunity for collaborative engagement with adults in school leadership positions.

Figure 3

Mitra Pyramid of Student Voice (2006)

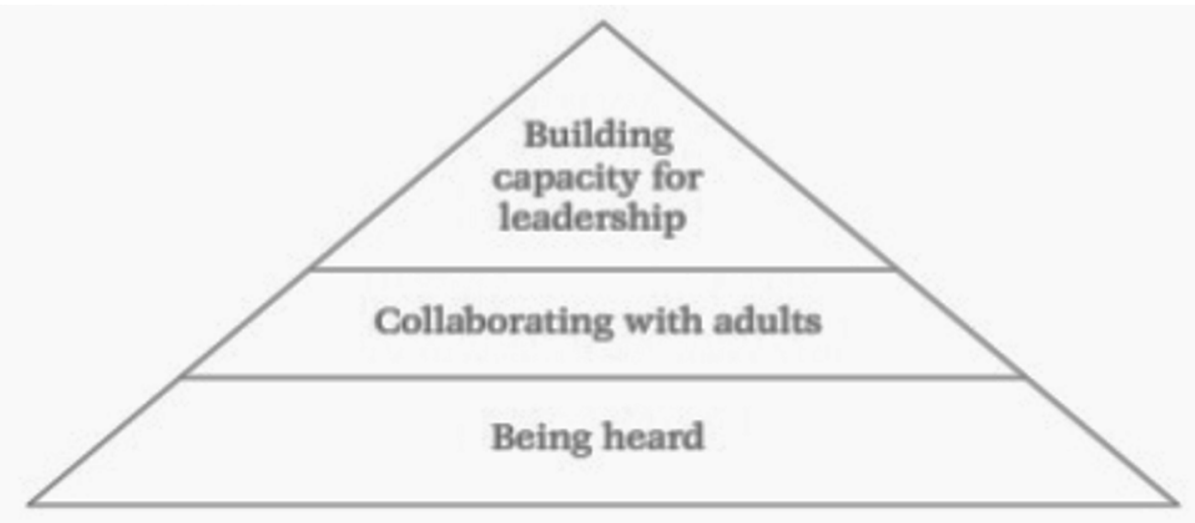

The research conducted involved both a pilot study and research study of high school principals in Illinois. The study asked principals to respond to 18 multiple choice and open- 
ended questions on an online survey through Qualtrics. For the research survey, 130 principals from across the state responded. The results of the survey are highlighted in the following section.

\section{Major Findings}

The high school principals that participated in this research study provided insight related to school climate surveys but also other areas in which they perceive student voice has value. When provided an opportunity to rank order ten opportunities commonly available to student in the United States, they did not rate the student data from the Illinois 5Essentials Survey in the top five. This is concerning as we mandate that all Illinois public school students in grades 4 through 12 be given an opportunity to participate annually yet those providing leadership closest to the students find it to be one of the least valuable opportunities available to students. Furthermore, this is a quality indicator in the Illinois ESSA plan. The ten opportunities that were listed and provided for ranking on the research survey are shown in Table 22. This table also includes the ranking responses by the principal and the tier on Mitra's Pyramid of Student Voice. 
Table 22

Student Voice Opportunities in the United States

\begin{tabular}{|c|c|c|c|}
\hline Item & Student Voice Opportunity & Ranking & $\begin{array}{l}\text { Mitra's Pyramid of } \\
\text { Student Voice Tier }\end{array}$ \\
\hline 1 & $\begin{array}{l}\text { Students participating as member on a school } \\
\text { board }\end{array}$ & 9 & Middle \\
\hline 2 & Students receiving personalized learning & 1 & Middle \\
\hline 3 & $\begin{array}{l}\text { Students participating in research partnerships } \\
\text { with teachers }\end{array}$ & 5 & Middle \\
\hline 4 & Students serving on school improvement teams & 4 & Middle \\
\hline 5 & $\begin{array}{l}\text { Student data being utilized from the Illinois } \\
\text { 5Essentials Survey }\end{array}$ & 7 & Bottom \\
\hline 6 & $\begin{array}{l}\text { Students serving and being served by student } \\
\text { government }\end{array}$ & 6 & Middle \\
\hline 7 & $\begin{array}{l}\text { Students involved and leading school } \\
\text { recognized student led clubs and activities }\end{array}$ & 2 & Middle \\
\hline 8 & $\begin{array}{l}\text { Students participating in school approved } \\
\text { student activism opportunities }\end{array}$ & 8 & Bottom \\
\hline 9 & $\begin{array}{l}\text { Students who are the primary members of a } \\
\text { Principal Advisory Committee }\end{array}$ & 3 & Middle \\
\hline 10 & $\begin{array}{l}\text { Students who are always included as partners } \\
\text { in school leadership }\end{array}$ & 10 & Top \\
\hline
\end{tabular}

The principals responded that they perceive that other opportunities have a greater impact on school climate. Personalized learning was given the highest ranking. Personalized learning allows for students to create paths for their achievement based on their own interests therefore giving them voice in the type of instructional opportunities that best meets their own needs. Using Mitra's Pyramid of Student Voice, this falls in the middle tier as it is an activity conducted in collaboration with adults (Mitra, 2006). Whereby, student surveys are in the lowest tier of student voice as it is one-way dialogue of simply being heard. The two items classified as bottom tiered were both rated by the principals as having some of the lowest impact on school climate. These items were student surveys and student activism. 
Students serving in the capacity of participating in a principal advisory committee and student led clubs and activities were ranked highly and are categorized as tier 2 in the pyramid. Also ranked very highly was students that were serving on school improvement teams. These are also tier 2 activities on Mitra's Pyramid of Student Voice (Mitra, 2006) The principals rated students participating on the school board as one of the lowest opportunities that impact school climate. Students on school boards are typically token members with no voting rights which may have resulted in the responses made by the principals. They also rated research partnerships with teachers in the top five of the ten possible.

The highest tier of the pyramid of student voice is Building Student Voice Capacity in Leadership. This tier represents leadership with adults and students as equal and as stated earlier, rarely achieved but has the greatest potential for impact. Principals did not identify as valuable that the culture of students who are always included as partners in school leadership would highly impact school climate. It is difficult to explain the reasons in which the principals perceived this and an open-ended question was not provided to gather additional information. Their responses are contrary to the pyramid. One reasons for this may be lack of understanding or experience in school environments with highly involved student school leadership.

To gain a better understanding of the usage of the Illinois 5Essentials Survey, data was obtained through specific research survey questions which requested information about the actions of the high school principals related to the survey. The statewide data obtained from these research questions provide baseline information about the sample. Overwhelmingly, the high school principals responded that they feel well prepared to utilize the data from the Illinois 5Essentials Survey. Approximately 97 percent of the principals stated that they have the 
knowledge to use the student response data. However, only 36 percent of the principals responded that the district provided or supported professional development on interpreting, analyzing, and presenting survey results. Furthermore, nearly 57 percent responded that the district ensures that they are knowledgeable about the use and implementation of the Illinois 5Essentials Survey. If principals have not received professional development and the district is not ensuring that the principals are knowledgeable, the principals' confidence that they are indeed knowledgeable is concerning. In this instance, the principals may not fully comprehend what they do not know.

The statewide data from the research study reflects that a high percentage of principals use the Illinois 5Essentials student data for planning and continuous school improvement. Approximately $72.4 \%$ of the participants use it for that purpose. However, only $56.9 \%$ of the principals will modify the school improvement plan based on the student data from the Illinois 5Essentials Survey. While this is a large percentage of the participants, fewer principals would revise an existing SIP plan because of the data.

Upon receipt of the data from the Illinois 5Essentials Survey, it is highly unlikely that principals will share the student data with students or parents. They are most likely to discuss it with building and district administrators as well as teachers. If a student has the interest in learning more about their data, they are expected to look at the data on the school website or in general school communications. There is minimal effort to provide a focused and guided explanation to students directly from their principal or other school leadership.

The summative designations that schools receive from ISBE are obtained as a result of student achievement. These ratings include exemplary, commendable, underperforming and lowest performing schools. School districts do not receive an overall rating rather schools 
themselves earn the designation. The data from the study identified that the quality level of the ISBE summative designation for public high schools does not impact the student voice data usage from the Illinois 5Essentials Survey. Regardless of the summative designations, the principals in each rating had varied use of the student data from the Illinois 5Essentials Survey. Therefore, one cannot assume that the use of data has a positive or negative impact on achievement and is not the cause of the designation.

From a geographical perspective, there are differences across the state in how common the Illinois 5Essentials Survey data is utilized as a tool for student voice by high school principals. For this study, the state was divided into six areas according to the map created by the Illinois Association of Regional School Superintendents. While the survey was created in Chicago, the schools in Area one which include suburban Cook County and the collar counties are the least likely to use it. Areas three and four which include central Illinois from the east and west borders of the state are most likely to use it. The Illinois State Board of Education in Springfield is located in Area 3; the staff member that is charged with supervising the Illinois 5Essentials Survey is located there. It is unknown as to whether or not additional professional development or communication related to the Illinois 5Essentials was provided to the communities closest to ISBE in Springfield which resulted increased usage.

The enrollment size of schools was broken down into six categories from less than 300 to more than 2000. Leadership and involvement was not directly impacted by the school enrollment size. Principals in the various school sizes implement and respond to student voice data in ways that are not correlated to school enrollment. While many larger districts may have staff to assist with data collection and utilization, principals in those districts did not use the student data more than principals in much smaller schools. 
The participating principals responded with a greater percentage that they do perceive that the student data from the Illinois 5Essentials Survey can aid them in supporting school climate. With other principals stating that it serves little or no purpose. Unfortunately, when students participate in the Illinois 5Essentials Survey they are unaware if their building principal values the results and if the information will be utilized. As the educational leader in the school, the principal sets the tone for the survey use through their words and actions. If a principal perceives that the information is valuable, they are more likely to use it. Students may feel like their principal has wasted their time by mandating that they take the survey with no intention of using the information.

\section{Implications and Recommendations}

The literature on student voice is expansive. However, the research on the applicable use of student data from school climate surveys is minimal. With states across the country implementing mandated school climate surveys, it becomes more important to determine how the data is used and best practices for using student survey data. It is evident from the openended comments that the Illinois 5Essentials Survey continues to have a reputation of providing unusable and inaccurate data. The turnaround time for the data is relatively slow and principals commented that they would like it much sooner. Administrators identified or inferred that professional development was lacking and that it might be beneficial in using the data. The development of best practices for using the results from the Illinois 5Essentials Survey would guide administrators in the process of data response. The entire administration and implementation process of student surveys needs to have an action plan that is specific with assurances that the feedback loop is closed. Failure to communicate results and actionable steps 
to student input may result in students viewing school climate surveys as student voice tokenism.

As a researcher employed by a Regional Office of Education, I feel compelled to take my research and infuse it into my profession. From a regional educational system, the offices can take a greater role in implementation of the Illinois 5Essentials Survey. While we are not employed by ISBE, we can support the effort to improve the reputation and usage of school climate surveys. As a conduit, we can provide professional development focused not only on best practices for survey implementation but also on the high-quality research that supports the survey. Because the survey rollout was sloppy from the inception, it has built a reputation of being unreliable. It would take a concentrated effort to improve the consistency of the survey utilization across the state. Our students benefit from having a new generation of administrators that understand SEL standards that may be more interested in obtaining student voice through school climate surveys.

\section{Policy Implications}

The usage of the Illinois 5Essentials Survey was implemented throughout the state of Illinois as a measure of school climate and effectiveness. The requirement by school districts to utilize the survey was a matter of public policy. While this policy originated as a requirement for every other year for students in grades 6-12, it transitioned into an annual requirement under ESSA for students in grades 4-12 to be offered the opportunity to complete the survey of school conditions. Naturally, the topic of school mandated surveys and the rights of children are embroiled with policy implications at the national, state, and local level. This section will focus specifically on policy concerns related to student surveys. 
National. At the national level, there are conflicting messages sent regarding the rights of a child and the value placed on student surveys. While the U. S. Department of Education supports student surveys as a measure in ESSA, the United States government is the only country that has not signed the Convention on the Rights of the Child (Mehta, 2020). Article 5 and Article 12 of the Convention provides that children are allowed certain entitlements including "support, encouragement, and recognition in taking decisions for themselves in accordance with their wishes and capacity" (Lansdown, 2005, p. 4). One might view that there is contradiction in asking for students' perspective yet publicly acknowledging that the federal government does not fully recognize student voice. Without the recognition of democracy for children, the efforts by the federal government to honor student voice may be seen as tokenism.

State. The legislators in the state of Illinois are reinforcing student voice with recent legislation regarding public elections. Beginning in June 2020, students have the right to be absent from school during an election day to vote. According to PL101-0624, students that are legally allowed to vote can miss two hours during the school day to participate in public elections (Election Code, 2020). In order to continue to give all students voice, the legislators in Illinois also passed legislation that required schools to provide instruction on LGBTQ history. According to the Illinois Safe School Alliance, the proper implementation of the Inclusive Curriculum legislation will nurture an environment that honors all students and will improve school climate by providing positive instruction on the LGBTQ contributions to society ("LGBTQ Curriculum Bill," 2019). While it may seem like a stretch to consider voting a form of student survey, the government is honoring their viewpoint in a confidential manner by allowing them the time to submit their choices in candidates. 
The state has a policy expectation to fully fund the Illinois 5Essentials Survey; however, the survey is not inclusive of all school aged children. Students in grades lower than fourth do not have the opportunity to share even the smallest detail about their school experience including the safety of the environment on a mandated school climate survey. Many of the questions on the Illinois 5Essentials Survey could be reworded or reduced to be age appropriate for the younger students. In addition, they could add a read aloud option to the survey so students that the questions could be auditory. If early childhood education is a priority, we need to consider how we are giving voice to our younger students. Because ISBE directly controls the survey selection for school districts, it would be their responsibility to prioritize younger voices and make the necessary adjustments to the Illinois 5Essentials Survey.

As an expansion to the current mandated survey, states should move past the issuing and data collection of the results towards usage of the data. ISBE should ensure that the information gained from the Illinois 5Essentials Survey is used to inform and impact policy changes. By involving students in reviewing the results at the state level, student surveys have more relevancy. "States should involve students in data analysis and any subsequent actions" (Benner, Brown, \& Jeffrey, 2019, p. 24).

One way of including students in the decision-making process at the state level is by allowing students to serve as voting members of the state school board. There are very few states where the student member of the board has actual voting rights. The students that serve on these boards should be selected through a democratic process and provided training on how to best serve as a student representative that honors diverse perspectives (Benner et al., 2019). While the state of Illinois has a student advisory council that meets with the state superintendent and ISBE staff on school related concerns, this group of approximately 20 
students is project based ("ISBE Student Council," 2019). They are not a group that ISBE refers to when student-based concerns arise. This type of student committee should meet regularly and provide advice to state policymakers on the pertinent matters that directly impact educational laws, regulations, and policies (Benner et al., 2019). The example of being inclusive of student voice at the state level could set the tone for local school boards providing the same opportunity. They would be setting policy to have students on the school board as voting members and active student advisory councils that dramatically impact school-based decisions. When selecting participants, schools need to ensure that historically marginalized students are represented. This same group of students could provide insight regarding the Illinois 5Essentials Survey and address the concerns of the survey with ISBE. Students are given the questions on the survey to respond to but are not involved in the development of the actual questions.

Local School District and School Buildings. At the local level, school administrators should reinforce to all students that they are aware and responsive of survey results. Board policy should define how results will be used and communicated to the public. They should support not only the mandated survey but also create surveys that are more pertinent to local needs. Proper communication of the survey results should be completed, and changes made as a result of the survey results should be publicized. The results of this research highlighted the lack of professional development for administrators. Districts need to make it a practice to ensure that administrators at the building level fully comprehend the results of their student survey and how to communicate that information to their stakeholders.

While the Illinois 5Essentials Survey is only offered from grades 4 through 12, schools districts and teachers should seek student input from those students in PK-3. They should develop policy and practices that integrate the usage of student voice at younger ages. While the 
Illinois 5Essentials Survey may not be the appropriate instrument, school districts should require that educators involve younger students in developmentally appropriate opportunities for choice and voice in their classrooms. Our younger children need to feel like their voices are heard especially children who are the victims of abuse and neglect. They should be immersed in an environment at school where they feel they can trust that the adults will protect them and that their story will be believed. These children may only speak their truth once and should experience adults that honor their voices.

In March 2020, Illinois students had their education completely uprooted as a result of COVID-19. The educational impact was seen on the national, state, and local level from PK through college. Many college students had experienced online learning, but this is not the norm for students in Kindergarten through grade 12. While some school districts were able to move to an e-learning or remote learning plan, the state superintendent at ISBE Dr. Carmen Ayala stated that most school districts did not have the capability as a result of access to broadband and digital devices (An \& Karp, 2020). School districts rapidly developed e-learning plans with minimized restrictions because of the pandemic and the fear that the on-site school year would end nearly three months early. This situation is an opportune time for school districts to seek student voice on the implementation of e-learning. The consumers of the experience can best provide the insight to the student experience while off campus. Gaining first-hand knowledge from the participants in E-learning, blended learning, and personalized learning may help to propel this type of learning as a successful platform for elementary and secondary schools. This school shutdown has unearthed the significant equity issues in Illinois. Discussions about the lack of technology, food, and parent supervision were common and students may desire to give voice to those concerns. These topics could be added to the Illinois 5Essentials Survey or a school-based 
surveys; the responses could inform future decisions by school districts as it relates to remote learning and emergency planning.

\section{Areas for Future Study}

There are multiple angles that student voice can be further studied. Perspectives of student voice can occur through the lens of legislator, teacher, student, principal, and superintendents. While much of the research associated with student voice is qualitative, there are opportunities to expand this research through quantitative measures. Given that this research was focused on high school aged students, future studies could focus on other age ranges from early childhood through post-secondary education.

Research on the topic of using student voice could further be expanded by considering the impact of using school climate surveys at the elementary and middle school level. The effect on the words, actions, and beliefs of educators to use the lower grade level student voice in any capacity including surveys is unknown. With the expansion to middle school grades for the Illinois 5Essentials Survey, it is appropriate to survey principals at the younger grade levels to determine how they would use the student data results.

This study was focused primarily on building principal perspective of student voice and excluded other participants including students. With the recent changes in ISBE expectations, students will be participating in the Illinois 5Essentials Survey annually from grades four through twelve. With their survey, students may provide insight on the questions and protocols of the Illinois 5Essentials Survey. They may also be willing to provide suggested questions that were not included in the survey. This student input could also provide dialogue that could lead to better use of the survey data. Students may have opinions about being questioned about their school environment without feedback coming back to them in any formal method. By gaining 
student insight on the quality of the Illinois 5Essentials Survey, it may or may not lend credibility to the data.

While the Illinois 5Essentials Survey is a part of the Illinois ESSA Plan, it does not directly impact public policy at the state or federal level that impacts student voice. ISBE does not provide guidance or professional development for use of the data at the local and state level. This results in school districts using inconsistent methods of using the data. Therefore, it is unknown how this survey can be used to integrate student voice in public policy if school districts do not find value in the data. The mandate does not require assurances that there is equitable collection of data from all students. The ESSA Plan only looks at the aggregate percentage of students for meeting the requirements. Further research could be conducted on public policy and commitment to equitable student voice in other states.

Additional research could include examining the impact of the strength on the five essential areas on student achievement either as a combination of the five or individual areas. With the mandated standardized tests, one could determine if there is a linkage between the Illinois 5Essentials and scores on the ISAT and PSAT. Other connections could include five essential areas and graduation rate, dropout rate, and attendance rates. These data points are available on the Illinois School Report Card ("ISBE Report Card," n.d.).

Further research regarding social media platforms and student voice should be explored. Studies could identify schools that work to communicate in the technological platform in which the students are engaged. There are many educators and administrators that make a conscious effort to use Facebook and Twitter to interact with the school community including the students. However, many young people are more likely to be found on Snapchat and Instagram. By interacting with students in a technical environment, there may be challenges; 
but, students may have more immediate responses from educators outside of the school day. Surveys conducted through social media may get a different response rate if conducted in the platform that students use. If school administrators wanted to gauge student response to a school issue, they could do it quickly through Internet based technology such as Google or Twitter. The immediacy of survey results with technology at the local level eliminates the need to wait several months for the data to be returned by the state. The research opportunities for student voice through technology could illuminate the substantial difference between the generations that are in the schools from board members, administrators, teachers, and students. By identifying these differences, one can expand their approach to improving communications with students.

Given that this study was focused exclusively in Illinois, it may be beneficial to conduct research in other states that require school climate survey participation. In addition, one could take a deeper dive qualitatively to examine how high school principals are finding successful uses for the student data and determining best practices for using the data. Using school climate surveys, one could research how the Illinois 5Essentials and other surveys can positively impact social emotional learning, restorative practices, and trauma informed practices. Student voice research can be expanded by recognizing that surveys and other student-centered actions could improve conditions for students and be inclusive of culturally responsive teaching.

Future research opportunities in student voice are endless. As students and technology changes, there will be consistent opportunities to engage youth in research opportunities. Surveys are a consistent way of garnering input at the baseline level so that students have a voice in their schools. While there may be concerns with considering surveying younger students, all children would like for adults to ask for their thoughts and opinions on topics and choices that concern them. It would be beneficial for public policy to expand and support student voice. 
However, these efforts have historically been introduced and developed at the local level. Expansion of research in this area could engage legislators on discussion of the policies related to the Illinois 5Essentials Survey and further opportunities to involve youth in decision making.

\section{Summary and Conclusions}

The purpose of this study was to determine to what extent and for what purposes high school principals use the student voice data on the Illinois 5Essentials Survey. Principals go to great lengths to provide opportunities for students to take the survey but make little or no effort to ensure that the students receive the results. The results illuminated that principals were more likely to share the results with their school building educators than parents and students. Meaningful student involvement must be fostered by building leaders in a sustainable and realistic manner. While this study focused exclusively on students participating in mandated school climate surveys, there are countless ways to encourage student engagement in all facets of the school environment. Children have had voice in their schools but many times it is superficial and may only serve a certain segment of the student population. The utmost challenge for administrators is to ensure equitable and appropriate student voice opportunities for all children. 


\section{REFERENCES}

About IDEA. (n.d.). Retrieved from https://sites.ed.gov/idea/about-idea/

Adams, Jr., J. E., \& Ginsberg, R. (n.d.). Education reform-Overview, reports of historical significance. Retrieved from http://education.stateuniversity.com/pages/1944/EducationReform.html

American Youth Congress. (n.d.). Retrieved from https://www2.gwu.edu/ erpapers/teachinger/glossary/american-youth-congress.cfm

An, S., \& Karp, S. (2020). Most Illinois school districts are unprepared for e-learning. Retrieved from https://www.wbez.org/shows/wbez-news/most-illinois-school-districts-unpreparedfor-elearning/3d92a704-246a-4855-9ea7-

1f51b93d1f18?utm_source=email\&utm_medium=referral\&utm_campaign=Web-Share

Angus, L. (2006, October-December). Educational leadership and the imperative of including student voices, student interests, and students' lives in the mainstream. International Journal of Leadership in Education, 9(4), 369-379. http://dx.doi.org/10.1080/13603120600895544

Bartholet, E. (2011, January). Ratification by the United States of the Convention on the Rights of the Child: Pros and cons from a child's rights perspective. The Annals of the American Academy, 633, 1-22. http://dx.doi.org/10.1177/0002716210382389

Benner, M., Brown, C., \& Jeffrey, A. (2019). Elevating student voice in education. Retrieved from https://www.americanprogress.org/issues/education-k12/reports/2019/08/14/473197/elevating-student-voice-education/ 
Bradshaw, C., Waasdorp, T., Debnam, K., \& Lindstrom Johnson, S. (2014, September). Measuring school climate in high schools: A focus on safety, engagement, and the environment. Journal of School Health, 84(9), 593-604.

Branch, G. F., Hanushek, E. A., \& Rivkin, S. G. (2013, Winter). School leaders matter: Measuring the impact of effective principals. Education Next, 13(1), 62-69. Retrieved from https://www.educationnext.org/school-leaders-matter/

Bump, P. (2018). Why Parkland students have emerged as a powerful political voice. Retrieved from https:/www.washingtonpost.com/news/politics/wp/2018/02/19/why-parklandstudents-have-emerged-as-a-powerful-politicalvoice/?noredirect $=$ on\&utm_term $=.19066 \mathrm{a} 4 \mathrm{~b} 303 \mathrm{~b}$

Butin, D. W. (2010). The education dissertation: A guide for practitioner scholars. Thousand Oaks, CA: Corwin.

Carpenter, J. (2013). Thomas Jefferson and the Ideology of Democratic Schooling. Democracy \& Education, 21(2). Retrieved from https://democracyeducationjournal.org/home/vol21/iss2/5

Cartwright, J. M., Simon, P., \& Lockhart, R. (2019). Illinois. Retrieved from https://www.britannica.com/place/Illinois-state

Ciccone, P. A., \& Freibeg, J. (2013). School climate and the National School Climate Standards. Retrieved from National School Climate Center: http://www.schoolclimate.org/publications/practice-briefs.php 
Clifford, M., Menon, R., Gangi, T., Condon, C., \& Hornung, K. (2012). Measuring school climate for gauging principal performance: A review of the validity and reliability of publicly accessible measures. Retrieved from American Institutes for Research website: https://www.air.org/sites/default/files/downloads/report/school_climate2_0.pdf

Conner, J. O., \& Pope, D. C. (2013, January). Not just robo-students: Why full engagement matters and how schools can promote it. Journal of Youth \& Adolescence, 42(9), 14261442. http://dx.doi.org/10.1007/10964-0139948-y

Conner, J. O., Ebby-Rosin, R., \& Brown, A. S. (2015). Introduction to student voice in American education policy. National Society for the Study of Education, 114(1), 1-18.

Consolidated State Plan Under the Every Student Succeeds Act. (2017). Retrieved from https://www.isbe.net/Documents/ESSAStatePlanforlllinois.pdf\#search=essa\%205\%20ess entials

Convention on the Rights of the Child. (1989). Retrieved from http://www.ohchr.org/EN/ProfessionalInterest/Pages/CRC.aspx

Cook-Sather, A. (2006, Winter). Sound, presence, and power: "Student voice" in educational research and reform. Wiley, 36(4), 359-390. Retrieved from http://www.jstor.org/stable/4124743

Countryman, M. (2006). Up South: Civil rights and Black power in Philadelphia. Philadelphia: University of Pennsylvania Press.

Creswell, J. W. (2012). Educational research: Planning, conducting, and evaluating quantitative and qualitative research (4th ed.). Boston, MA: Pearson.

De La Ossa, P. (2005, Fall). "Hear my voice:" Alternative high school students' perceptions and implications for school change. American Secondary Education, 34(1), 24-39. 
Dear colleague letter. (2013). Retrieved from

https://www2.ed.gov/about/offices/list/ocr/letters/colleague-201104.html

DeFur, S. H., \& Korinek, L. (2010). Listening to student voices. The Clearing House, 83(1), 1519.

Election Code, Public Act 101-0624 Illinois General Assembly § 10 ILCS 5/7-42 (2020).

Elias, M. J. (2010, September). School climate that promotes student voice. Principal Leadership, 11(1), 22-27.

Fletcher, A. (2014). The guide to student voice (2nd ed.). Olympia, WA: SoundOut.

Fletcher, A. (2018). A short history of student voice in the United States. Retrieved April 15, 2018, from https://soundout.org/a-short-history-of-student-voice-movement-in-theunited-states/

Flowerday, T., \& Schraw, G. (2000). Teacher beliefs about instructional choice: A phenomenological study. Journal of Educational Psychology, 92(4), 634-645. http://dx.doi.org/10.1037/0022-0663.92.4.634

Fraenkel, J. R., Wallen, N. E., \& Hyun, H. H. (2012). How to design and evaluate research in education (8th ed.). New York, NY: McGraw-Hill.

Gage, N. A., Larson, A., \& Chafouleas, S. (2016). The Meriden School Climate Survey-student version: Preliminary evidence of reliability and validity. Assessment for Effective Intervention, 4(2), 67-78. http://dx.doi.org/10.1177/1534508415596960

Garn, A. C., \& Jolly, J. L. (2014). High ability students' voice on learning motivation. Journal of Advanced Academics, 25, 7-24. 
Gonzalez, T. E., Hernandez-Saca, D. I., \& Artiles, A. J. (2016, October 13). In search of voice: Theory and methods in K-12 student voice researchin the US, 1990-2010. Educational Review, 69(4), 451-473. http://dx.doi.org/10.1080/00131911.2016.1231661

Gross, B., \& Gross, R. (1977). The children's rights movement: Overcoming the oppression of young people. New York, NY: Anchor Press/Doubleday.

History-Brown v. Board of Education Re-enactment. (n.d.). Retrieved from http://www.uscourts.gov/educational-resources/educational-activities/history-brown-vboard-education-re-enactment

Iceman Sands, D., Guzman, L., Stephens, L., \& Boggs, A. (2007). Including student voices in school reform: Students speak out. Journal of Latinos and Education, 6(4), 323-345.

Illinois 5Essentials Survey. (2012). Retrieved from https://illinois.5-essentials.org/2012/

Illinois Report Card. (n.d.). Retrieved from https://www.isbe.net/ilreportcard

Imandoust, S. B. (2011, September). Relationship between education and social capital. International Journal of Humanities and Social Science, 1(12), 52-57.

Improving basic programs operated by local education agencies (Title 1, Part A). (2015). Retrieved from https://www2.ed.gov/programs/titleiparta/index.html

Jia, Y., Konold, T. R., \& Cornell, D. (2016). Authoritative school climate and high school dropout rates. School Psychology Quarterly, 31(2), 289-303. http://dx.doi.org/10.1037/spq0000139

Jonathan Kozol books. (n.d.). Retrieved from http://www.jonathankozol.com/books/savageinequalities/ 
Jordan, P. W., \& Hamilton, L. S. (2020). Walking a fine line: School climate surveys in state ESSA plans. Retrieved from FutureEd Website: https://www.future-ed.org/wpcontent/uploads/2020/01/FutureEdSchoolClimateReport.pdf

Joselowsky, F., \& Aseltine, E. (2009). Students as co-constructors of the learning environment: Building systemic approaches for youth engagement. Washington: Youth on Board and the Academy for Educational Development.

Kleeman, R. P. (1972). Student rights and responsibilities: Courts force schools to change. An education U.S.A. special report. Retrieved from ERIC: https://files.eric.ed.gov/fulltext/ED071171.pdf

Klostermann, B. K., White, B. R., Lichtenberger, E. J., \& Holt, J. K. (2014). Use of the Illinois 5Essentials Survey data (IERC 2014-2). Edwardsville, IL: Illinois Education Research Council at Southern Illinois University Edwardsville: .

Klugman, J., Gordon, M., Bender Sebring, P., \& Sporte, S. (2015). A First Look at the 5Essentials in Illinois Schools. Retrieved from: https://files.eric.ed.gov/fulltext/ED577587.pdf

Lansdown, G. (2005). Innoncenti insight: The evolving capacities of the child. Retrieved from United Nations Children's Fund (UNICEF) Website: https://www.unicefirc.org/publications/pdf/evolving-eng.pdf

Leana, C. R., \& Pil, F. K. (2014). A new focus on social capital in school reform efforts. Retrieved from http://shankerinstitute.org/blog/new-focus-social-capital-school-reformefforts 
Lemley, J. B., \& Schumacher, G. (2014, March 28). What learning environments best address 21st-century students' perceived needs at the secondary level of instruction. NASSP Bulletin, 98, 101-125. http://dx.doi.org/10.1177/0192636514528748

Levin, B. (2000, June). Putting students at the centre in education reform. Journal of Educational Change, 1(2), 155-172.

LGBTQ inclusive curriculum bill approved by Illinois Gov. JB Pritzker. (2019). Retrieved from https://www.ilsafeschools.org/latest-news/lgbtq-inclusive-curriculum-bill-approved

Liou, T., \& Chang, N. (2008, September). The applications of social capital theory in education. Hsiuping Journal of Humanities and Social Sciences, 11, 99-122.

March for our lives. (2018). Retrieved from https://marchforourlives.com/home/

Marshall, C., \& Gerstl-Pepin, C. (2005). Re-framing educational politics for social justice. Boston, MA: Pearson Education.

McKown, H. C. (1944). The origin and development of participation in school control. In The student council (pp. 1-23). Retrieved from http://www.constitution.org/sg/mckown.txt

Mehta, S. (2020). There's only one country that hasn't ratified the convention on children's rights: US. Retrieved from https://www.aclu.org/blog/human-rights/treaty-ratification/theresonly-one-country-hasnt-ratified-convention-childrens

Merriam, S. B. (2009). Qualitative Research: A guide to design and implementation. San Francisco, CA: Jossey-Bass.

Mertler, C. A. (2018). Introduction to Educational Research (2nd ed.). Arizona State University: Sage Publications. 
Mineola High School students strike after clash between pupil and teacher. (1922, September 23). New York Times, p. 13. Retrieved from https://timesmachine.nytimes.com/timesmachine/1922/09/23/99077679.pdf

Mitra, D. L. (2006). Increasing student voice and moving toward youth leadership. Prevention Researcher, 13(1), 520-553.

Mitra, D. L. (2006, October-December). Student voice from the inside and outside: The positioning of challengers. International Journal of Leadership in Education, 9(4), 315328. http://dx.doi.org/10.1080/13603120600895379

Mitra, D. L. (2009, March). Strengthening student voice initiatives in high schools: An examination of the supports needed for school-based youth-adult partnerships. Youth \& Society, 40, 311-335.

Mitra, D. L. (2009, March). Strengthening student voice initiatives in high schools: An examination of the supports needed for school-based youth-adult partnerships. Youth \& Society, 40, 311-335. http://dx.doi.org/10.1177/0044118X08316211

Mitra, D. L., \& Gross, S. J. (2009). Increasing student voice in high school reform: Building partnerships, improving outcomes. Educational Management Administration \& Leadership, 37(4), 522-543. http://dx.doi.org/10.1177/1741143209334577

Mitra, D. L., Sanders, F. C., \& Perkins, D. F. (2010). Providing spark and stability: The role of intermediary organizations in establishing school-based youth-adult partnerships. Psychology Press, 4(2), 106-123. http://dx.doi.org/10.1080/10888691003738285

Mitra, D., Lewis, T., \& Sanders, F. (2013). Architects, captains, and dreamers: Creating advisor roles that foster youth-adult partnerships. Journal of Educational Change, 14, 177-201. http://dx.doi.org/10.1007/s10833-012-9201-6 
Mitra, D., Serriere, S., \& Kirshner, B. (2014). Youth participation in U.S. contexts: Student voice without a national mandate. Children \& Society, 28, 292-304. http://dx.doi.org/10.1111/chso.12005

Mitra, D., Serriere, S., \& Stoicovy, D. (2012). The role of leaders in enabling student voice. Management in Education, 26(3), 104-112. http://dx.doi.org/10.1177/0892020612445678

O'Rourke, N., Hatcher, L., \& Stepanski, E. (2005). A step-by-step approach to using SAS for univariate \& multivariate statistics (2nd ed.). Cary, NC: SAS Institute and Wiley.

Ozer, E. J., \& Wright, D. (2012). Beyond school spirit: The effects of youth-led participatory action research in two urban high schools. Journal of Research on Adolescence, 22(2), 267-283. http://dx.doi.org/10.1111/j.1532-7795.2012.00780.x

Pedder, D., \& McIntyre, D. (2006, May). Pupil consultation: The importance of social capital. Educational Review, 58(2), 145-157. http://dx.doi.org/10.1080/00131910600584009

Peguero, A. A., \& Bracy, N. L. (2014). School order, justice, and education: Climate, discipline, practices, and dropping out. Journal of Research on Adolescence, 25(3), 412-426. http://dx.doi.org/10.1111/jora.12138

Pritchard, R. J., Morrow, D., \& Marshall, J. C. (2005, June). School and district culture as reflected in student voices and student achievement. School Effectiveness and School Improvement, 16(2), 153-177. http://dx.doi.org/10.1080/09243450500101196

Rudduck, J., \& Fielding, M. (2006, May). Student voice and the perils of popularity. Educational Review, 58(2), 219-231. http://dx.doi.org/10.1080/00131910600584207

School climate survey compendia. (n.d.). Retrieved from https://safesupportivelearning.ed.gov/topic-research/school-climate-measurement/schoolclimate-survey-compendium 
Schultz, B., \& Oyler, C. (2006). We make this road as we walk together: Sharing teacher authority in a social action curriculum project. Curriculum Inquiry, 36(4), 423-447.

Social capital. (). Retrieved from https://www.oecd.org/insights/37966934.pdf

Student Advisory Council. (2019). Retrieved March 24, 2020, from

https://www.isbe.net/studentadvisory

Students for a Democratic Society (SDS). (n.d.). Retrieved from http://www.sds-1960s.org/

Students' freedom of speech and symbolic speech rights in schools. (n.d.). Retrieved from http://www.uscourts.gov/about-federal-courts/educational-resources/supreme-courtlandmarks/tinker-v-des-moines-podcast

Summative Designations. (n.d.). Retrieved from https://www.isbe.net/Pages/SummativeDesignations.aspx

Title I-Improving the academic achievement of the disadvantaged. (2004). Retrieved from https://www2.ed.gov/policy/elsec/leg/esea02/pg1.html

Title IX and sexual violence in schools. (n.d.). Retrieved from https://www.aclu.org/title-ix-andsexual-violence-schools?redirect=womens-rights/title-ix-and-sexual-violence-schools

Toshalis, E., \& Nakkula, M. J. (2012). Motivation, engagement, and student voice. Retrieved from https://studentsatthecenterhub.org/wp-content/uploads/2012/04/Exec-ToshalisNakkula-032312.pdf

U.S. Department of Education Every Student Succeeds Act (ESSA). (n.d.). Retrieved April 22, 2018, from https://www.ed.gov/ESSA

U.S. Department of Education NCLB. (2010). Retrieved from https://www2.ed.gov/policy/elsec/leg/esea02/index.html 
United States Secret Service National Threat Assessment Center. (2019). Protecting America's schools: A U.S. Secret Service analysis of targeted school violence. Washington D.C.: U.S. Secret Service, Department of Homeland Security.

Villenas, C., \& Zilinski, S. (2018). Creating school communities of courage: Lessons from the field. Retrieved from https://www.schoolclimate.org/themes/schoolclimate/assets/pdf/NSCC\%20Lessons\%20fr om\%20the\%20Field_Executive\%20Summary.pdf

Watson, S. (2003, June). Closing the feedback loop: Ensuring effective action from student feedback. Tertiary Education and Management, 9(2), 145-157.

Yonezawa, S., \& Jones, M. (2009). Student voices: Generating reform from the inside out. Theory Into Practice, 48(3), 205-212. http://dx.doi.org/10.1080/00405840902997386

Yuen, W. (2010, November 3). Engaging students in school governance: A case study of the challenges and the way forward. International Studies in Education Administration, $38(3), 57-79$. 
APPENDIX A: ILLINOIS 5ESSENTIALS SURVEY STUDENT QUESTIONS 
5Essentials Survey - Student

1) How much do you disagree or agree with the following statements about your school?*

Strongly disagree, Disagree, Agree, Strongly agree

a) I worry about crime and violence in this school.

b) Students at this school are often teased or picked on.

c) Students at this school are often threatened or bullied.

2) How safe do you feel...

Not safe, Somewhat safe, Mostly safe, Very safe
a) In the hallways of the school?
b) In the bathrooms of the school?
c) Outside around the school?
d) Traveling between home and school?
e) In your classes?

3) How much do you disagree or agree with the following statements about students in your school? Most students in my school...*

Strongly disagree, Disagree, Agree, Strongly agree
a) Like to put others down.
b) Help each other learn.
c) Don't get along together very well.
d) Treat each other with respect.

4) How much do you disagree or agree with the following statements about your school?* Strongly disagree, Disagree, Agree, Strongly agree
a) I feel like a real part of my school.
b) People here notice when I'm good at something.
c) Other students in my school take my opinions seriously.
d) People at this school are friendly to me.
e) I'm included in lots of activities at school.

5) How much do you disagree or agree with the following statements?*

Strongly disagree, Disagree, Agree, Strongly agree
a) I can always find a way to help people end arguments.
b) I listen carefully to what other people say to me.
c) I'm good at working with other students.
d) I'm good at helping other people.

6) How much do you disagree or agree with the following statements?* Strongly disagree, Disagree, Agree, Strongly agree
a) I always study for tests.
b) I set aside time to do my homework and study.
c) I try to do well on my schoolwork even when it isn't interesting to me.
d) If I need to study, I don't go out with my friends. 
5Essentials Survey - Student

7) To what extent do the following describe you?*

Not at all like me, Not much like me, Somewhat like me, Mostly like me, Very much like me

a) I finish whatever I begin.

b) I am a hard worker.

c) I continue steadily toward my goals.

d) I don't give up easily.

8) How much do you agree with the following statements?

Strongly disagree, Disagree, Agree, Strongly agree

a) When my teachers tell me not to do something, I know they have a good reason.

b) I feel safe and comfortable with my teachers at this school.

c) My teachers always keep their promises.

d) My teachers will always listen to students' ideas.

e) My teachers treat me with respect.

9) How much do you disagree or agree with the following statements about the community in which you live?*

Strongly disagree, Disagree, Agree, Strongly agree

a) Adults in this neighborhood know who the local children are.

b) During the day, it is safe for children to play in the local park or playground.

c) People in this neighborhood can be trusted.

d) There are adults in this neighborhood that children can look up to.

e) The equipment and buildings in the neighborhood, park, or playground are well kept.

10)In your ENGLISH/READING/LITERATURE class this year, how often do you do the following:

Never Once or twice a semester, Once or twice a month, Once or twice a week, Almost every day

a) Debate the meaning of a reading.

b) Discuss connections between a reading and real life people or situations.

c) Discuss how culture, time, or place affects an author's writing.

d) Improve a piece of writing as a class or with partners.

e) Rewrite a paper or essay in response to comments.

f) (Grades 9-12 Only) Explain how writers use tools like symbolism and metaphor to communicate meaning.

11)In your MATH class this year, how often do you do the following:

Never Once or twice a semester,Once or twice a month, Once or twice a week, Almost every day

a) Apply math to situations in life outside of school.

b) Discuss possible solutions to problems with other students.

c) Explain how you solved a problem to the class.

d) Write a few sentences to explain how you solved a math problem.

e) Write a math problem for other students to solve.

f) (Grades 9-12 Only) Solve a problem with multiple steps that takes more than 20 minutes. 
5Essentials Survey - Student

12)In your SCIENCE class this year, how often do you do the following:*

Never Once or twice a semester, Once or twice a month, Once or twice a week, Almost every day

a) Use laboratory equipment or specimens.

b) Write lab reports.

c) Generate your own hypotheses.

d) Use evidence/data to support an argument or hypothesis.

e) Find information from graphs and tables.

(Target $=$ English or Math)

13)How many students in your [TARGET] class...

None, A few, About half, Most

a) Feel it is important to come to school every day?

b) Feel it is important to pay attention in class?

c) Think doing homework is important?

d) Try hard to get good grades?

14)How much do you disagree or agree with the following statements about your teacher in your [TARGET] class? My teacher...*

Strongly disagree, Disagree, Agree, Strongly agree

a) Often connects what I am learning to life outside of the classroom.

b) Encourages students to share their ideas about things we are studying in class.

c) Often requires me to explain my answers.

d) Encourages us to consider different solutions or points of view.

e) Doesn't let students give up when the work gets hard.

15)How often does the following occur? In my [TARGET] class, we talk about different solutions or points of view.*

Very little, Some Quite a bit, A great deal

16)How much do you disagree or agree with the following statements about your [TARGET] class:

Strongly disagree, Disagree, Agree, Strongly agree

a) This class really makes me think.

b) I'm really learning a lot in this class.

17) To what extent do you disagree or agree with the following statements: In my [TARGET] class, my teacher...

Strongly disagree, Disagree, Agree, Strongly agree

a) Expects everyone to work hard.

b) Expects me to do my best all the time.

c) Wants us to become better thinkers, not just memorize things. 
5Essentials Survey - Student

18) In your [TARGET] class, how often...

Never, Once in a while, Most of the time, All of the time

a) Are you challenged?

b) Do you have to work hard to do well?

c) Does the teacher ask difficult questions on tests?

d) Does the teacher ask difficult questions in class?

19)How much do you disagree or agree with the following statements about your [TARGET] class?*

Strongly disagree, Disagree, Agree, Strongly agree

a) I usually look forward to this class.

b) I work hard to do my best in this class.

c) Sometimes I get so interested in my work I don't want to stop.

d) The topics we are studying are interesting and challenging.

20)How much do you disagree or agree with the following statements about your [TARGET] class? The teacher for this class: Strongly disagree, Disagree, Agree, Strongly agree

a) Helps me catch up if I am behind.

b) Is willing to give extra help on schoolwork if I need it.

c) Notices if I have trouble learning something.

d) Gives me specific suggestions about how I can improve my work in this class.

e) Explains things in a different way if I don't understand something in class.

(Grades 9-12)

21)How much do you disagree or agree with the following statements? At my high school... Strongly disagree, Disagree, Agree, Strongly agree

a) Teachers make sure that all students are planning for life after graduation.

b) Teachers work hard to make sure that all students are learning.

c) High school is seen as preparation for the future.

d) All students are encouraged to go to college.

e) Teachers pay attention to all students, not just the top students.

f) Teachers work hard to make sure that students stay in school.

22)How much do you disagree or agree with the following statements?* Strongly disagree, Disagree, Agree, Strongly agree

a) My classes give me useful preparation for what I plan to do in life.

b) High school teaches me valuable skills.

c) Working hard in high school matters for success in the workforce.

d) What we learn in class is necessary for success in the future.

All content denoted with an asterisk is supplemental

https://core-

docs.s3.amazonaws.com/documents/asset/uploaded_file/269168/5Essentials_Survey_Questions_ 18-19.pdf

Illinois5 Essentials Survey questions provided by UChicago Impact. 
APPENDIX B: RESEARCH SURVEY 


\section{Research Survey}

Q1 Please tell us about your school location. In what area of the state is your school located? Using the map of Illinois provided, please select from the following area options connected with your county. (RQ3)

Area1 (1)

Area 2 (2)

Area 3 (3)

Area 4 (4)

Area 5 (5)

Area 6 (6)

Q2 What is your school enrollment?

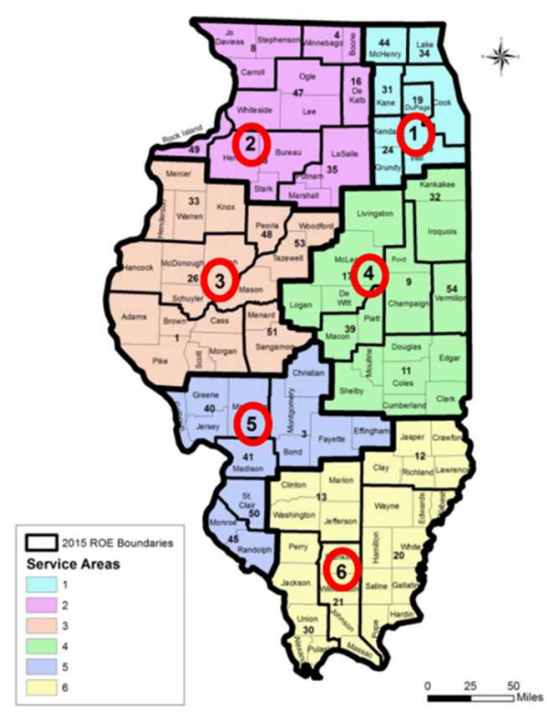

Less than 300 (1)

300-599 (2)

600-999 (3)

$1000-1500(4)$

$1500-2000(5)$

More than 2000 (6)

Q3 What is the ISBE Summative Designation that your school received in October 2018 as posted on the Illinois School Report Card?

Exemplary School (1)

Commendable School (2)

Underperforming School (3)

Lowest-Performing School (4)

Q4 According to ISBE, what percentage of your students responded to the Illinois 5 Essentials Survey this year?

0-20 Percent (1)

21-40 Percent (2)

41-60 Percent (3)

61-80 Percent (4)

81-100 Percent (5) 
Q5 Thinking about the specific experiences of your school, please rate the extent to which you agree or disagree with the following statements about your school's use of survey data.

Select one answer for each statement

\begin{tabular}{l|cccc}
\hline & $\begin{array}{c}\text { Strongly } \\
\text { Agree } \\
(1)\end{array}$ & Agree (2) & Disagree (3) & $\begin{array}{c}\text { Strongly } \\
\text { Disagree (4) }\end{array}$ \\
$\begin{array}{l}\text { a)The principal has the } \\
\text { knowledge to use the student } \\
\text { response data. (1) }\end{array}$ \\
$\begin{array}{l}\text { b) My school has made use } \\
\text { of this data for planning } \\
\text { and/or continuous } \\
\text { improvement. (2) }\end{array}$ \\
$\begin{array}{l}\text { c) My school has modified } \\
\text { our School Improvement } \\
\text { Plan based on results from } \\
\text { the 5Essentials Survey. (3) }\end{array}$
\end{tabular}

Q6 a) My school has made use of the Illinois 5Essentials data for other reasons. Please describe your other uses of survey data. 
Q7 Thinking about the specific experiences of your school, please rate the extent to which you agree or disagree with the following statements about the Illinois 5Essentials student survey you completed this school year.

Select one answer for each statement

\begin{tabular}{|cccc}
\hline Strongly & Agree (2) & Disagree (3) & $\begin{array}{c}\text { Strongly } \\
\text { Agree (1) }\end{array}$
\end{tabular}

a) The principal perceived that the student data was valuable for school improvement efforts (1)

b) The principal perceived that the student data was valuable for addressing school climate issues (2)

c) The communication my school received was sufficient to successfully administer the student survey. (3)

d) The survey administration procedures in place were adequate for my school to generate fair, reliable data from the student survey. (4)

e) School building administration ensured that all high school students were given the opportunity to take the survey. (5)

f) My school district provided or supported professional development on interpreting, analyzing, and presenting survey results. (6)

g)My school district ensures that I am knowledgeable about the use and implementation of 5Essentials Survey data. (7) 
Q8 Thinking about the STUDENT responses on the Illinois 5Essentials Survey, please rate the extent to which you agree or disagree with the following statements regarding your school's utilization of the Illinois 5Essentials data or reports?

\begin{tabular}{l|cccc} 
& \multicolumn{3}{|c}{ Select one response for each question } \\
\hline & $\begin{array}{c}\text { Strongly } \\
\text { Agree (1) }\end{array}$ & Agree (2) & Disagree (3) & $\begin{array}{c}\text { Strongly } \\
\text { Disagree (4) }\end{array}$
\end{tabular}

a) Made efforts to ensure STUDENTS have received the data in student email (1)

b) Made efforts to ensure STUDENTS have received the data in a student assembly (2)

c) Made efforts to ensure STUDENTS have received the data in the school newspaper (3)

d) Made efforts to ensure STUDENTS have received the data in student focused small group meetings. (4)

e) Made efforts to ensure STUDENTS have received the data in classroom presentations (5)

f) Student data was discussed with individual students at your school (6)

g) Data was featured on the school website or in school communications including social media (7)

h) Data reports were presented to student organizations (8)

i) Reviewed/discussed student results at the district leadership level (9)

j) Reviewed/discussed results in school improvement teams with no students present (10) 
Q11 Please describe the other types of groups/teams that involved students in which data was reviewed or discussed with.(OPTIONAL)

Q12 Thinking about the PARENT responses on the Illinois 5Essentials Survey, please rate the extent to which you agree or disagree with the following statements regarding your school's utilization of the Illinois 5Essentials data or reports?

Select one response for each statement

\begin{tabular}{l|cllc}
\multicolumn{4}{|c}{ Select one response for each statement } \\
\hline Strongly & Agree (2) & Disagree (3) & Strongly Disagree \\
Agree (1) & (4)
\end{tabular}

a) Made efforts to ensure PARENTS have received the data in a parent email (1)

b) Made efforts to ensure PARENTS have received the data in a parent assembly (2)

c) Made efforts to ensure PARENTS have received the data in the community newspaper (3)

d) Made efforts to ensure PARENTS have received the data in parent focused small group meetings (4)

e) Made efforts to ensure PARENTS have received the data in a community presentation (5)

f) Data was discussed with individual parents (6)

g) Data reports were presented to parent organizations (7)

h) Reviewed/discussed parent results at the district leadership level (8)

i) Reviewed/discussed parent results in school improvement teams with no parents present (9)

j) Reviewed/discussed parent results in school improvement teams in which parents are also members (10) 
Q13 Parent data was reviewed/discussed in other groups that involved parents; please describe the other teams/groups. (OPTIONAL)

Q14 Thinking about the EDUCATOR responses on the Illinois 5Essentials Survey, please rate the extent to which you agree or disagree with the following statements regarding your school's utilization of the Illinois 5Essentials data or reports?

Select one response to each question

rants

\section{Strongly \\ Agree}

(1)

a) Made efforts to ensure

EDUCATORS have received the data in staff email (1)

b) Made efforts to ensure EDUCATORS have received the data in all staff assembly (2)

c) Made efforts to ensure EDUCATORS have received the data in a staff newsletter (3)

d) Made efforts to ensure EDUCATORS have received the data in staff focused small group meetings (4)

e) Made efforts to ensure EDUCATORS have received the data in staff presentations (5)

f) Data was discussed with individual EDUCATORS at your school (6)

g) Data reports were presented to EDUCATOR organizations (7)

h) EDUCATOR data results were reviewed/discussed at the district leadership level (8)

i) EDUCATOR results were reviewed/discussed in school improvement teams with no classroom educators present (9)

j) EDUCATOR results were Reviewed/discussed in school improvement teams in which classroom educators are also members (10)

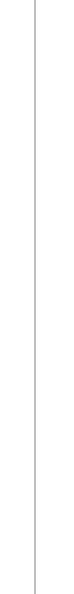

O

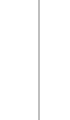

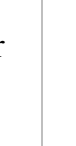

(n)

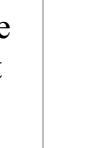

(9)

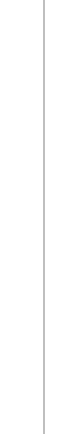

Strongly Disagree

Agree (2)

Disagree (3)

4) 
Q15 If EDUCATOR results were reviewed/discussed in other groups that involve educators, please describe the other groups/team(s).

Q16 Thinking about the specific experiences in student voice opportunities available to students in the United States, please rank in order of importance the following student voice opportunities that you believe have the greatest impact on school climate. With 1 (one) being the most valuable and 10 (ten) being the least valuable. Click and drag each of the statements to place them in order of importance.

Students participating as member on a school board (1)

Students receiving personalized learning (2)

Students participating in research partnerships with teachers (3)

Students serving on school improvement teams (4)

Student data being utilized from the Illinois 5Essentials Survey (5)

Students serving and being served by student government (6)

Students involved and leading school recognized student led clubs and activities (7)

Students participating in school approved student activism opportunities (8)

Students who are the primary members of a Principal Advisory Committee (9)

Students who are always included as partners in school leadership (10)

Q17 Do you feel that the Illinois 5Essentials Survey student data helps you as a principal to address school climate issues in your school?

YES (1)

NO (2)

Please explain your response (3)

Q18 In what way(s) have you as a principal utilized the student voice data from the Illinois 5Essentials Survey to address school climate issues? 
APPENDIX C: INFORMED CONSENT LETTER 


\section{INFORMED CONSENT}

(The informed consent as it appeared in the emails sent directly from Qualtrics with the Research survey)

\section{Dear Participant:}

I am a doctoral student under the direction of Dr. Guy Banicki, Illinois State University, Education Administration and Foundations. The purpose of this study is to analyze the use by high school principals of the Illinois 5Essentials Survey student data as a student voice opportunity.

\section{Follow this link to the Survey: $\$\{1: / /$ SurveyLink?d=Take the Survey $\}$}

You are invited to participate in this study. This survey will take approximately 8 minutes. Participation in this study is optional, you may choose not to participate, withdraw, or skip items without penalty. You must be 18 to participate. You are eligible to participate because you are an active public high school principal in the State of Illinois.

All information for this study is provided anonymously. It is anticipated that participating will not pose any risks greater than those you encounter in everyday life. Results of the research study may be used for publishing or presenting, but no names or organizations will be identified.

\section{Follow this link to the Survey: $\$\{1: / /$ SurveyLink?d=Take the Survey $\}$}

There are no direct benefits to participants. However, your participation will help us gain useful knowledge about the ways in which mandated school climate surveys support student voice efforts. By filling out the survey, you are consenting to participate in the study. You may save a copy of the form for your records.

If you have any questions concerning the research study, please call me at (815) 735-3060 or email me at dloliver44@yahoo.com. If you have any questions about your rights as a participant, or if you feel you have been placed at risk, contact the Illinois State University Research Ethics \& Compliance Office at (309) 438-5527 or IRB@ilstu.edu.

Sincerely,

Deanna Oliver

\section{Follow this link to the Survey: \$ $\{1: / /$ SurveyLink?d=Take the Survey $\}$}

Or copy and paste the URL below into your internet browser:

$$
\$\{1: / / \text { SurveyURL }\}
$$

Follow the link to opt out of future emails: $\$\{1: / / O p t O u t L i n k ? d=$ Click here to unsubscribe $\}$ 
APPENDIX D: SUMMARY OF QUALITATIVE COMMENTS-OPEN ENDED QUESTION 


\section{SUMMARY OF QUALITATIVE COMMENTS-OPEN ENDED QUESTION}

6. My school has made use of the Illinois 5Essentials data for other reasons. Please describe your other uses of survey data.

1. 5 essential data will be used in the creation of my buildings 5 year plan.

2. Administrative share out, dialogue with parent, staff, and student committees

3. Climate development/monitoring; idea exploration

4. Collaborative Teaching. Collective Teacher Efficacy.

5. Currently, our district does not mandate we use the data for any given purpose. We have, however, used the data in attempts at improving s hook culture and teacher relationships.

6. Currently, we are not use the data from the 5 Essentials survey.

7. First, our Instructional Leadership Team used the 5E Student Response data to analyze our instructional core program with an emphasis on English and Math Instruction. We developed a data analysis protocol that we then used with all teachers during our beginning of year school improvement planning. Our teachers set goals around their analysis of the data.

8. General ideas but the output doesn't tell us how they answered a specific question. Question - Do you fell safe in your schools restrooms Output generality of school safety

9. I am a second your principal, so we used the data to analyze the two year trend in a lot of areas. We use the data to discuss our leadership within the school, climate, and culture.

10. I do not find the data useful.

11. I share it with staff to celebrate our school culture, using student voice

12. My school has also used the 5 Essential to monitor the climate as reported by teachers. We create climate goals for students and teachers.

13. N/A

14. NA

15. none

16. None

17. One of the primary issues at our school when I started as principal 7 years was teacher trust in administration and teacher-teacher trust. We have used our 5Essentials data, which has steadily improved, as positive reinforcement for the outstanding work our staff has done in these areas. 
18. Our CORE team (teacher leadership team) is in the process of examining the data from last year just this week. We rank a few priority areas of concern to focus on the for year as part of our School Improvement Plan.

19. Our survey data has primarily served as a springboard during school improvement discussions. However, this discussion is limited based on the lack of applicability to high schools outside of CPS (see Klugman et al., 2015 or Gordon et al., 2016).

20. Planning for staff and/or professional development, school improvement planning, goal setting for next year

21. Reporting to Board of Education.

22. Shared with teachers at staff meetings

23. Staff feedback on the survey has been utilized for school improvement. Student safety indicators have been considered.

24. Survey data is utilized by individual departments to inform curriculum, instruction, and student support services.

25. Teacher response data - communication, educational leader, etc.

26. Teacher to teacher trust

27. The survey is shared with the teachers for informational purposes.

28. To make informed decisions on creating a positive school climate, working with staff effectively, guiding change for the better.

29. Trends

30. We are reviewing all of the data to see how we might consider using it in the future. Staff feedback about themselves was valuable. Comparing the differences in perception of the same topic from the different groups was also interesting.

31. We don't share the information with others, but as principal, I consider feedback as we plan initiatives and programs

32. We generate School Improvement Plan Goals related to those areas we deem to be weak.

33. We have reflected upon and changed some communication pieces.

34. We have reviewed the information. We have not formally made and changes based on the results. 
35. we have take feedback but will continue down our (district's) own path

36. We have used the data to help identify goals

37. We take the 5Essentials as required, but I have found the data not relevant to our school. I do include the general data in our School Improvement Plan, but other than a simple data point it has not impacted our plans for improvement.

38. We use 5 essentials to create goals for our district and local strategic plan.

39. We use it to gage our school climate.

40. We use it to see how challenged and safe students feel. Also use it to see how the teacher-principal relationship is rated.

41. We use the 5Essentials data to develop professional learning and to inform our strategic planning

42. We use the data to drive many components of our SIP including safety, climate \& culture, academic press, student involvement, teacher trust/improving collaboration

43. We use the data to illustrate needs in professional development.

44. yes, to help guide SIP.

\section{Please describe the other types of groups/teams that involved students in which data was reviewed or discussed with. (OPTIONAL)}

1. Classroom presentations by the principal prior to taking the survey.

2. Classrooms

3. Discussed data with parent groups.

4. DNA

5. I do not find this survey useful, at all.

6. ILT, Teacher Course Teams, Department Teams, Local $\mathrm{s}$ Principal Meetings.

7. None

8. Our school improvement and data teams have reviewed the data.

9. Parent groups 
10. Plan is to review with student advisory group later this year to gather their thoughts on the data.

11. Principal student committee

12. School and district level administration, whole staff presentations.

13. SIP

14. Student SIP Team Staff meetings, School Improvement team and Teacher Leaders (Dept. chairs)

15. The data were initially very useful, but after we did better on the survey, we found fewer areas to focus on because our performance was so good.

16. The Principal's Student Advisory Group reviewed/discussed the data.

17. Waste of time

18. We have discussed our data with the Principal's Advisory Council (student group,) Student Government, Democracy School leaders (student and staff group,) Superintendent and District Leadership team, High School Administrative team, School Improvement team (administration and staff,) and our School Climate Committee.

\section{Parent data was reviewed/discussed in other groups that involved parents; please describe the other teams/groups. (OPTIONAL)}

1. Data was not presented because we did not have enough parents participating. Therefore, there was no data to present.

2. minimal parent responses

3. None

4. PTSO

5. PTSO, Superintendent's Community Council

6. Surveys should be at the school level, not district level.

7. We can't get the parents to complete the survey so the validity is poor. We didn't even meet the benchmark this past year in the number of parents needed to complete the survey.

8. We did not administer the parent survey

9. We did not receive parent results but I had to choose a response.

10. We discussed the results as a staff 


\section{If EDUCATOR results were reviewed/discussed in other groups that involve educators, please describe the other groups/team(s).}

1. Again the results don't tell us much they are generalities and not specifics to improve on. Question - faculty is allowed input on discretionary funds What does that mean - they are allowed to purchase supplies, they are allowed to buy a $\$ 10,000$ printer. Those are two different concepts in a school our size.

2. An anonymous survey is useless. If it is $\mathrm{OK}$, we should evaluate teachers anonymously.

3. None

4. Parent groups

5. School improvement teams \& at a staff meeting with all staff present

6. SIP team, lead teacher teams

7. This survey is not useful to anyone involved.

8. We are a small school, so we do not divide into small groups. We did discuss the results as part of a staff meeting.

9. We have discussed educator results in just about every way imaginable: Union, School Improvement Team, Climate Committee, Discipline Committee, Administrative team, etc.

10. We will be doing this during 2 nd and 3 rd quarter 
17.. Do you feel that the Illinois 5Essentials Survey student data helps you as a principal to address school climate issues in your school? - Please explain your response - Text

1. Any feedback from students should be taken seriously by school leadership.

2. As with many surveys, responses can come mainly from constituents that are unhappy for one reason or another.

3. Byes and anonymous

4. Data is extremely limited and difficult to interpret.

5. District-wide data collected vs. individual buildings.

6. I also send out my own version of a climate survey.

7. I believe the data is applicable for me as a principal to review and reflect on once a year. The 5Essentials was developed as a tool for organizational improvement but not classified as a "school climate diagnostic assessment" until adopted by Illinois through legislation. I think more applicable measures of climate would be given on a more frequent basis for continuous use.

8. I believe the data is invalid due to the way it is collected.

9. I believe the information is true and meant to help

10. I feel it has provided data to help determine areas of improvement.

11. I feel that upper management presses of obtaining just the minimum number of participants just to suffice the requirement from the district

12. I haven't used it for that purpose. It may have that potential.

13. If we could get close to $100 \%$ of honest answers then the data would be helpful

14. It is a one size fits all assessment that does not address the issues that different size schools have.

15. It is a waste of time

16. It is once piece I use

17. it somewhat helps. the survey is long and therefore students tend to just click and click through it without being thoughtful about responses. this makes me question the reliability of the results.

18. NO - We do our own classroom specific surveys twice a year. This data is far more specific and valuable.

19. Not at a glance - when you look at individual responses it may, but many questions are not worded so they easily interpreted by students who take the survey 
20. Nothing more than a yearly required activity that takes time away from classroom instruction to assure participation.

21. Please do NOT give the survey late in the school year. Give it at the begginning of the school year and you will see a big change. When they give the survey in March and April teachers and students are exhausted and the data is not reliable.

22. Provides a research-based blueprint

23. Student feedback is always the best way to analyze what is going on in schools

24. The data is received too late and it is hard to determine what metric the school is compared to.

25. The data received supports the idea that our programs aimed at generating positive school climate are working.

26. The survey provides me insight into the students thoughts on how things are going into the school. This allows me to identify what is going well and what areas may need our attention.

27. The survey shows us perceived strengthens and weaknesses in the eyes of the students

28. This is one source of data we use to discuss climate with our stakeholders

29. Trend data is helpful for us to understand the general attitude of our staff and students, allowing us to make adjustments to how we deal with them.

30. Very minimally. I have found that anyone with a grudge is going to air it out on this survey regardless of how bad or good the school climate is. In a small school setting one or two people with a grudge will skew the results.

31. We break down the data and really dig into what is going on in our building around climate. We have developed smaller surveys to question students about safety, student involvement, academic press, student pride, student interactions, service; it helps us to know what opportunities we may need to provide more of.

32. We examine the data annually, ensure that we get a very representative sample of our students taking it, and use the results to make systemic changes in the building.

33. we had a large enough pool to feel the feedback was valid

34. We have used the results to track our improvements in school climate, and are currently using the results to address student reported deficiencies in the areas of Grit and Perseverance. 
35. When reviewing our data as a team we noticed that one of our ratings was at a $9=$ least on the $0-100$ scale. When we delved into it we noticed that we had $80-90 \%$ of students who responded positively and it caused us to question how things were being scored. We spoke to 5 essentials and they explained that the data was norm referenced last in 2013 with all Illinois Schools. They stated that it will be re-referenced this year which will skew the data in the next taking. We asked if we could aggregate the data out to compare to similar school districts and 5 Essentials said that we cannot. For a question such as do you feel school prepares you for the future a high percentage of our students responded yes but we are marked least because of the comparison to other schools in the state in 2013.

36. Yes, as an individual Principal, this is beneficial. That said, my district does not put emphasis on the survey, thus it is hard to develop buy-in surrounding the survey results. This is something we are working on.

37. Yes, i look to it in developing SIP plans 


\section{Q18: In what way(s) have you as a principal utilized the student voice data from the Illinois 5Essentials Survey to address school climate issues?}

1. 5essentials gives a snapshot of how the students feel. he key (challenge) is to get close to $100 \%$ participation to get a true report

2. Adjustments to how we check in with our students. Adjustments to what courses we offer.

3. As information to my decision-making process \& sharing with the school improvement team members.

4. As supportive data for the programs we have incorporated through other channels.

5. Climate program planning. School improvement planning.

6. Collective Teacher Efficacy.

7. Despite what we found in reviewing the data, we are focusing on a college and career component based on students response in a question that inquired about school preparing them for their future career.

8. Discuss with SIP team and School Safety team

9. Discussed it with our staff members.

10. during summer leadership team planning retreats we look at the areas of growth, decline, and lowest scoring measures.

11. Emphasize what we've done well. Focus on the areas we need improvement in.

12. Explore student experience and impact of school strategies

13. Have not

14. Have not used it. Don't appreciate a one size fits all survey being handed down from the state bureaucracy. All staff are required to create their own classroom specific survey using google forms which collects data specifically on that teacher and that teacher's classroom environment. This data is far more valuable than any one size fits all state survey.

15. I am a first year principal so I have not had this opportunity yet.

16. I have analyzed the data with my team using the problem solving protocol to get to the root cause of negative data and create an action plan to address the problem.

17. I have only used the data in my School Instructional Leadership Team - it does not fully show the whole picture. I would much prefer having a one on one conversation with student groups

18. I haven't

19. I read it as a generality. A survey conducted two years ago in my building by the University of Michigan, provided me so much more insight than the 5 essentials.

20. I've tried to share the data with our BLT and entire staff, but it is not easy to interpret or easy to get to on the new website to be able to share it with the staff. 
21. In presentations to department chairs and the entire faculty. Also presented at department meetings. Also shared with student advisory group. Have not presented to largte groups of students or parents.

22. Influences professional development and changes in our environment

23. Looked for trends to share with student council and get feedback on how to improve this and ways the students want to see things improve for school climate

24. $\mathrm{n} / \mathrm{a}$

25. N/A

26. None

27. None- we use Panorama (like everyone else is starting to do)

28. Not the data, but the premise is an ongoing dialogue within team meetings

29. Nothing concrete - it just affirms what I am thinking or challenges it

30. Our biggest issue on the recent survey was School Spirit. Students are a part of a leadership team, student run activities, and are running pep assemblies.

31. Principal student advisory committee

32. Reviewed data with administration and teachers. Developed goals surrounding school climate. Created new goal-oriented program through homeroom.

33. School improvement opportunities and by clarifying questions that could/were be misinterpreted.

34. see above

35. Sip presentations to staff and board

36. Students report they do not persevere through difficult tasks, so this has become an area of focus for our school.

37. Take the information as a suggestion rather than factual data.

38. The 5Essentials is a combination of teacher and student voice, and we have not separated the two groups within results. Our discussions have been more focused on the actual areas rather than an intentional focus on student responses.

39. The complaint that comes up the most is the quality of teachers. However, I often get the last pick of teachers due to the amount we pay compared to surrounding districts.

40. To examine areas the students are concerned about that they did not vocalize to us

41. To share our buildings climate and culture with staff and community.

42. Used to inform teachers of student and parent attitudes towards the school, used as part of the SIP to include parents more and keep them informed.

43. We have looked into improving our school safety initiatives based upon how the student feel within our building.

44. We have not spent intentional time at this point looking at that data. 
45. We have often used this data as a jumping off point with staff and students.

46. We have used the data to indirectly make policy and procedures to help improve the overall climate of our school.

47. We look at trends in the data and areas where we can have immediate impact in improving the trends.

48. We made the decision to invest in a School Resource Officer to help make students feel safer in school.

49. We will be sharing it with the Student Advisory Group

50. We've started advertising our efforts more readily. There were areas where we were rated lower than we felt was accurate (ex: student safety), so we made efforts to ensure students/families knew what we were doing to keep school safe. We have been tracking data on student-teacher relationships and used that data to encourage our staff to make minor adjustments. For example, our student-teacher trust score was 58 in 2015 , but with steady games over the past few years is now at 82 . 